\title{
Diagnosis of Peripheral Arterial Disease Based on Distal Limb Pressures
}





\section{Diagnosis of Peripheral Arterial Disease Based on Distal Limb Pressures}

PhD Thesis by

Christian Høyer

Department of Clinical Physiology, Viborg Regional Hospital, Denmark

and 
ISBN 978-87-93102-77-4 (paperback)

ISBN 978-87-93102-78-1 (e-book)

Published, sold and distributed by:

River Publishers

Niels Jernes Vej 10

9220 Aalborg $\varnothing$

Denmark

Tel.: +45369953197

www.riverpublishers.com

Copyright for this work belongs to the author, River Publishers have the sole right to distribute this work commercially.

All rights reserved (C) 2014 Christian Høyer.

No part of this work may be reproduced, stored in a retrieval system, or transmitted in any form or by any means, electronic, mechanical, photocopying, microfilming, recording or otherwise, without prior written permission from the Publisher. 


\section{Contents}

$\begin{array}{lll}\text { Preface ix } & \text { ix }\end{array}$

List of publications $\quad$ xi

$\begin{array}{lll}\text { Abbreviations } & \text { xiii }\end{array}$

Supervisors and evaluation committee $\quad$ XV

1. Introduction 1

1.1 Peripheral arterial disease ........................................................... 1

1.2 Small-vessel versus large-vessel arteriosclerotic disease ................ 3

1.3 The value of PAD screening ......................................................... 3

1.4 Methods for PAD diagnosis and evaluation of lower limb

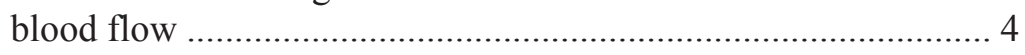

1.5 Methodological requirements in studies of diagnostic

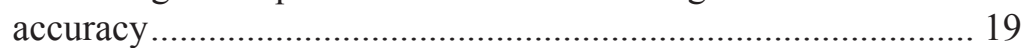

1.6 Conclusions leading to the present thesis .................................... 20

2. Aims 21

3. Materials and methods 23

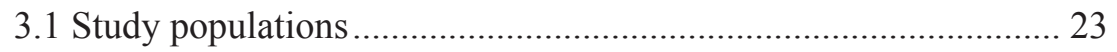

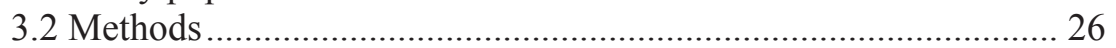

4. Study I: Randomised diagnostic accuracy study of a fully automated portable device for diagnostic peripheral arterial disease by measuring the toe-brachial index 31

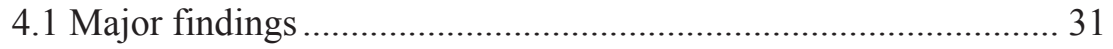

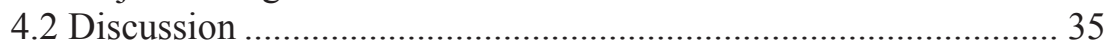

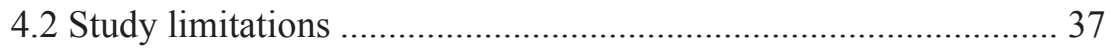

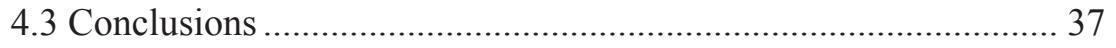


5. Study II: Reliability of mercury-in-silastic strain gauge plethysmography curve reading: Influence of clinical clues and observer variation

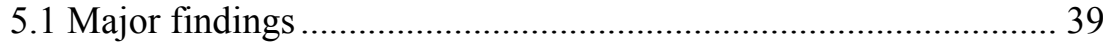

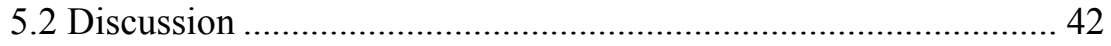

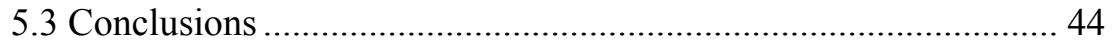

6. Study III: Diagnostic accuracy of laser Doppler flowmetry vs. strain gauge plethysmography for segmental pressure measurement

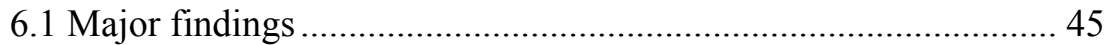

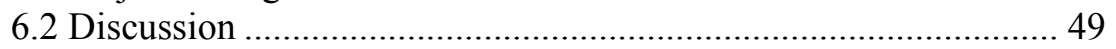

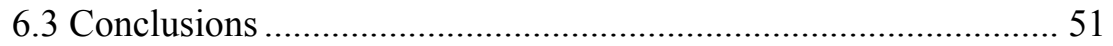

7. Study IV: Number of distal limb and brachial pressure measurements required when diagnosing peripheral arterial disease by laser Doppler flowmetry 53

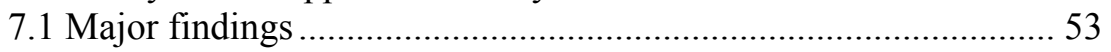

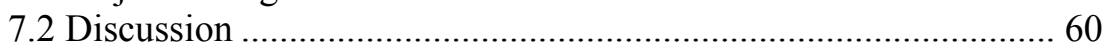

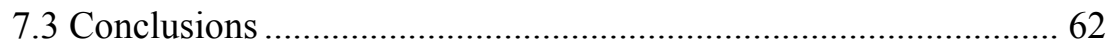

8. Study V: Reliability of laser Doppler flowmetry curve reading for measurement of toe and ankle pressures: Intra- and inter-observer variation $\quad 63$

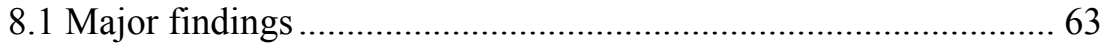

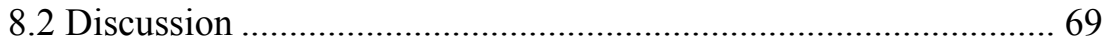

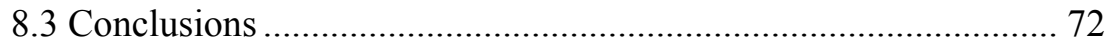

9. General conclusions 73

10. Perspectives 75

11. English summary 77

12. Dansk resumé (Danish summary) 79

$\begin{array}{ll}\text { References } & 81\end{array}$

$\begin{array}{ll}\text { Appendix A } & 103\end{array}$ 
Appendix B

Appendix C

Appendix D

Appendix E 



\section{Preface}

This $\mathrm{PhD}$ thesis is based on studies performed at the Department of Clinical Physiology, Viborg Regional Hospital from 2010 - 2013. Financial support was generously provided by the Morten Scheibel Foundation, the Region Midt Research Foundation, the Aase og Ejner Danielsens Foundation, the Snedkermester Sophus Jacobsen Foundation, the RHVS Research Foundation, the Rosa and Asta Jensen Foundation, Aalborg University, and Aalborg University Hospital.

First of all, I would like to thank my principal supervisor Lars J. Petersen for his guidance and contributions; his structured approach to science and inspirational enthusiasm has been invaluable. Likewise, I thank my cosupervisor Jes Sandermann for keeping focus on the clinical perspectives of the research. It has been a true privilege to gain from his vast knowledge on vascular disorders. Additionally, I would like to thank Jan Abrahamsen for providing a firm theoretical introduction on the field of physiology and vascular pathology as well as providing optimal settings for my research. José A. Bierrun Manresa is thanked for sharing his immense statistical knowledge, and keeping the projects on a short leash in terms of the methodological matters.

I am deeply indebted to all members of the staff at the Department of Clinical Physiology. Their laborious and endless efforts to help me in my research have been exceptional, especially considering that my trials were performed supplementary to daily routine examinations at a busy laboratory. In particular, I would like to express my sincere gratitude to Susanne Pavar, Begitte H. Pedersen, and Jens Peder D. Paludan for their commitment and contributions to the studies. My fellow PhD students including my sister Marie are thanked for discussions, support, and sharing fun, and frustrations. Finally, I dedicate this thesis to my dear wife Anette, and my two wonderful daughters Line and Emma. Without their love and unparalleled support, this thesis would have been completed at least one year earlier.

Christian Høyer, Viborg, October 2013

ix 



\section{List of publications}

This PhD thesis is based on the following five papers:

Paper I Høyer C, Sandermann J, Petersen LJ. Randomised diagnostic accuracy study of a fully automated portable device for diagnosing peripheral arterial disease by measuring the toebrachial index. Eur J Vasc Endovasc Surg 2013 Jan; 45(1):57-64.

Paper II Høyer C, Pavar S, Pedersen BH, Manresa JAB, Petersen LJ. Reliability of mercury-in-silastic strain gauge plethysmography curve reading: influence of clinical clues and observer variation. Scand J Clin Lab Invest 2013 Aug; 73(5):380-6.

Paper III Høyer C, Sandermann J, Paludan JP, Pavar S, Petersen LJ. Diagnostic accuracy study of laser Doppler flowmetry vs. mercury-in-silastic strain gauge pletysmography for segmental pressure measurement. J Vasc Surg 2013 Dec;58(6):1563-70.

Paper IV Høyer C, Manresa JAB, Petersen LJ. Number of measurements required and influence of brachial blood pressure when diagnosing peripheral arterial disease by laser Doppler flowmetry. Physiol Meas 2013 Sep 18;34(10):135162.

Paper V Høyer C, Paludan JP, Pavar S, Manresa JAB, Petersen LJ. Reliability of laser Doppler flowmetry curve reading for measurement of toe and ankle pressures: Intra- and interobserver variation. Eur J Vasc Endovasc Surg 2014 Mar;47(3):311-18. 



\section{Abbreviations}

$\begin{array}{ll}\text { ABI } & \text { Ankle-Brachial Index } \\ \text { BBP } & \text { Brachial Blood Pressure } \\ \text { CI } & \text { Confidence Interval } \\ \text { CLI } & \text { Critical Limb Ischaemia } \\ \text { CT } & \text { Computer Tomography } \\ \text { CV } & \text { Coefficient of Variance } \\ \text { CVD } & \text { Cardiovascular Disease } \\ \text { DTA } & \text { Diagnostic Test Accuracy } \\ \text { DUS } & \text { Doppler Ultrasonography } \\ \text { GRADE } & \text { Grading of Recommendations Assessment, Development } \\ & \text { and Evaluation } \\ \text { ICC } & \text { Intraclass Correlation Coefficient } \\ \text { LDF } & \text { Laser Doppler Flowmetry } \\ \text { LoA } & \text { Limits of Agreement } \\ \text { MAC } & \text { Mediacalcinosis } \\ \text { MRI } & \text { Magnetic Resonance Imaging } \\ \text { PAD } & \text { Peripheral Arterial Disease } \\ \text { PAL } & \text { Palpation of Foot Arteries } \\ \text { PP } & \text { Photo-Plethysmography } \\ \text { P-PP } & \text { Portable Photo-Plethysmography } \\ \text { PU } & \text { Perfusion Units } \\ \text { QUADAS } & \text { Quality Assessment of Diagnostic Accuracy Studies } \\ \text { QUAREL } & \text { The Quality Appraisal of Reliability Studies } \\ \text { SGP } & \text { Strain Gauge Plethysmography } \\ \text { STARD } & \text { The Standards for Reporting of Diagnostic Accuracy } \\ \text { STC } & \text { Stethoscope } \\ \text { TBI } & \text { Toe-Brachial Index }\end{array}$





\section{Supervisors and evaluation committee}

\section{Supervisors}

Lars Jelstrup Petersen, Professor, M.D., D.M.Sc.

Dept. of Nuclear Medicine, Aalborg University Hospital \&

Dept. of Clinical Medicine, Aalborg University

Denmark

Jes Sandermann, Ass. Professor, M.D.

Dept. of Vascular Surgery, Viborg Regional Hospital \&

Dept. of Clinical Medicine, Aarhus University

Denmark

\section{Evaluation Committee}

Peter Søgaard, Professor, M.D., D.M.Sc. (chairman)

Dept. of Cardiology, Aalborg University Hospital \&

Dept. of Clinical Medicine, Aalborg University

Denmark

Eric Wahlberg, Professor, M.D., Ph.D., M.B.A.

The Heart Center, Linköping University Hospital \& Linköping University

Sweden

Lene Rørdam, Ass. Professor, M.D., D.M.Sc.

Dept. of Clinical Physiology and Nuclear Medicine

Bispebjerg University Hospital \& Copenhagen University

Denmark 



\section{Introduction}

\subsection{Peripheral arterial disease}

Arteriosclerosis is a generalised condition that causes stenosis of the blood vessels by formation of fibro-fatty plaques throughout the arterial tree. ${ }^{1}$ In the lower limbs, this condition can manifest itself as peripheral arterial disease (PAD) and induce a broad spectrum of clinical conditions ranging from asymptomatic disease to critical limb ischaemia. ${ }^{2}$ Presence of PAD indicates a severe degree of systemic atherosclerosis, and PAD often coexists with cardiovascular disease (CVD) and cerebrovascular disease which $65 \%$ of the patients with PAD suffers from. ${ }^{3}$ Due to the generalised nature of $\mathrm{PAD}$, diagnosis of the condition is concurrently a strong predictor of risk of cardiovascular morbidity and mortality ${ }^{4}$, even in the absence of traditional cardiovascular risk factors. ${ }^{5}$ It is estimated that the prevalence for having PAD is approximately $15-20 \%$ of people over 70 years, and more than $50 \%$ of the cases are non-symptomatic. ${ }^{3,6}$ Asymptomatic PAD patients have nearly the same risk of cardiovascular events as symptomatic patients. ${ }^{7}$ The development of arteriosclerosis is associated with conditions with modifiable risk factors such as smoking, diabetes, chronic kidney disease, dyslipidaemia, hypertension, and hyperhomocysteinaemia, as well as non-modifiable risk factors, e.g. age, genetics, and gender. ${ }^{8}$

Formation of a stenosis of the vessel lumen can be generated by subintimal calcification, which can lead to the reduction of peripheral flow and, thus, a decrease in distal limb pressures. PAD can correspondently be diagnosed non-invasively by measuring distal limb blood pressures and relating it to the brachial blood pressures by calculating an ankle-brachial index (ABI) or a toe-brachial index (TBI). ${ }^{2}$ Patients with an $\mathrm{ABI} \leq 0.90$ have a three- to six-fold increased risk of cardiovascular mortality, with relative risk increasing with decreasing $\mathrm{ABI} .{ }^{2}$ However, patients with increased ABI (> 1.40) likewise have an increased risk of cardiovascular events, which is 
contributed by another major entity of arteriosclerotic disease: mediacalcinosis. In this condition, medium to small-size muscular arteries in particular are affected by circumferential medial thickening and calcification. ${ }^{9}, 10$ This leads to arterial stiffness and reduced wascular compliance and is associated with diabetes, chronic kidney insufficiency, rheumatic arthritis, and advanced age. ${ }^{11-13}$ Additionally, the development of PAD can also result from trauma, vasculitis, or inflammation. ${ }^{8}$

The symptoms of PAD are traditionally categorised according to the Fountain Classification system from level I-IV in which I, II, III, and IV constitute no symptoms, intermittent claudication, rest pain, and tissue loss, respectively. ${ }^{2}$ If the perfusion is reduced to an extent to which the microcirculation and nutrient flow are severely disturbed, it is referred to as critical limb ischaemia (CLI). ${ }^{14}, 15$ The treatment of peripheral arterial disease includes optimisation of the regional flow by open or endowascular revascularisation or by improving the existing network of collateral arteries through exercise. ${ }^{16}$ Together with the treatment to improve local perfusion, reduction of modifiable risk factors by medication, diet, and smoking cessation is needed to limit the generalised extent of arteriosclerotic development along with the treatment of co-existing vascular conditions. ${ }^{17}$

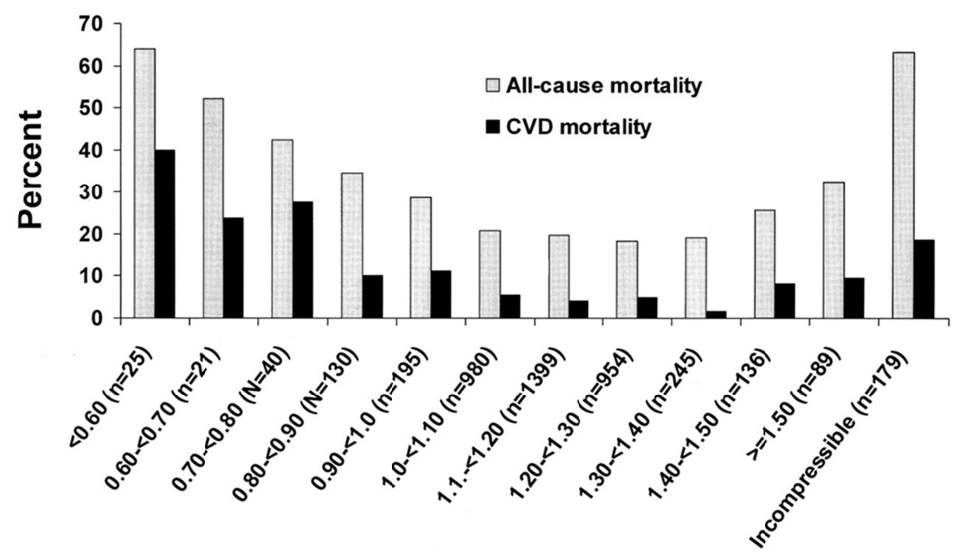

Baseline ABI

Figure 1. All-cause and cardiovascular disease 10-year mortality according the ABI category in the Strong Heart Study. Reprinted with permission by Wolters Kluwer Health (Circulation) from Resnick et al. (2004). ${ }^{18}$ 


\subsection{Small-vessel versus large-vessel arteriosclerotic disease}

Peripheral arterial disease is conventionally sub-divided into large- and small-vessel disease, where the latter concerns vessels with a diameter below $2-3 \mathrm{~mm}$ (or distally to the ankle level). ${ }^{19}$ Atherosclerosis is a chronic inflammatory disease, and accumulations of inflammatory cells are prominent in atheromatous plaques. ${ }^{20}$ It is considered a dynamic condition with gradual progression over time. It has been argued that the development of small-vessel disease constitutes an early phase of arteriosclerotic disease, which is supported by the fact that a large proportion of small-vessel conditions deteriorate to large-vessel disease. ${ }^{21-24}$ This is important because the current methods used for PAD screening mainly target large-vessel disease and largely underestimate the true disease prevalence. ${ }^{25,26}$ However, it has been argued that small-vessel PAD constitutes an entity of its own. ${ }^{19,27-29}$ Analyses of risk factors have shown that small-vessel disease to some extent seems to be epidemiologically distinct from large-vessel disease. ${ }^{30}$ Studies have shown that atherosclerotic plaques are distributed according to the dominant risk factors. For instance, smokers are prone to develop proximal lesions, whereas patients with diabetes have a higher ratio of distal lesions. ${ }^{19}$ Aorto-iliac disease has been shown to predominantly affect younger individuals and has a more rapidly progressive course than distal disease. It has been shown that cigarette smoking, lipids, and inflammation contribute to large-vessel disease progression, whereas diabetes is a significant predictor of small-vessel disease progression. ${ }^{24}$ In terms of lower limb disease, the prevalence for having an indication of small-vessel PAD (low TBI) but no large-vessel disease (a normal $\mathrm{ABI}$ ) in different large-scale studies ranges from 9\%$27 \%$. $^{21,22,30-33}$

\subsection{The value of PAD screening}

Complications of atherosclerosis remain the primary case of mortality in industrialised countries despite massive efforts to limit risk factors. Given that more than $50 \%$ of PAD cases are asymptomatic, screening programs have been proposed to detect the large group of patients at high risk for developing symptomatic arteriosclerosis. ${ }^{34}$ In theory, the detection of PAD at an early stage could improve cardiovascular risk management on a population basis and, ultimately, reduce or even prevent complications related to arteriosclerosis. ${ }^{35}$ 
Ferket et al. (2011) performed a systematic review of major cardio-vascular guidelines to investigate the recommendations for PAD screening. ${ }^{36} \mathrm{~A}$ total of eight guidelines meet the inclusion requirements of evidence-based structure, five of which recommended the implementation of screening. The dominant approach to screening is Doppler derived measurement of the ABI (large-vessel PAD) as the primary tool in age groups varying from 40-60 years. The overall conclusion of the study was that there is currently lack of sufficient evidence in the literature to assess the value of screening for early PAD detection. However, no randomised controlled trials of PAD screening versus no screening have been performed. A more opportunistic approach to screening has likewise been proposed in which the target group include high-risk patients e.g., with high Framingham risk scores or known cardio-vascular morbidity. ${ }^{37}$ When screening high-risk patients in primary care, by using appropriate age groups and known cardio-vascular risk factors, studies have reported prevalences for PAD of $27-29 \% .^{38,39}$

Thus far, PAD screening has focused on large-vessel disease by measuring the ABI, and the measurement of the TBI is generally recommended as a secondary tool in patients where the ABI is unreliable. ${ }^{2,40}$ This is mainly due to the easy access to Doppler-derived ABI. Measurement of the TBI has historically been limited to vascular laboratories due to expensive and cumbersome techniques. However, recently developed methods have been introduced that allow improved access to TBI assessment. ${ }^{41}$ Implementation of the TBI as a primary test for PAD could potentially allow the detection of PAD patients who remain undiagnosed by current methods.

\subsection{Methods for PAD diagnosis and evaluation of lower limb blood flow}

The pathophysiology leading to claudication, ischaemic resting pain, or tissue loss involves a composite line of factors leading to reduced tissue oxygenation, and reduced deliverance of nutrients. These involve systemic factors such as blood oxygenation, haemoglobin content, cardiac output, central blood pressure, and local factors such as regional blood pressure, tissue metabolism, and oedema which can alter the diffusion path. ${ }^{42}$ To assess local perfusion, new methods have been introduced based on the measurement of tissue oxygenation, such as transcutaneous oxygen measurement ${ }^{43}$, near infrared spectroscopy ${ }^{44}$, and laser Doppler Imaging. ${ }^{45}$ 
These methods have, for instance, been introduced in the field of wound treatment but are mainly used in experimental settings.

The reference standard for having PAD is, by many vascular laboratories, considered to be the finding of an obstruction of $>50 \%$ of the vessel lumen in at least one major lower limb vessel. ${ }^{8}$ The likelihood of having PAD can be approximated by a variety of low cost methods such as clinical examination including pulse palpation ${ }^{46}$ and patient history. ${ }^{8}$ The presence of vessel stenosis can be visualised by a range of different imaging techniques such as contrast angiography, magnetic resonance angiography (MRI), computed tomography angiography (CT), and Duplex Ultrasonography (DUS). ${ }^{47}$ The advantage of these methods is that they allow for detection of the vessel lesion site and thus aid in planning of a subsequent vessel revascularisation. In a systematic review by Collins et al. (2007) based on 107 studies, contrast enhanced MRI angiography was found to have a median sensitivity of $95 \%$, and a specificity of $97 \%$ for detecting a lower limb stenosis $>50 \%$ when using contrast angiography as the reference. ${ }^{47}$ The corresponding numbers for CT angiography were $91 \%$ for the sensitivity and $91 \%$ for the specificity. Finally, DUS showed a sensitivity of $88 \%$ and a specificity of $96 \%$ for the same comparison. However, a major problem regardless of the method used is that a substantial stenosis can be present without leading to limitation of lower limb flow. ${ }^{48}$ This problem can be solved exercise testing or by measuring the pressure gradient over the stenosis by the use of pressure catheters. However, the latter requires an invasive procedure. ${ }^{49}$ Another way to predict the presence and severity of vessel stenosis is by the use of pulse wave analysis, which has been used increasingly in recent years. ${ }^{50}$

Measuring distal limb pressures remains a simple non-invasive approach to assess the blood-flow in the lower limbs and has been used for this purpose for more than 50 years. ${ }^{51}$ Distal pressures can be used to predict the presence of a vessel stenosis that limits blood flow as well as to assess the level of blood flow reduction. Distal blood pressures can be measured in a resting state as well as during exercise using, e.g., treadmill testing. ${ }^{52,52,53}$ During exercise, an increased blood flow across a vessel stenosis increases the pressure gradient, resulting in a decline in distal pressures. Normal distal pressures in a resting state and reduced pressures during exercise testing can thus imply a vessel stenosis that only restricts blood-flow upon increased haemodynamic requirements. ${ }^{54-57}$ Studies have shown that 
approximately $30 \%$ of patients suspected of PAD with a normal ABI, show abnormal exercise testing. ${ }^{52,53,58,59}$ Furthermore, by measuring the limb pressures at different levels (segmental pressure measurement) the location of the vessel stenosis can be approximated. ${ }^{14}$

\subsubsection{Distal limb pressure assessment}

A variety of methods have been used to assess distal limb pressures. ${ }^{60}$ Traditionally, an occlusion cuff is positioned on the site of measurement (e.g., ankle or toe), and inflated to a supra-systolic pressure level. The cuff is then gradually deflated, and when the systolic pressure is reached, the blood flow returns as originally described by Riva-Rocci in $1896 .{ }^{61}$ The different methods in use apply different techniques for detecting the reestablishment of blood-flow. ${ }^{62}$ Although the mechanism behind the systems used for blood-flow detection differs, they all generate a signal that reflects the return of pulsation (a fast $\mathrm{AC}$ signal) and changes in absolute blood flow/volume increment (a rather slow DC signal). ${ }^{63}$ However, the different methods in use have different qualities regarding applicability and are influenced differently by factors such as low blood flow, limb tremor, and other factors. ${ }^{64}$ Accuracy in low pressures is vital because the important diagnosis of critical limb ischaemia entails the measurement of toe pressures below $30 \mathrm{mmHg}{ }^{2}$

The higher of the right and left brachial pressures is usually used as a reference to the lower limb pressures. However, peripheral arterial disease can also affect the upper limbs, e.g., causing stenosis of the subclavian artery, leading to a pressure difference between the arms. ${ }^{65}$ However, arterial occlusive disease involving vessels to both arms can, in rare cases, mask this condition.

In patients with severe arteriosclerosis, the distal limb pressure is highly affected by the gravitational pull on the blood column and thus increases when the limb is positioned lower than heart level and decreases when the limb is elevated above heart level. ${ }^{66}$ This can be used as an alternative approach to distal pressure measurement by continuously measuring flow and gradually elevating the limb until the flow disappears in a patient resting in supine position. The pressure can then be calculated by inserting the distance to the bench in a formula: the so-called Pole test. This method has been shown to have a closer relation with intra-arterial blood pressure 
measurement than cuff-derived assessment in patients with severe limb ischaemia. However, the method, is limited to patients with ankle pressures $<60 \mathrm{mmHg}{ }^{66,67}$

\subsubsection{Strain Gauge Pletysmography}

Strain gauge plethysmography (SGP) involves a mercury-based strain gauge positioned distal to the occlusion cuff. ${ }^{68}$ This method is based on the detection of volume changes using the theory of Wheatstone's bridge and was introduced in the $1960 \mathrm{~s} .{ }^{69}$ It is still considered the method of reference in many vascular laboratories in northern Europe due to ample validation against intra-arterial pressure and angiographic findings. ${ }^{70,71}$ However, this method is gradually being replaced by other techniques worldwide due to the mercury content involved. Lately, new strain gauges based on an indium-gallium alloy have been introduced. ${ }^{72}$

\subsubsection{Laser Doppler Flowmetry}

One of the relatively new methods in the field is laser Doppler flowmetry (LDF). The method has previously predominantly been used for microvascular research. ${ }^{63}, 73$ LDF allows measurement of capillary flow by emission of monochromatic laser light carried by a fibre-optic probe. The light hits moving objects such as blood cells, which leads to a change in wavelength (the Doppler Shift), and the scatter is detected by a sensor. ${ }^{63}$ This method has been shown to be sensitive for measurement of severely reduced pressures. ${ }^{64,74-76}$

\subsubsection{Photo-plethysmography}

Another method that is increasingly used internationally is photoplethysmography, which is an optical method that can detect blood filling by measuring the changes in light absorption in erythrocytes. ${ }^{50,77} \mathrm{~A}$ light source illuminates the tissue, and a photo-detector measures the changes in light intensity associated with changes in blood-volume in the capillaries. ${ }^{78}$ Photo-plethysmography has been used in a number of new portable methods for measurement of toe pressures. ${ }^{41,79-82}$ 


\subsubsection{Doppler Ultrasound}

Doppler ultrasound derived measurement of ankle pressures by hand-held devices are widely used internationally. ${ }^{83-85}$ The method features piezoelectric crystals, which can transmit and receive ultrasonic waves. The magnitude of the signal (the Doppler frequency shift) is dependent on flow velocity, flow direction, and the angle of insonation. The signal is weak in cases with low blood-flow, which makes it less successful in, for instance, the measurement of toe pressures. ${ }^{85,86}$ Doppler-based measurements of the ABI allows assessment of the pressure based on flow in the posterior tibial and dorsalis pedis arteries independently. ${ }^{67}$

\subsubsection{Oscillometry}

Oscillometry is the standard method for automated measurements of brachial blood pressures but has also been used for distal limb pressure measurements. ${ }^{87,88}$ The pressure within the occlusion-cuff fluctuates with the pulse, which can be used to detect the point of blood return by monitoring subtle pressure changes (oscillations) in the occlusion system. ${ }^{89}$ The principle of oscillometry has furthermore been used in new automated methods for ABI assessment, but studies have shown that the method is unreliable in patients with low ankle pressures. ${ }^{89,90}$

\subsubsection{Other techniques}

Low-cost methods such as ankle pressure assessment by stethoscope $\mathrm{e}^{91,92}$ or digital palpation of foot arteries ${ }^{93,94}$ have also been introduced with varying success.

\subsubsection{Settings and requirements for measurements}

Comparable prerequisites regarding study procedures are essential when addressing whether the methods are interchangeable. ${ }^{95}$ Most vascular laboratories that perform method comparison in distal limb pressure measurement use rooms with stabile room temperature along with a resting period before the test. ${ }^{84}$ This allows for stabilisation of the haemodynamics and minimises the effects of ischaemia induced by, for instance, walking prior to the measuring procedure. 
The approach to limb heating prior to the tests is markedly different among vascular laboratories. Different heating methods in use include heating overlays/pads, electric blankets, or even hair dryers. ${ }^{21}$ Measurements such as toe pressures have been shown to be highly susceptible to distal temperature changes, and it has been argued that insufficient heating leads to disease misclassification, which is the reason for recommending lower limb heating. ${ }^{96-98}$ Pre-test heating reduces the influence of sympathetic vasomotion, which induces vasodilation, and thus strengthens the signal regardless of the method. ${ }^{74}$ However, it could be hypothesised that diagnosis based on non-heated limbs is closer to the pathophysiologic normal situation for the patient. The signal when using e.g., LDF or PP can also be optimised by local heating in the vicinity of the probe. ${ }^{74}$ However, the sole use of local heating would challenge the test-retest reproducibility due to the effects on limb temperature of hyperaemia induced by inflammation, recent surgery, or seasonal temperature changes because the measured toe pressures correspond to the limb temperature. ${ }^{96}$

Other factors that can potentially influence the measurements are peripheral vasoconstriction caused by medication or smoking prior to the test. However, studies have shown that, for instance, beta-blockers have limited effect on skin microcirculation. ${ }^{99}$ Additionally, appropriate sizes and shapes of the occlusion cuffs are essential for diagnostic accuracy and reproducibility. ${ }^{100-102}$

The measurement of reliable toe pressures has traditionally been limited to vascular laboratories that restrict the access. One of the major problems with e.g., SGP, LDF, and PP is the requirement of expensive equipment along with well-trained observers. To overcome this issue, new costeffective automatic or semi-automatic methods have been introduced to allow measurement of pressures for screening purposes, e.g., bedside or at the general practitioner. ${ }^{41,79-81,84,89,103}$ Data showing studies of diagnostic accuracy for different methods are shown in Table I (laboratory methods) and Table II (automatic or semi-automatic non-laboratory methods). Moreover, software-based reading of curves has been introduced to reduce observer bias. ${ }^{104}$ 


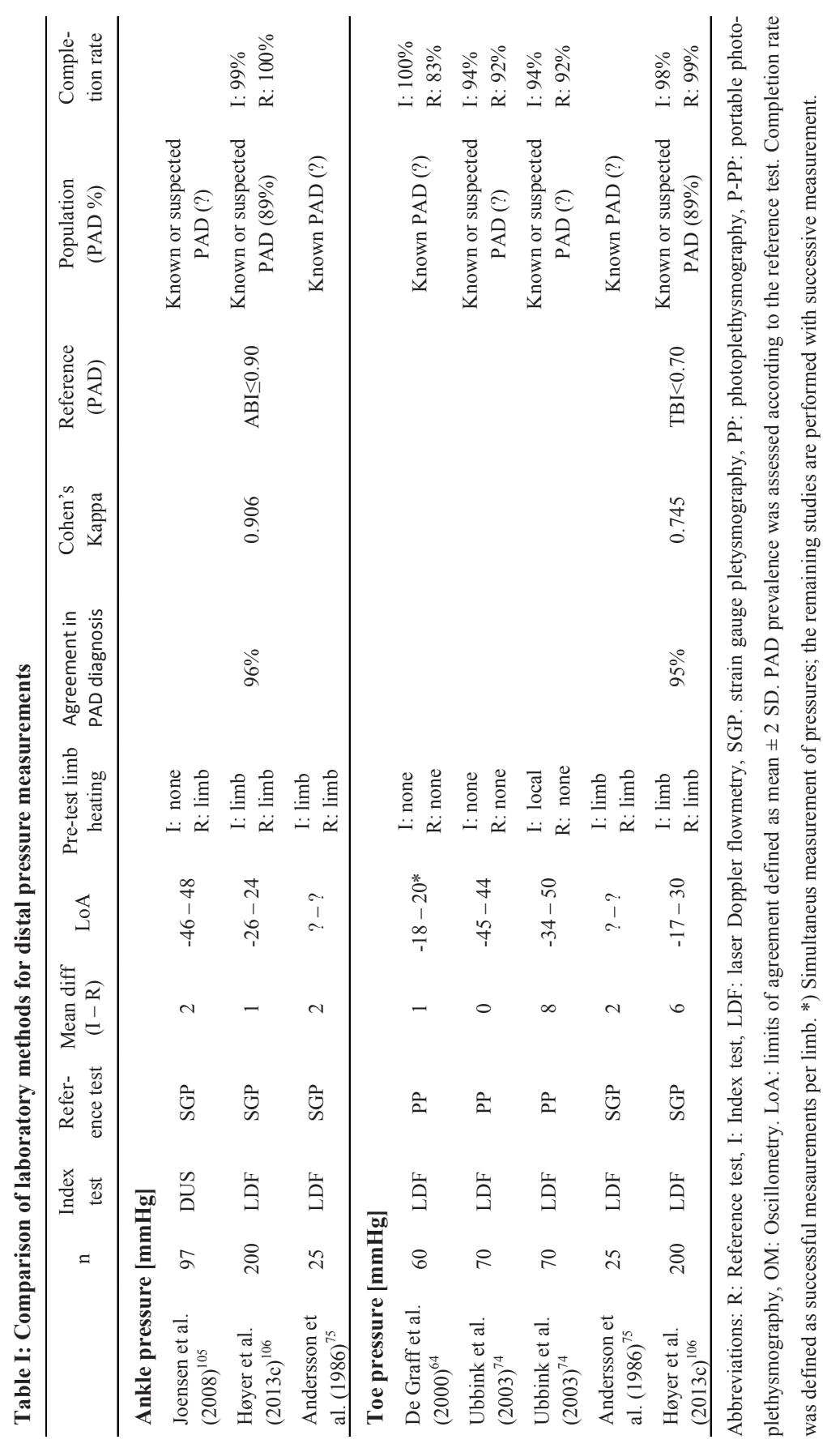




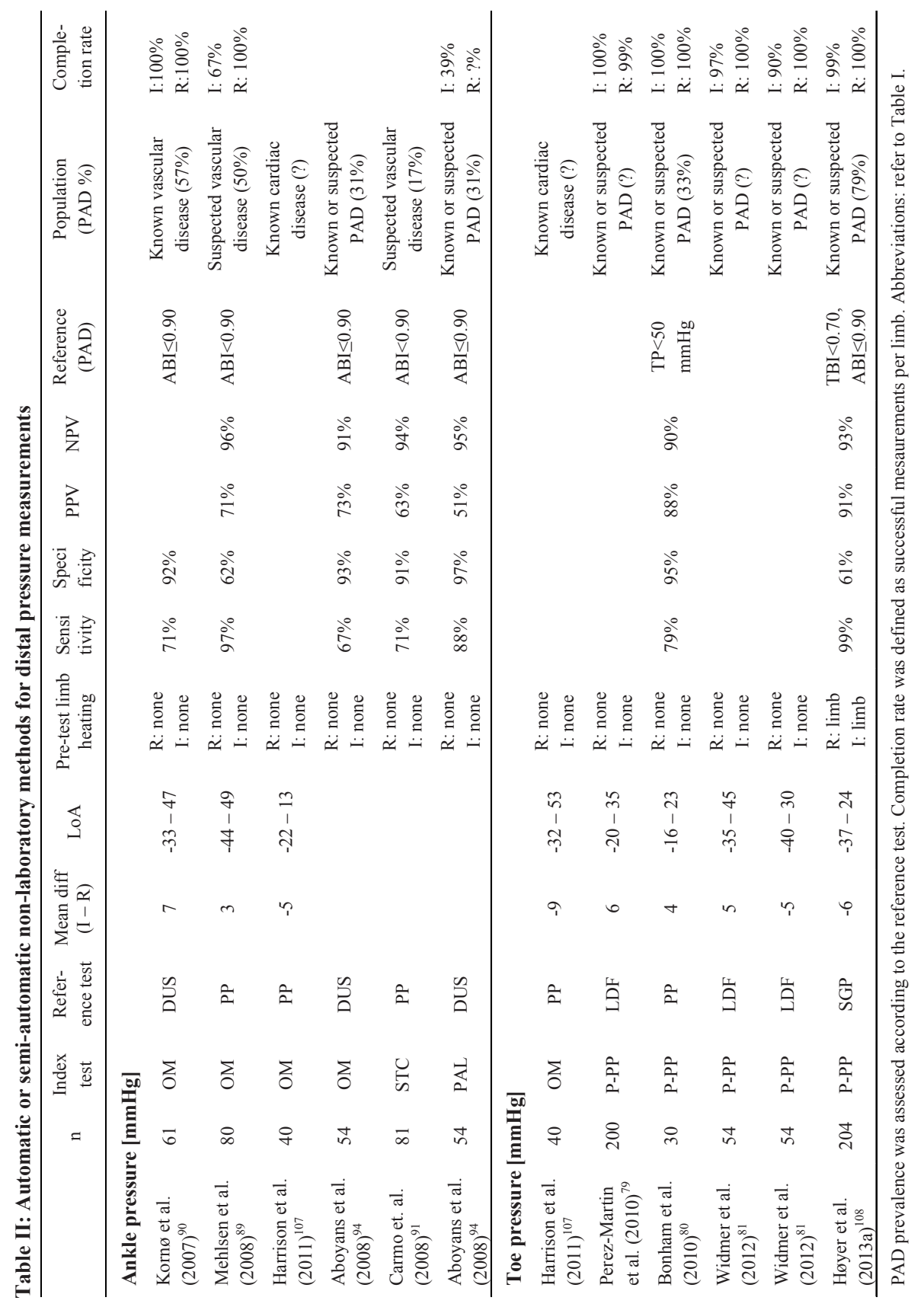




\subsubsection{Physiology of distal blood pressure}

Blood pressure is a function of cardiac output and peripheral vascular resistance. ${ }^{109}$ The amplitude of the blood pressure waveform increases as it travels distally from the heart, leading to increased systolic blood pressure and decreased diastolic blood pressure. ${ }^{83}$ The amplification of the systolic pressure is partly due to the additive effect of the retrograde wave reflection from the resistant distal arterioles and other sites of the vascular bed. Consequently, the systolic blood pressure is higher at ankle level than centrally under normal conditions. In agreement with this, there is a correlation of systolic ankle pressures and body height, although the clinical relevance of this is negligible. ${ }^{110,111}$

The segmental blood pressure is also dependent of the total blood vessel area, which increases distally as the arteries divide into smaller vessels. The systolic blood pressure at toe level is lower than the blood pressure at ankle level in the normal situation. Because distal pressure is affected by changes in central blood pressure as well as reflection from resistant distal arterioles, it has been speculated that the indices are not fixed. ${ }^{83}$ In line with this reasoning, factors such as increased heart rate or changes in blood volume could, in theory, affect the distal pressures due to consequent changes in peripheral vascular resistance. However, studies on this have shown that these factors have limited clinical relevance. ${ }^{112,113}$

Blood pressure is furthermore dependent of the elasticity of the arterial system, and reduced vessel compliance lead to further increase in the amplitude. In the presence of advanced vessel stiffness, the cushioning Windkessel function of the aorta is reduced due to fragmentation of elastin fibres leading to a more pulsative distal flow, increment of vessel diameter, and the risk of tissue damage. ${ }^{114,}{ }^{115}$ In medium to small-size muscular arteries such as the radial artery, inter-mammary arteries, and ankle arteries, medial arterial calcinosis (MAC) causes circumferential calcification of the tunica media and increased vessel rigidity with a similar change in flow transmitation. ${ }^{116}$

During measurement of distal limb pressures, the gradual deflation of the occlusion cuff leads to different phases with an initial complete vessel occlusion, followed by a period of arterial inflow but compromised venous flow, and lastly gradual return of venous flow. The normal response to the release of an arterial occlusion is post-occlusive reactive hyperaemia which 
induces brief vasodilation followed by vasoconstriction. ${ }^{117}$ In microvascular pathology such as endothelial dysfunction, which is associated with, e.g., diabetes, this response pattern is dampened. ${ }^{118}$ When a venous stasis is present, the so-called veno-arteriolar reflex is activated, leading to vasoconstriction and ultimately a reduction in peripheral blood flow. ${ }^{119}$ This reflex is activated when a venous pressure larger than $40 \mathrm{mmHg}$ is present and can induce an up to $50 \%$ reduction of the arterial inflow. ${ }^{120}$ Studies have shown that this reflex is diminished in patients with microvascular disease. ${ }^{121}$ Furthermore, repeated measurements, pain, or low temperature can lead to vasospasm and can thus reduce the relative flow.

Recently, there has been increasing attention on the uneven distribution of lower limb perfusion in different vascular territories of the foot known as angiosomes. ${ }^{122}$ Six major angiosomes of the foot and ankle have been identified, originating from the three main arteries and their branches. These angiosomes are connected by collateral blood flow, which can be limited, but the clinical relevance has been disputed. ${ }^{123}$

Figure 2 [next page]. An example of toe pressure measurement by laser Doppler flowmetry (measuring capillary flow) and Strain Gauge Plethysmography (detecting changes in peripheral volume). First, the occlusion cuff is inflated to a supra-systolic level, inducing zero flow at the site of measurement. Secondly, the occlusion cuff is slowly released, ultimately leading to re-establishment of blood-flow. The return of blood-flow is a composite signal involving re-flow in the supplying vessels in a given order, systolic pressure reached followed by diastolic, reactive hyperaemia, the veno-arteriolar reflex, inflow until venous stasis compromise capillary flow, and the release of venous stasis (based on own data). 

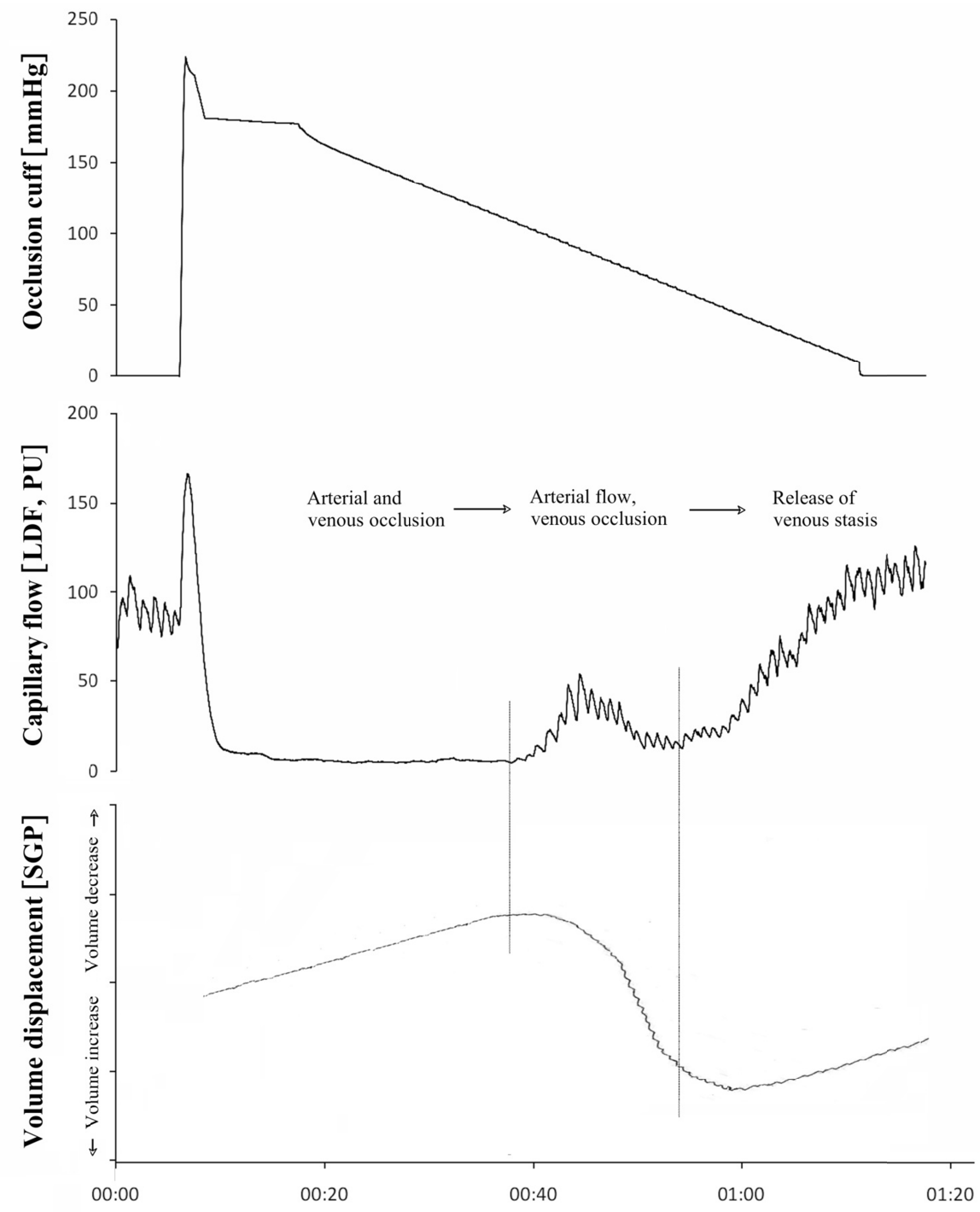

Time [min:sec] 


\subsubsection{Strengths and pitfalls of the ankle-brachial index}

The ankle-brachial index is calculated as the ratio between the ankle pressure and brachial pressure. ${ }^{83}$ The vast majority of inter-society consensus guidelines and reviews advocate the use of $\mathrm{ABI} \leq 0.90$ or $\mathrm{ABI}<$ 0.9 as being diagnostic for PAD. ${ }^{2}, 37,41,124-129$ The magnitude of ABI decrease has been shown to correlate with symptoms including walking distance. ${ }^{76}$ It has been suggested that the limit used should be non-fixed and change depending on the accuracy of the method in use and the number of measurement performed. ${ }^{130}$

Despite the fact that an $\mathrm{ABI} \leq 0.90$ is considered robust in PAD diagnostics, correlation with angiographic findings remains ambiguous. Dachun et al. (2012) showed in a systematic review that the sensitivity for this cut-off ranged from $15-79 \%$ and the specificity ranged from $83-100 \%$ for detecting $>50 \%$ vessel stenosis in the lower limb. ${ }^{131}$ The sensitivity was particularly low in elderly patients and in patients with diabetes. This is in agreement with findings showing that ABI may underestimate the severity of PAD, particularly in patients with diabetes or severe arterial calcification. ${ }^{132-136}$

Fowkes et al. (2008) reviewed the evidence supporting the ABI as a prognostic marker combined with Framingham risk factors in a metaanalysis. Based on 16 population cohort studies $(n=48,294)$, they showed an inverse J-shaped correlation with $\mathrm{ABI}$ and death with a low risk for 1.11 $<\mathrm{ABI}<1.40{ }^{4} \mathrm{An} \mathrm{ABI} \leq 0.90$ was associated with a two-fold increase in 10 -year mortality, cardiovascular mortality, and major coronary events compared with the overall rate in each Framingham risk factor category. They suggested that $0.91<\mathrm{ABI}<1.00$ constituted a borderline abnormal finding due to the increased mortality when compared to patients with a $1.00<\mathrm{ABI}<1.30{ }^{4}$ This borderline classification has also been proposed in other studies. ${ }^{137,138}$ Aboyans et. al (2010) showed in the Multi-ethnic Study of Atherosclerosis that $\mathrm{ABI}<1.00$ is associated with coronary artery disease despite the absence of traditional arteriosclerotic risk factors. ${ }^{139}$ Furthermore, the ABI has been shown to correlate with glomerular filtration rate ${ }^{140}$ and survival ${ }^{141}$ in patients with chronic kidney failure, as well as coronary artery calcification. ${ }^{142}$

In cases with advanced vessel stiffness, the ankle arteries can be incompressible and the pressure cannot be measured despite inflation of the 
occlusion cuff $>250 \mathrm{mmHg} .{ }^{143}$ In situations with less advanced vessel stiffness, the ankle artery systolic pressure is measurable but exceeds the normal range. The limits recommended for diagnosis of supra-normal ABI are controversial, with different limits being used, such as ABI $>1.15^{32}$, $\mathrm{ABI}>1.30^{11,124,128,132}, \mathrm{ABI}>1.40^{2,18,126,129}$ (recommended by TASC-II), and $\mathrm{ABI}>1.50 .{ }^{39}$ Regardless of the limits used, the $\mathrm{ABI}$ has been shown to underestimate the presence of MAC when compared to findings from imaging techniques. ${ }^{144}$ Typical radiological findings of MAC are linear railroad track-type calcifications. ${ }^{9,} 11$ Studies have shown that more than half of the patients with supra-normal ABI have masked multilevel PAD, based on angiography. ${ }^{32,145}$ X-ray verified MAC has been shown as a prognostic indicator for cardiovascular disease and death in patients with chronic kidney failure. ${ }^{144}$

\subsubsection{Strengths and pitfalls of the toe-brachial index}

The toe-brachial index is defined as the ratio between toe pressure and brachial pressure. Høyer et al. 2013f (by the author and supervisors of this thesis) reviewed the literature regarding the evidence supporting the use of the TBI in the diagnosis of PAD. ${ }^{146}$ The measurement of absolute toe pressures is well validated in the diagnosis of critical limb ischaemia and is a prognostic marker for wound healing. ${ }^{14,71,147,148}$ However, the review showed that the use of the TBI for the diagnosis of PAD remains highly controversial, particularly regarding the diagnostic limits. Although most guidelines ${ }^{2}, 125,138$ and reviews on PAD diagnostics ${ }^{124,126,128,129}$ advocated a TBI of $<0.70$ as the cut-off, it is not strictly evidence-based. Other limits are frequently used in observational studies and clinical settings such as TBI $<0.75^{149}$, TBI $<0.74^{21}$, TBI $<$ $0.65^{150}, \mathrm{TBI}<0.64^{23,41,151}, \mathrm{TBI}<0.60^{11,31,32,132,152}$ or TBI $\leq 0.54 .^{15^{3}}$

A total of eight studies in normal populations were identified in the review, of which only one study ruled out arterial stenosis using imaging techniques. ${ }^{21,149,153-157}$ A normal range (mean \pm 2 SD) of $0.71-1.14$ was estimated based on the weighted average in studies with pre-heating of the limbs as shown in Figure 3. However, large methodological issues were detected, such as a lack of imaging techniques to exclude PAD, small study sample sizes, inclusion of persons with inappropriate age distributions, and the use of different and likely not directly comparable techniques. 
The review identified seven studies that showed correlations of the TBI with angiographic findings. ${ }^{32}, 88,145,156,158$ These studies showed a sensitivity of $90-100 \%$ and specificity of $65-100 \%$ for the TBI for the detection of vessel stenosis but were based on highly selective populations that could bias the findings. In addition to the different diagnostic limits used in these studies, there were large methodological discrepancies.

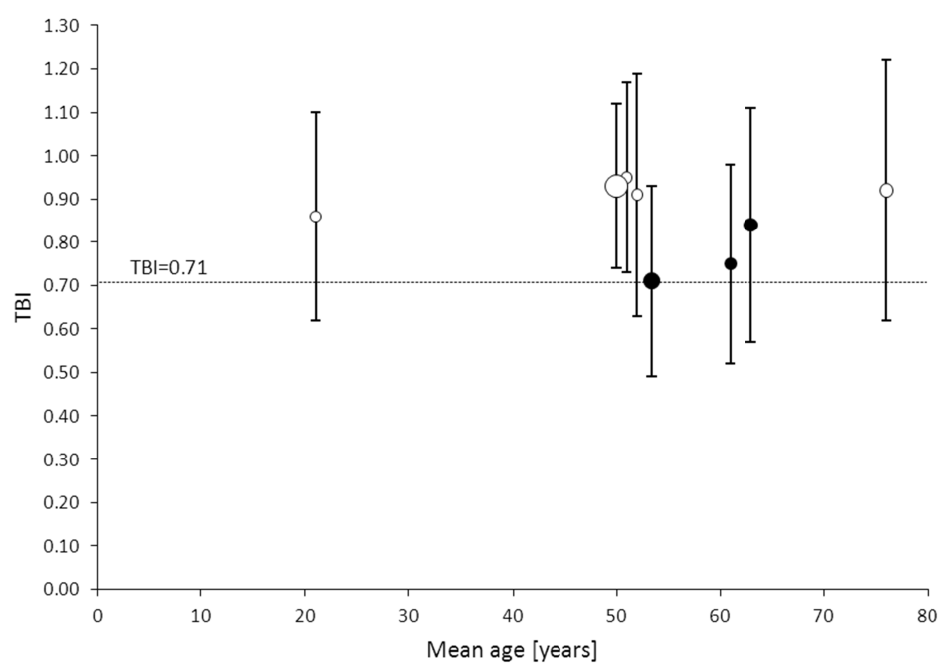

Figure 3. Data from studies on normal population. Values show mean TBI +/- 2: SD. The size of the dot representing the mean illustrates the sample size. Hollow dots represent studies with pre-heating of the limb prior to blood pressure measurements. The vertical line shows the weighted mean of the lower limit based on studies using pre-test limb heating. Reprinted with permission from Elsevier (J Vasc Surg) from Høyer et al. (2013f). ${ }^{146}$

Only a few studies have investigated the value of the TBI as a prognostic marker on cardiovascular mortality and morbidity, and no firm conclusions could be made. ${ }^{132,147,159}$ The TBI is generally considered a stronger tool than $\mathrm{ABI}$ in the diagnosis of PAD in patients with diabetes due to a large prevalence of vessel stiffness. ${ }^{160}$ Studies have shown that the TBI is more closely associated with estimated the glomerular filtration rate, the degree of albuminuria, ${ }^{161}$ inflammatory markers ${ }^{162,}{ }^{163}$, and the presence of peripheral neuropathy ${ }^{156,164}$ in patients with diabetes. Additionally, the TBI has been shown to have a stronger association than ABI with risk factors 
associated with chronic kidney failure ${ }^{31,150,165}$, coronary artery stenosis ${ }^{152}$, micro-vascular diseases ${ }^{166}$ such as erectile dysfunction ${ }^{167}$, and systemic sclerosis. ${ }^{157}$ Furthermore, the TBI has been shown to be a predictor for restenosis following percutaneous trans-luminal angioplasty. ${ }^{168}$

It has been proposed that a low TBI in the setting of a normal ABI reflects small-vessel disease, while patients with a low ABI have large-vessel disease. ${ }^{24,30}$ However, the group is more heterogeneous because a subgroup of patients with vessel stiffness would produce a falsely normal ABI, and mask the presence of true large-vessel disease. ${ }^{32,66,133,134}$ Moreover, because the toe vessels are susceptible to vasoconstriction ${ }^{63}$, patients without PAD could falsely be classified as having a low TBI. This effect can be minimised by measuring the TBI under standardised conditions, such as using rooms with stable temperatures and implementing pre-test limb heating. ${ }^{96,97}$ Under standardized conditions, the day-to-day variation of toe pressures seems comparable to that of ankle pressures. ${ }^{169}$ Studies have shown that approximately one-third of the patients with a TBI $<0.7$ and a normal ABI progress to an abnormal ABI after a 4.6 year-followup. $^{22}$

\subsubsection{Variation in distal pressure measurements}

Distal limb pressures are known to be prone to substantial variation between measurements contributed by biological variation as well as variation attributed to the method. ${ }^{64}$ Important factors compromising reproducibility include observer variation ${ }^{170}$, temperature control $^{96}$, occlusion cuff $\operatorname{siz}^{100}$ and positioning ${ }^{101}$, and the interpretation of the derived signal. ${ }^{104,169}$

The important influence of short-term biological variation, for instance, caused by alterations in haemodynamics and vasospasm, is revealed by the substantial improvement in agreement between methods when conducting measurements simultaneously as opposed to subsequently. ${ }^{64,75}$

A mean day-to-day variation for the SGP method (standard deviation of mean pressure differences) ranging from $6-10 \mathrm{mmHg}$ for toe pressures and 9-11 mmHg for ankle pressures has been reported. ${ }^{169,171-173}$ Studies on LDF reproducibility have shown an intra-day variation ranging from 5-27 $\mathrm{mmHg}$ and week-to-week variation ranging from 13-34 $\mathrm{mmHg}$ for toe 
pressures. ${ }^{43,43}$ Studies on PP reproducibility have shown a week-to-week variation of $17 \mathrm{mmHg}$ for toe pressures. ${ }^{64}$ The corresponding findings for Doppler ultrasound ankle pressure measurements are 5-18 $\mathrm{mmHg}$ for intraday variation and 11-23 mmHg for week-to-week variation. ${ }^{43}$

To cope with the known overall variation of distal pressure measurement, a change of $>0.15$ in the $\mathrm{ABI}$ is usually required to be considered clinically significant. ${ }^{83}$ No similar definition has been made for the TBI. ${ }^{146}$

\subsubsection{Strategies for calculating the distal limb pressures}

One of the key differences in measurements across vascular laboratories is the use of different test strategies when calculating the blood pressures. ${ }^{174}$ In some cases, the pressure indices are calculated by single measurements and, in some cases, as an average of multiple measurements. ${ }^{79,} 83$ The evidence supporting these standards is sparse. In other laboratories, the number of measurements is based on a predefined reproducibility criterion. ${ }^{81,} 108$ This type of strategy to improve the reliability of measurements of brachial blood pressure measurements for diagnosis of arterial hypertension is recommended by the American Heart Association. ${ }^{87}$ To minimise the effect of variation due to changes in haemodynamics between measurements, the brachial blood pressure can be measured simultaneously with each corresponding segmental pressure to allow for calculation of the indices. However, some laboratories calculate all indices based on a single brachial pressure. ${ }^{83}$

\subsection{Methodological requirements in studies of diagnostic accuracy}

A major problem in studies of diagnostic accuracy is biased findings caused by the study design. To cope with this issue, a series of tools have been developed to aid in designing studies including standards for reporting diagnostic accuracy studies such as the STARD recommendations. ${ }^{175}$ Additionally, tools have been developed for grading the methodological quality of studies, such as GRADE ${ }^{176}$, QAREL ${ }^{177}$, QUADAS-I/-II ${ }^{95,178}$, and the Cochrane diagnostic test accuracy criteria. ${ }^{179}$ A common theme in these recommendations is to ensure a consecutive non-selective study population with a disease prevalence that is representative of the target population for the given method. Moreover, for the sake of generalisability, the 
equipment, standards, and observers used should be representative of intended future use in a clinical setting. Furthermore, when comparing methods, it is crucial to have a well-validated reference standard, proper randomisation, and a low influence of clinical clues. Knowledge on e.g., clinical clues, patient history can potentially bias the findings and can be minimised by blinding observers. ${ }^{180}$ However, the study should still be as close to the clinical setting as possible. ${ }^{179}$

\subsection{Conclusions leading to the present thesis}

Despite the many promising findings regarding the introduction of different automated portable methods for the measurement of toe pressures, the presented studies have huge methodological problems, especially concerning patient selection and operators. Diagnostic test accuracy studies according to the standards mentioned in the previous section (1.5) are pivotal for assessing the diagnostic potential of this approach for diagnosing PAD. This is needed before being able to assess whether TBI assessment could be used as a screening supplementary to or instead of the current standard; Doppler-based ABI.

Regardless of the fact that the LDF method is increasingly used as a reference standard in vascular laboratories, only a few large-scale studies have been conducted on the interchangeability with other laboratory methods, using a representative line of patients with appropriate blinding.

Correct signal interpretation is pivotal for correct diagnostic classification and is an important factor in the overall reproducibility. However, only a few small studies have assessed the reproducibility of curve readings for methods such as SGP and LDF.

Lastly, because different vascular laboratories use different approaches to calculating distal limb pressures regarding the number of measurements and comparisons to brachial arm pressures, studies are needed to explore the agreement among the different strategies. 
1) To evaluate the diagnostic characteristics and feasibility of a new portable method for diagnosing PAD by measuring toe pressures when using strain gauge plethysmography as a reference standard. (Study I)

2) To assess the reproducibility of strain gauge plethysmography curve reading and to investigate the potential influence of clinical clues for toe and ankle pressure measurements when using laboratory technologists as observers. (Study II)

3) To assess the interchangeability between the two laboratory standards, laser Doppler flowmetry and strain gauge plethysmography, for toe and ankle pressure measurements. (Study III)

4) To investigate the influence of different measuring strategies concerning the number of measurements and the importance of obtaining brachial pressures corresponding to each regional pressure for diagnosis of PAD and agreement with absolute pressures. (Study IV)

5) To assess the reproducibility of laser Doppler flowmetry curve reading for toe and ankle pressure measurements when using laboratory technologists as observers. (Study V) 



\section{Materials and methods}

\subsection{Study populations}

\subsubsection{Study I-II}

During a predefined period of two months from 1 September to 31 October 2010, all patients referred to the vascular laboratory for distal blood pressure measurements were invited to participate. The cohort was comprised of inpatients and outpatients with known or suspected PAD. If a patient was referred more than once during the trial period, only the data from the first referral was used. The eligibility criteria were age $>18$ years and mental capacity for complying with the study procedures. Patients were excluded if time constraints interfered with the study procedure. Ankle pressure measurements were not performed in cases with recent local revascularisation due to the risk of thrombosis. ${ }^{83}$ Finally, the Central Denmark Region Committee on Biomedical Research Ethics required that the patients had no less than three hours upon receiving and reading the letter of invitation to consider participation in the study. The dataflow is shown in Figure 4.

\subsubsection{Study III-V}

Consecutive patients referred for distal blood pressure measurements in the Spring of 2012 with known or suspected PAD were screened for inclusion in the trial. Two hundred patients were scheduled for inclusion in the study. The same inclusion criteria were applied as used in Study I-II, with the exception that the Central Denmark Region Committee on Biomedical Research Ethics did not require a minimum time to consider participation in the study. A total of 223 patients were screened, and 200 patients $(90 \%$ of referred patients) were included in the period between February 20 and April 10, 2012. The dataflow is shown in Figure 5. 
Figure 4. Diagram showing the dataflow in Study I-II. *) Not performed due to recent vascular surgery or large wounds.

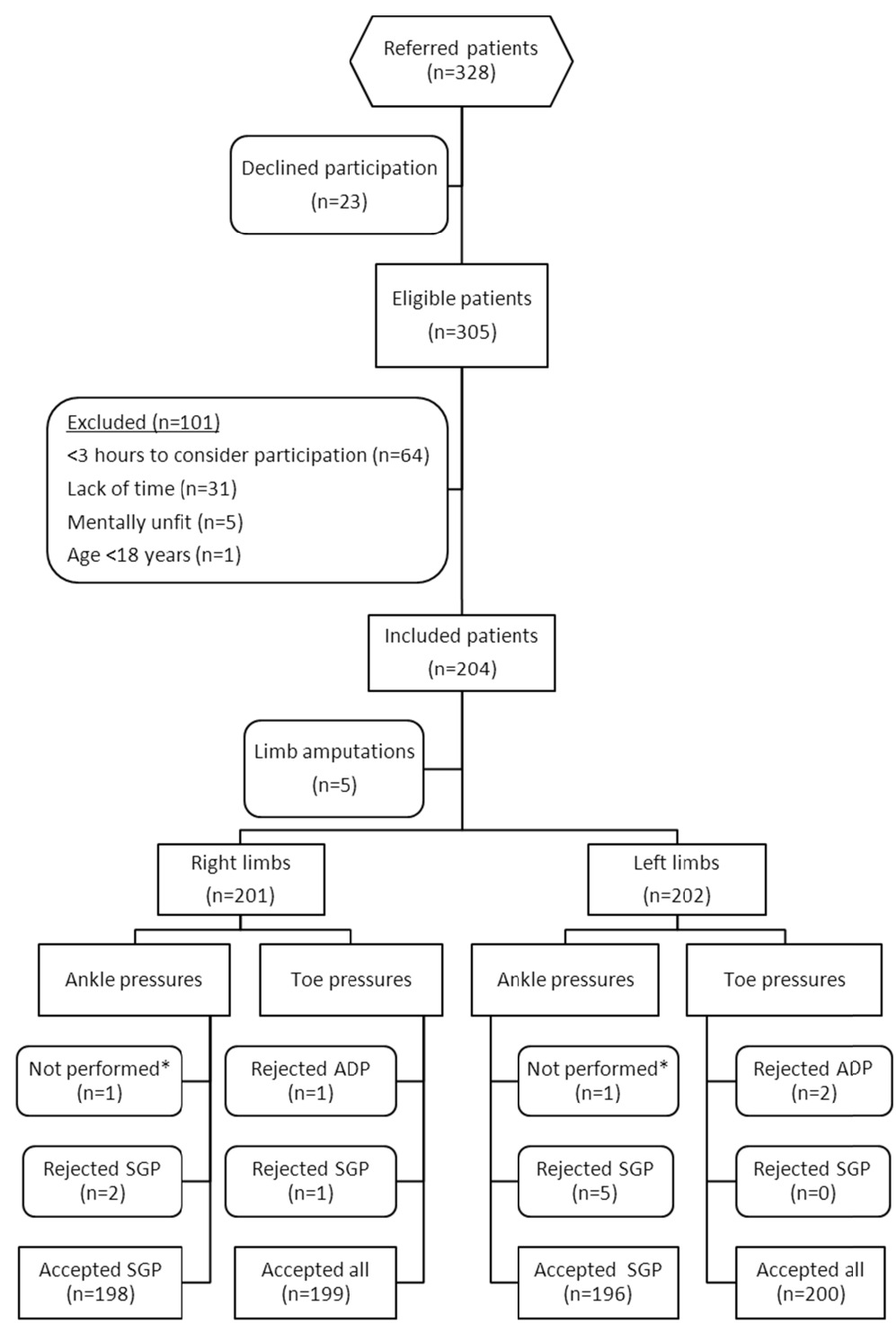


Figure 5. Diagram showing the dataflow in Study III-V. *) Not performed due to recent vascular surgery, large wounds or fractures.

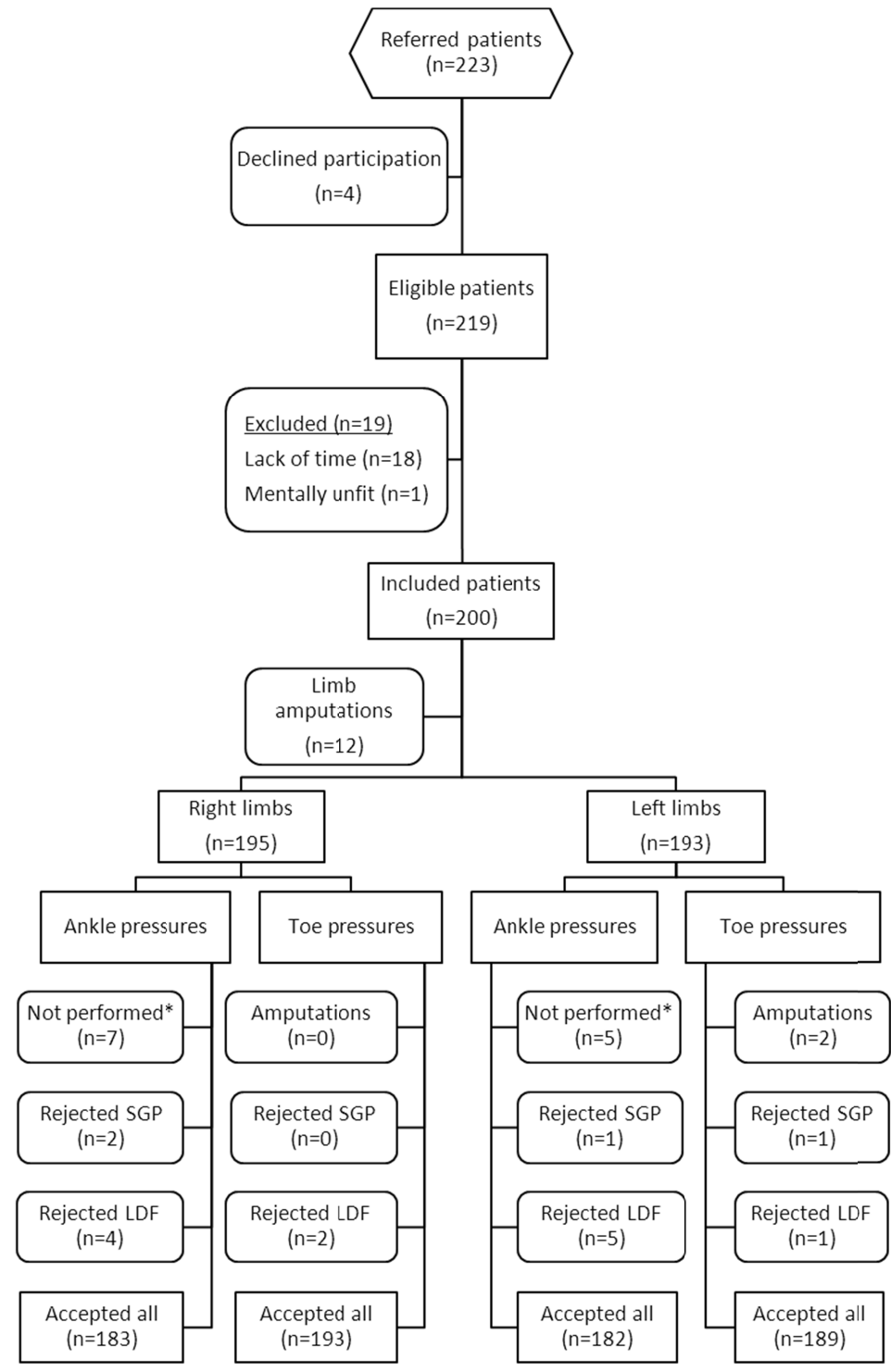




\subsection{Methods}

\subsubsection{Test standards (Study I+III)}

The patients rested in a supine position in a room with stable temperature for at least 15 minutes prior to the measurements. Adequate limb temperature was provided by heating the lower extremities with heating overlays (Action Shear Smart ${ }^{\circledR}$, Action Products Inc., Hagerstown, MD, USA) at $35-40^{\circ} \mathrm{C}$. The skin temperature of the first toe was measured prior to each segmental pressure assessment using an infrared thermometer (TN1 thermometer ${ }^{\circledR}$, Electronic Temperature Instruments Ltd., Worthing, UK).

\subsubsection{Accepted measurements (Study I+III)}

All measurements in Study I + III were made at least in duplicate at each measuring site. The measurements were repeated until two readings were obtained with a maximum difference of $10 \mathrm{mmHg}$. A maximum of five measurements were performed at each site. An average of the two measurements with a difference $\leq 10 \mathrm{mmHg}$ was used to calculate the segmental pressure. In cases where three pressures were obtained with a difference of $\leq 20 \mathrm{mmHg}$ between the highest and lowest value, an average of the three was used.

\subsubsection{Measuring sequence (Study I)}

Toe pressures were measured by the index test and reference test in both limbs by two different operators blinded to the results of the other test. In the case of toe amputations or an inability to apply the cuff to the first toe, measurements were performed on the second toe using both methods. All patients were randomised in blocks of four (opaque, sealed envelopes) to determine which test would be used first. Following the measurement of toe pressures by the index and reference tests, ankle pressures were assessed by SGP in all patients.

\subsubsection{Measuring sequence (Study III)}

Eligible patients were randomised for measurements by both techniques in one of the two sequences: (1) $\mathrm{SGP}_{\text {toe pressures }}-\mathrm{LDF}_{\text {toe pressures }}-\mathrm{SGP}_{\text {ankle pressures- }}{ }^{-}$ $\mathrm{LDF}_{\text {ankle }}$ pressures or (2) $\mathrm{LDF}_{\text {toe }}$ pressures $-\mathrm{SGP}_{\text {toe }}$ pressures $-\mathrm{LDF}_{\text {ankle }}$ pressures ${ }^{-}$ 


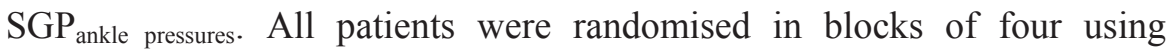
opaque, sealed envelopes to determine the sequence. Measurements were obtained by different operators for each method, who were blinded to the results of the other test. Pressure measurements at the toe or ankle level were conducted in both limbs simultaneously. The same occlusion cuffs were used by both systems, and there was no repositioning of the cuffs between tests. The occlusion cuffs were connected to pressure controllers specific for each device.

\subsubsection{Blood pressure measurements}

\subsubsection{Reference test: SGP (Study I+III)}

A Digitmatic DM2000® (Medimatic A/S, Hellerup, Denmark) was used for the SGP with measurements of both limbs conducted simultaneously. A mercury-in-silastic strain gauge was wrapped around the pulp of the toe for all SGP measurements. For the toe pressure measurements, appropriately sized pneumatic occlusion cuffs (ranging 90-130x15-25 mm) were placed at the base of the toe. Prior to filling the occlusion cuff, a 10-second manual pressure was applied to the pulp of the toe to empty the vascular bed. For the ankle pressure measurements, occlusion cuffs of 290-420x120 mm were used, and the lower limbs were elevated $50-70 \mathrm{~cm} 30$ seconds prior to inflation to reduce the peripheral blood volume. The deflation time for the occlusion cuff (average $3 \mathrm{mmHg} / \mathrm{sec}$ ) and the sensitivity were adjusted appropriately by the primary observer according to the institution's practice.

\subsubsection{Index test: ADP (Study I)}

The automated photoplethysmographic device (SysToe $\AA$, Atys Medical, Soucieu-en-Jarrest, France) was used. A $120 \times 25$ or 90x15 mm pneumatic occlusion cuff was placed on the base of the toe (proximal cuff). The sensor was positioned on the toe pulp with two-sided adhesive tape and covered by another pressure cuff (distal cuff). ${ }^{79}$ Upon initiation of an automated sequence, the distal cuff was inflated to empty the vascular bed of the toe. After five seconds, the proximal cuff was automatically inflated to 300 $\mathrm{mmHg}$, followed by a rapid deflation of the distal cuff. During the automatic deflation of the proximal cuff $(3 \mathrm{mmHg} / \mathrm{sec})$, the photosensor detected the influx of erythrocytes when the segmental pressure superseded the pressure in the proximal cuff. The APD measures one limb at a time 
and uses a software algorithm that automatically calculates the toe pressures.

\subsubsection{Index test: LDF (Study III)}

The MoorVMS-LDF ${ }^{\circledR}$ (Moor Inc, Axminster, Devon, UK) system was used for the LDF measurements. The two probes (VP-1, Moor Inc, Axminster, Devon, UK) were embedded in a moulded flexible socket and secured using adhesive discs. The tubes from the occlusion cuffs were connected to the pressure controller (MoorVMS-PRES ${ }^{\circledR}$, Moor Inc, Axminster, Devon, UK). Following the positioning of the probe, an automated protocol was initiated that inflated the occlusion-cuff (inflation time approximately $3 \mathrm{sec})$ to a pressure selected by the operator $(150-250$ $\mathrm{mmHg}$ ), well above the systolic arm pressure. After a hold period of 10 seconds, the proximal cuff deflated automatically $(3 \mathrm{mmHg} / \mathrm{sec})$ with the probe measuring skin blood flow throughout the deflation period with a sampling rate of $40 \mathrm{~Hz}$.

\subsubsection{Brachial blood pressure (Study I+III)}

Brachial blood pressures were measured in the supine position using an automated device (Digital Blood Pressure Monitor, UA-852, A\&D Instruments, Abingdon, UK). The blood pressure was measured in both arms, and the side with the highest systolic pressure was selected as the reference for the ABI and TBI calculations. The brachial pressure was acquired simultaneously with all separate measurements of the toe and ankle pressures.

\subsubsection{Post-trial data reanalysis}

\subsubsection{Study I-II}

In addition to the on-site pressure reading, the SGP curves were re-analysed after the experiment was finalised following a period of at least three months. Two independent observers rated the curves with no information on patient history, signs, or symptoms. It was not permitted to make any marks or notes on the SGP curves during the sampling that could interfere with the subsequent blinded re-evaluation of the measurements. 


\subsubsection{Study III, V}

At least three months after the completion of the trial, two independent observers re-analysed the LDF curves without information regarding patient history, signs, or symptoms. The observers received supervised training in LDF curve interpretation during the study period and additional training prior to the readings.

\subsubsection{Study IV}

The segmental pressures derived from Study III, were re-calculated using the following three methods: [M-1], only the first measurement was used; [M-2], an average of the first two measurements, and [RC], an average of two measurements with a difference $\leq 10 \mathrm{mmHg}$ ("reproducibility criterion"). In cases where three pressures were obtained with a difference $\leq 20 \mathrm{mmHg}$ between the highest and lowest value, an average of the three was used. The TBI and ABI were calculated using (1) only the baseline brachial blood pressure obtained as a reference (BBP-one) and (2) all the corresponding brachial blood pressures (BBP-all).

\subsubsection{Observers}

\subsubsection{Study I-II}

The measurements and initial readings were performed by 13 laboratory technologists who routinely perform distal blood pressure measurements. Their experience with SGP ranged from 1.5 to 28 years (median 3.5 years). All of the technologists received supervised training with the APD before conducting the study. Two of these laboratory technicians, who were responsible for distal blood pressure methods at our department, were assigned to secondary re-reading of the curves; they had experience of 1.5 and 5 years with the SGP method.

\subsubsection{Study III-V}

The measurements and on-site readings were conducted by ten laboratory technicians with experience with the SGP method ranging from 2.8 to 29.3 years (median 4.8 years). They had no prior experience with LDF but received detailed training before and during the study. The two laboratory technicians who were assigned to secondary re-reading of the curves had 3.4 years of experience with distal pressure measurement. 


\subsubsection{Statistics}

The data are presented as the means \pm standard deviations. Agreement in diagnostic classification (PAD/not PAD) was analysed using Cohen's Kappa (к). A $\kappa$ value ranging from 0.41-0.60 indicated moderate agreement, a value between 0.61-0.80 indicated substantial agreement, and a value between 0.81-0.99 indicated almost perfect agreement. ${ }^{181}$ Quantilequantile plots and histogram analysis of the data were used to investigate whether the variables were normally distributed. Agreement on absolute pressure values and indices was assessed using an intra-class correlation coefficient (absolute agreement, single measures, two-way random model). Reproducibility for repeated measurements was assessed using coefficient of variance. Difference-mean plots (Bland-Altman) were constructed to assess the discordance in the range of pressures. ${ }^{182,}{ }^{183}$ In the case of heteroscedasticity, the difference-mean plots were substituted with differences expressed as relative differences vs. mean plots. ${ }^{184}$ Paired or unpaired $t$ tests were used for intragroup comparison of the variables of the various methods. A P-value $<0.05$ was considered to be statistically significant. Pre-test power calculations were not performed because the primary end-point was not to detect a systematic difference among the methods but to investigate the applicability of the methods in an everyday clinical setting. To ensure a representative study population, study sizes of approximately 200 patients were selected for the studies prior to inclusion. Statistical analysis was performed using SPSS software version 20.0 (SPSS Inc., Chicago, IL, USA). 


\section{Study I: Randomised diagnostic accuracy study of a fully automated portable device for diagnosing peripheral arterial disease by measuring the toe-brachial index}

\subsection{Major findings}

\subsubsection{Patients and data sampling}

Among the 204 patients, five patients had lower limb amputations leaving 201 right and 202 left limbs eligible for segmental pressure assessment. Ankle blood pressures were not measured in a few patients due to recent vascular surgery. All patients had successful toe pressure measurements by both methods in at least one limb. Of the 403 examined limbs, the APD was able to measure toe pressures in accordance with our reproducibility criteria in $400(99.2 \%)$ limbs, and SGP was able to measure toe pressures in $402(99.8 \%)$ limbs. Please confer to appendix A for demographic characteristics.

\subsubsection{Agreement in diagnostic classification}

Of the 204 patients, PAD was diagnosed using SGP in 161 patients (78.9\%) and using APD in 177 patients (86.8\%) based on TBI measurements. A total of 159 patients $(77.9 \%)$ were classified as having a TBI $<0.70$, and 25 patients $(12.3 \%)$ had a normal TBI according to both methods, leading to an overall agreement in diagnostic classification in 184 patients $(90.2 \%)$. Two patients $(0.9 \%)$ had a TBI $<0.70$ according to APD alone, and 18 patients $(7.8 \%)$ had a TBI $<0.70$ according to SGP only. When adding the ABI from the SGP measurements to diagnose PAD, two patients were re-classified from non-PAD to PAD. These two patients had a 
TBI $<0.70$, as measured by APD. A total of 35 of 204 patients $(17.2 \%)$ had an ABI $>0.90$ but a TBI $<0.70$ as measured by SGP. 34 of the 35 patients also had TBI $<0.70$ as measured by APD. Fourteen of these patients were suspected of vascular stiffness based on a history of diabetes or chronic kidney disease, or ABI > 1.40 .

Table III: Agreement in PAD diagnosis

\begin{tabular}{lccc}
\hline SGP & \multicolumn{3}{c}{ APD } \\
\cline { 2 - 3 } & PAD & Not PAD & Total \\
\hline PAD & 161 & 2 & 163 \\
Not PAD & 16 & 25 & 41 \\
\hline Total & 177 & 27 & 204 \\
\hline & $\kappa=0.685(95 \%$ CI: $0.546-0.824)$ \\
\hline
\end{tabular}

Table IV: Test accuracy of the APD with SGP as reference test

\begin{tabular}{lllll}
\hline & Sensitivity & Specificity & PPV & NPV \\
\hline $\mathrm{TBI}<0.7$ & $98.8 \%$ & $58.1 \%$ & $89.8 \%$ & $92.6 \%$ \\
$\mathrm{TBI}<0.7$ or $\mathrm{ABI} \leq 0.9$ & $98.8 \%$ & $61.0 \%$ & $91.0 \%$ & $92.6 \%$ \\
$\mathrm{CLI}$ & $83.3 \%$ & $97.8 \%$ & $78.9 \%$ & $98.4 \%$ \\
\hline
\end{tabular}

PPV: positive predictive value, NPV: negative predictive value. CLI diagnosis is based on Fontaine III/IV as well as SGP toe pressures. 


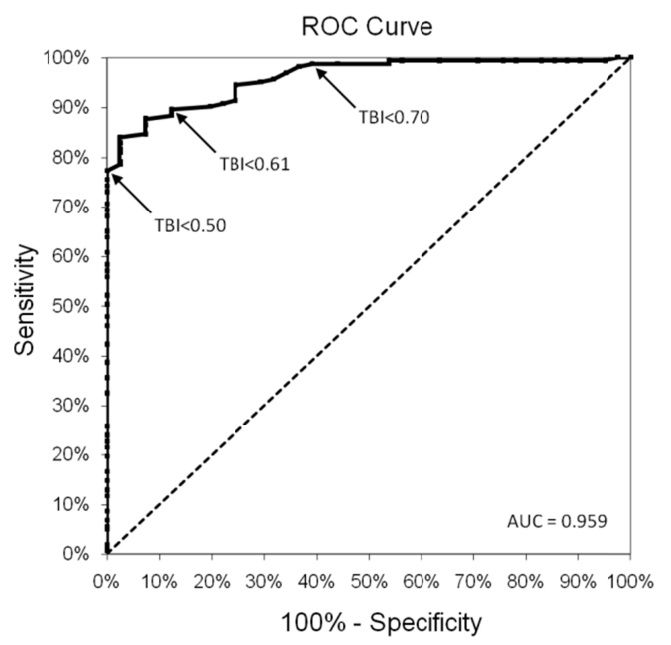

Figure 6. Receiver operator characteristics (ROC) curve for various APD cut-off values versus a full SGP examination.

A receiver operator characteristics curve for various APD cut-off values versus a full SGP examination was constructed (Figure 6). This showed excellent diagnostic characteristics based on an area under the curve of 0.959. The highest diagnostic accuracy was found using an APD cut-off of TBI $<0.61$, resulting in a sensitivity of $89.6 \%$ and specificity of $87.8 \%$. In addition, a TBI $<0.50$ was indicative of PAD diagnosed by the full SGP test (specificity of $100 \%$ ).

\subsubsection{Agreement in absolute toe pressures}

There was a close correlation between the absolute toe pressures measured by the index and reference tests, as demonstrated by an ICC of $0.937(95 \%$ CI $0.887-0.962)$ for the right toe pressures $(74.4 \pm 33.1 \mathrm{mmHg})$ and by $0.939(95 \% 0.908-0.958)$ for the left toe pressures $(74.3 \pm 32.5 \mathrm{mmHg})$. Accordingly, the ICC for the TBI was $0.934(95 \%$ CI $0.886-0.959)$ for the right limb $(0.54 \pm 0.23)$ and $0.929(95 \%$ CI $0.897-0.950)$ for the left limb $(0.54 \pm 0.23)$. On average, the APD produced $7.1 \pm 15.1 \mathrm{mmHg}$ and $5.4 \pm$ $15.2 \mathrm{mmHg}$ lower pressure readings than the SGP for the right and left toe pressures, respectively. 

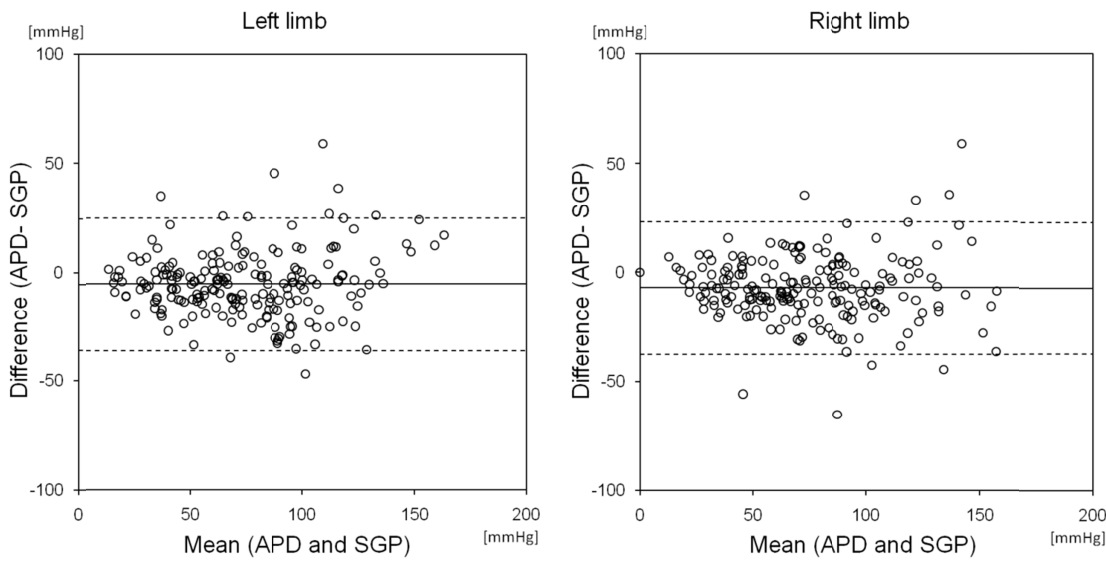

Figure 7. Difference-mean plots for the toe pressures by SGP versus APD for the left $(\mathrm{n}=200)$ and right limbs $(\mathrm{n}=199)$. The lines show the mean (full line $) \pm 2 \mathrm{SD}$ (dotted line).

\subsubsection{Test reproducibility}

The APD had a mean coefficient of variance (CV) of $6.83 \%$ for the absolute right toe pressure and $7.36 \%$ for the absolute left toe pressure. A subgroup analysis of readings from the different APD operators showed CV to vary from $3.34 \%$ to $14.06 \%$ for right side pressures and $4.01 \%$ to $11.67 \%$ for left side pressures. In comparison, the SGP had a mean CV of $5.58 \%$ and $6.01 \%$ for the right and left toe pressures, respectively. The number of measurements required to generate a dataset that met our reproducibility criterion was $2.4 \pm 0.8$ measurements with the APD. The corresponding figures were $2.4 \pm 0.7$ for the SGP toe measurements and 2.4 \pm 0.8 for the SGP ankle pressures.

\subsubsection{Time and pain}

The mean time (min:sec) for the APD examination was 12:24 $\pm 3: 17$ per patient and 6:16 $\pm 1: 40$ per limb. The time to conduct dual toe SGP measurements per patient was significantly shorter than the APD examination $(7: 09 \pm 3: 17 ; \mathrm{p}<0.05)$. A full SGP examination of the toe and 
ankle measurements lasted 15:16 \pm 7:18. The APD was less painful $(0.5 \pm$ 1.1) than SGP regarding the toe $(1.3 \pm 2.2)$ or ankle pressure measurements $(2.0 \pm 2.3)(\mathrm{p}<0.05)$

\subsection{Discussion}

Our results showed good correlation of segmental blood flow measurements between the APD and the SGP over a range of pressures, including patients with low pressures. Disease classification showed a large degree of agreement, suggesting excellent diagnostic characteristics of the APD. The APD had a high sensitivity for detecting PAD according to the TASC-II criteria, and a TBI reading below 0.5 using the APD was indicative of corresponding abnormal SGP findings. An APD $0.50 \leq \mathrm{TBI}<$ 0.71 would require an additional test to establish the PAD diagnosis.

The APD was able to perform measurements according to our reproducibility criteria in $99.2 \%$ of the included limbs. As the measuring sequence is fully automated, it offers an observer-independent interpretation of the segmental pressure. In addition, in our study, the APD induced less pain and was less time consuming compared to the SGP for measuring the TBI and ABI.

An earlier study (Pérez-Martin et al, 2010) has shown acceptable test-retest variation using the same equipment and found a good correlation with absolute pressures compared to laser Doppler flowmetry. ${ }^{79}$ However, this study did not focus on PAD diagnosis on a patient basis but absolute pressure comparisons, and it was conducted in a selected population. In addition to the device tested in this study, a number of other automatic and semi-automatic portable devices based on photoplethysmographic principles have been developed for practical and cost-effective toe-pressure measurements. ${ }^{41,103,104,170}$ These devices have all been compared to standardised distal pressure assessments with varying success. Generally, prior studies have failed to follow recommendations for diagnostic accuracy studies as outlined by STARD and Cochrane DTA, especially regarding patient selection and disease classification. The primary tool for PAD screening, which is Doppler derived measurement of ABI, has a low rate of success for toe pressure measurements. ${ }^{86}$ 
The segmental pressures in this study were acquired using a standardised laboratory setup, including pre-test limb heating and a stable room temperature. Inadequate limb heating leads to reduced toe pressures and disease misclassification. ${ }^{97}$ Nonetheless, the implementation of low-cost TBI screening in primary or secondary care using the APD seems plausible given the minimal observer training required. Making pre-test limb heating and limb temperature measurements standard prior to toe pressure assessment would be imperative to strengthen reproducibility in nonlaboratory settings.

Screening is a major key for detecting early-stage disease, which allows initiation of optimal medical treatment and reducing modifiable risk factors for high-risk patients. ${ }^{25}$ Current practical low-cost tools for PAD screening in primary care or for bedside use include clinical examination ${ }^{46}$ with pulse palpation $^{8}$, patient history ${ }^{8}$, and Doppler-ABI ${ }^{46,84}$ An abnormal ABI has been proven to be a valid predictor of cardiovascular morbidity and mortality. ${ }^{4}$ However, in patients with vascular stiffness, there is a risk of overestimating the ankle pressures, leading to disease misclassification. ${ }^{133}$ In contrast, the distal pedal arteries are less susceptible to media calcinosis, which makes the measurement of toe pressures useful. ${ }^{41}$ In concurrence, the toe blood pressure measurement is strongly endorsed by the TASC-II guidelines, ${ }^{2}$ and have previously been shown to correlate well to angiographic findings. ${ }^{158}$ An interesting observation is that $17.2 \%$ of the patients in this study who were diagnosed as having PAD according to the SGP-derived TBI had a normal ABI. As the SGP method at our Department previously has been shown to correspond to Doppler ABI, these patients would likely be classified as normal based on ABI screening only. ${ }^{105}$ This finding is in agreement with the results from studies in patients with diabetes ${ }^{21}$ or chronic kidney disease. ${ }^{31}$ Nonetheless, $60 \%$ of the patients with a normal ABI but TBI $<0.70$ in our study were not suspected of having vascular stiffness based on the diagnosis of diabetes, chronic kidney disease or ABI $>1.40$. The TBI-based APD method could potentially be used as an initial test for identifying patients who need further diagnostic vascular examination. This could lead to improved overall screening for PAD and potentially detect high-risk patients who remain undiagnosed by current standards. 


\subsection{Study limitations}

The patients recruited in this study had a higher prevalence of PAD than would be anticipated in an age-matched general population or in primary care.

\subsection{Conclusions}

Using SGP as a reference, the APD showed high sensitivity and acceptable specificity for detecting PAD. The APD could be justified as a gatekeeper for further vascular diagnostics with minimal observer training required. In addition, a good correlation in absolute toe pressures was found for APD and SGP. Nearly one in five patients had PAD according to TBI measurements but not according to the ABI measurements. This is a potential way to improve PAD screening and diagnosis in a subgroup of high-risk PAD patients, who remain undiagnosed by the current standards. 



\section{5}

\section{Study II: Reliability of mercury-in-silastic strain gauge plethysmography curve reading: influence of clinical clues and observer variation}

\subsection{Major findings}

\subsubsection{Patients and data sampling}

The 204 enrolled patients included 201 right and 202 left limbs (limb amputations, $n=5$ ) with a total of 804 curve-sets produced. One right and one left ankle pressure were not performed due to recent vascular surgery. The measuring site was excluded from analysis if one of the three observers deemed the entire dataset unacceptable. This was the case in eight of the 804 datasets $(1 \%)$ of which seven were rejected by observer B exclusively. This generated individual mean segmental blood pressure values from 200 right and 202 left toe readings and 198 right and 196 left ankle readings eligible for analysis.

\subsubsection{Diagnostic classification}

In the blinded versus non-blinded comparison of the 204 patients, 163 $(79.9 \%)$ were classified as having PAD and $39(19.1 \%)$ as not having PAD during the primary (A-1) as well as secondary reading (A-2). One patient deemed as having PAD during the primary investigation (A-1) was recategorised after reinterpretation with the observer blinded to clinical input (A-2) and one patient was also re-categorized for the opposite situation. This leads to an agreement in diagnostic classification on a patient basis (PAD/not PAD) in 202/204 (99.0\%). Analysis using Cohen's kappa showed a strong agreement with $\kappa=0.969(\mathrm{p}<0.001)$. 
In the inter-observer readings, $163(79.9 \%)$ patients were diagnosed with PAD and $38(18.6 \%)$ as not meeting the criteria for PAD by both observers (A-2 and $\mathrm{B}$ ). One patient was diagnosed as having PAD during the blinded re-reading (A-2) by the other blinded observer (B) only, and two patients according to observer A-2 only. The overall agreement for inter-observer readings was $201 / 204(98.5 \%)$ with $\kappa=0.953(p<0.001)$. Both observers diagnosed $18(24.7 \%)$ patients with Fontaine III-IV as having an ankle pressure $<50 \mathrm{mmHg}$ and/or a toe pressure $<30 \mathrm{mmHg}$, and 53 patients (72.6\%) who did not meet this criteria.

\subsubsection{Observer variation}

The comparison of mean individual data from the initial investigation to the blinded re-reading by the same observer (A-1/A-2) and another observer (A-2/B) are shown in table $\mathrm{V}$. The mean differences for A-1/A-2 and A-2/B data were less than $2 \mathrm{mmHg}$ in all instances. The blinded observer (A-2) reported significantly lower pressure in three of four measuring sites compared to the unblinded condition (A-1) ( $\mathrm{p}$ value $<0.043$ ). The interobserver data demonstrated significant differences in one of the four sites ( $\mathrm{p}$ value $<0.034$ ). Intraclass correlation coefficients showed excellent correlation (all $\geq 0.969$ ) for both blinded/non-blinded and inter-observer data (Table V). Bland-Altman plots for blinded/non-blinded data are shown in Fig. 8, and inter-observer data in Fig. 9. In both cases, the Bland-Altman plots showed that in general, there is less variation in toe pressure than in ankle pressure readings. 


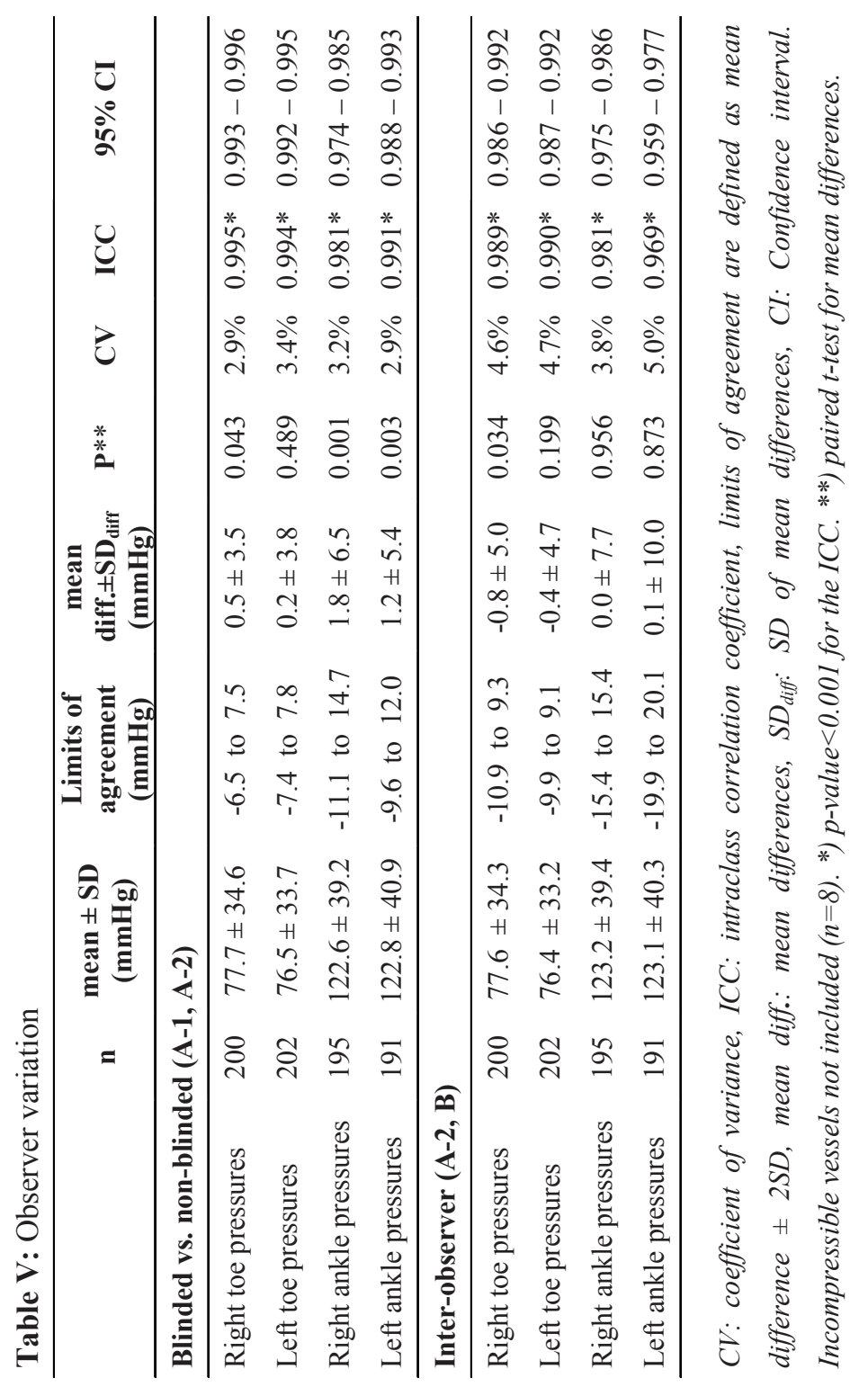



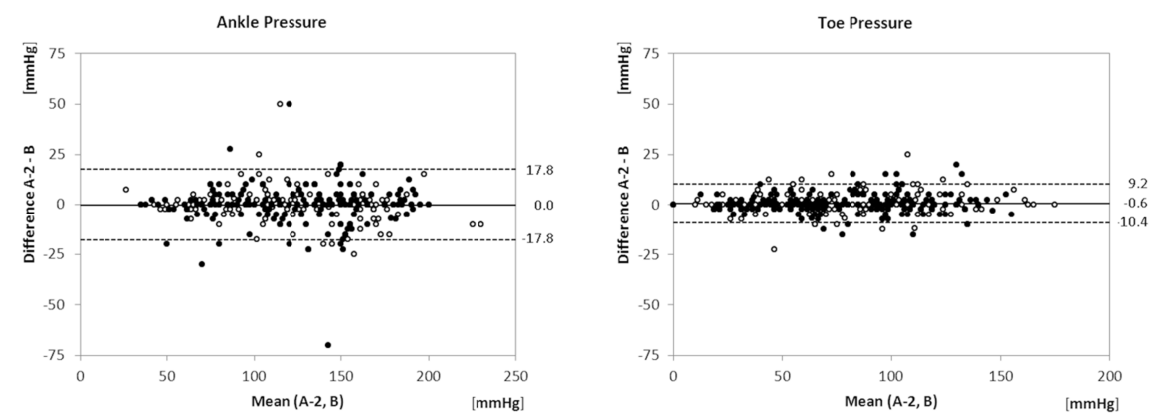

Figure 8. Difference-mean plots for blinded (A-2) vs. non-blinded (A-1) readings for right (open circles) and left limbs (closed circles). Dotted lines indicate $\pm 2 \mathrm{SD}$, and full lines indicate means.
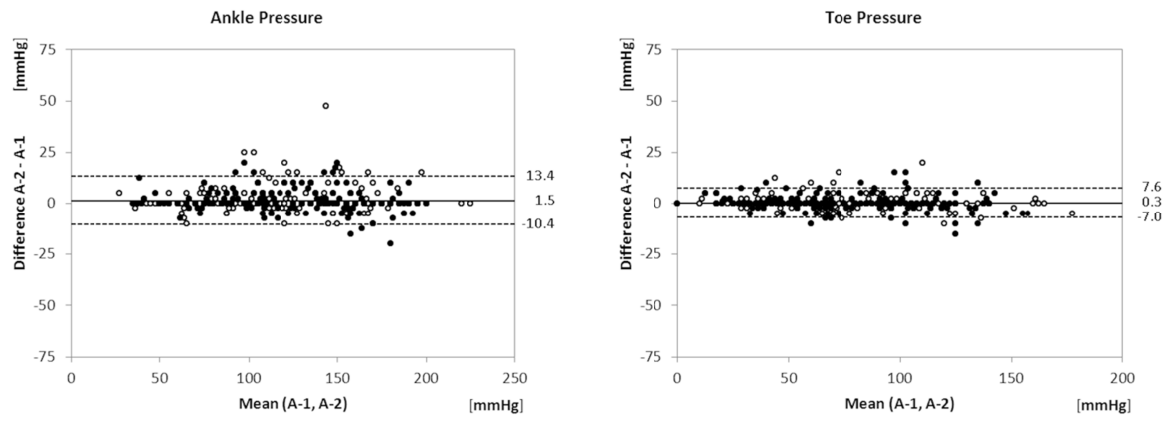

Figure 9. Difference-mean plots for inter-observer data for right (open circles) and left limbs (closed circles). Dotted lines indicate $\pm 2 \mathrm{SD}$, and full line indicate means.

\subsection{Discussion}

SGP is a frequently used method for blood pressure measurements. Despite its wide applications, studies of objectivity, in terms of reading of curves, as well as variation of such curve readings across laboratory technicians remain few in numbers. This study showed a low blinded/non-blinded and inter-observer variation when re-interpreting the SGP curves with excellent reproducibility regarding diagnostic classification on a patient basis. In the initial, clinical part of the study, the readers were aware of clinical clues 
such as objective findings, patient history, and the results of any previous distal blood pressure measurements. However, the readers were blinded to such information during the second interpretation. We hypothesized that the observers would be prone to include visual findings such as skin colour change during cuff deflation when interpreting the curves. The results of the study indicated low impact of clinical clues on interpreting of the curves. The average difference between the observers were less than 2 $\mathrm{mmHg}$ for both ankle and toe pressure measurements. Some of these small differences were found to be statistically significant since the large sample size allows the detection of small effects, although there is a possibility that some of the significant differences are due to chance. In any case, however, the average differences detected are smaller than the predefined curve reading accuracy of $5 \mathrm{mmHg}$. Our findings also indicate a low intraobserver variation, as re-reading of the curves by the same observer showed variation comparable to what was found in the inter-observer study, despite the different prerequisites regarding masking to clinical clues. A few measurements with major discrepancy between observer readings were primarily found in ankle-readings, which is in concurrence with the findings of Arveschoug et al. (2008) who investigated the influence of curve-reading by different observers on SGP reproducibility in a small study $(\mathrm{n}=30) .{ }^{169}$ In addition, our study indicates minimal influence of suspected or established vascular stiffness on the variation in curve interpretation.

Distal blood pressures, including SGP based measurements, have been subjected to numerous studies regarding day-to-day variation. ${ }^{43,} 169,171-173$ Our study has shown that observer variation has a minimal effect on SGP curve readings. However, overall variation of the method includes individual instrument settings such as sensitivity, speed of emptying of the air-filled reservoir, positioning of occlusion-cuffs etc. These aspects have previously been investigated in several studies describing low test-retest variation when repeating SGP measurements by the same observers. A mean day-to-day variation (standard deviation of mean pressure differences) ranging from $6-10 \mathrm{mmHg}$ for toe pressures and $9-11 \mathrm{mmHg}$ for ankle pressures have been reported. ${ }^{169,}{ }^{171-173}$ Compared to our findings, it would seem that variation based on observer readings in the SGP method account for less than half of the total test-retest variation. 
Low observer influence is highly relevant when using the SGP method for studies of diagnostic accuracy, since proper blinding of the observers is imperative for data quality. ${ }^{177}$ Studies have shown that non-blinded assessors generate substantially biased interpretation of the results. ${ }^{180}$ Interpretation of pressure curves is also an issue with other methods used for segmental pressure measurement. The photo-plethysmographic techniques detect changes in the blood filling of the capillaries, laser Doppler methods use the Doppler shift undergone by an emitted laser light which detects erythrocyte flux (numbers and movement), whereas SGP detect distal volume changes. ${ }^{63}$ All methods require manual curve interpretation since the automated computerised algorithms often fail. Although the mechanism behind the blood flow detection systems differs, they share generation of a curve which reflect changes in absolute blood flow/volume increment (the rather slow DC signal) and return of pulsation (a fast AC signal). ${ }^{63}$ To be best of the authors' knowledge, there is no consensus of which of these two parameters should be prioritized upon interpretation of a given pressure curve. It is likely that the detection of weak AC signals is better in some techniques than others, and studies have shown systematic bias between the various methods in use. ${ }^{74}$ Moreover, the observer repeatability of curve-readings in the various new methods remains to be clarified.

Mercury-in-silastic SGP is a well-established approach to distal blood pressure measurements and has been in use for over five decades. Despite the introduction and application of various new approaches for assessment of distal limb perfusion, the SGP still remains one of the best validated methods. Further studies are needed to test whether the different methods are fully interchangeable and equally reproducible.

\subsection{Conclusions}

The study showed no substantial effect of clinical clues or patient history on SGP curve readings with regard to final disease classification as well as absolute pressure values. In addition, the inter-observation among the technicians was very modest. The findings emphasized the robustness and repeatability of the SGP method. 
6

\section{Study III: Diagnostic accuracy of laser Doppler flowmetry vs. strain gauge plethysmography for segmental pressure measurement}

\subsection{Major findings}

\subsubsection{Patients and data sampling}

A total of 223 patients were screened, and 200 patients $(90 \%$ of referred patients) were included in the study. The recruitment period lasted 30 working days from February 20 to April 10, 2012. The skin temperatures averaged $30.8^{\circ} \mathrm{C}( \pm 1.9)$ during the toe pressure measurements and $29.8^{\circ} \mathrm{C}$ $( \pm 1.8)$ during the ankle pressure measurements with no significant difference between the temperatures during the index and reference tests. Please confer to appendix $\mathrm{C}$ for demographic characteristics.

\subsubsection{Variation in brachial blood pressures}

The mean brachial blood pressure was $138 \pm 20 \mathrm{mmHg}$ during the SGP toe pressure measurements and $138 \pm 21$ during the LDF toe pressure measurements with no significant difference between the methods $(\mathrm{P}=$ 0.107). The brachial blood pressure was significantly higher with SPG during the ankle measurements than with $\mathrm{LDF}(140 \pm 21 \mathrm{mmHg}$ vs. $137 \pm$ $21 \mathrm{mmHg}, \mathrm{P}<0.001)$.

\subsubsection{Agreement in segmental pressures and indices}

The absolute pressures and pressure indices obtained using the two methods are compared in Table VI. The LDF method measured significantly higher toe pressures than SGP on both sides, with a mean 


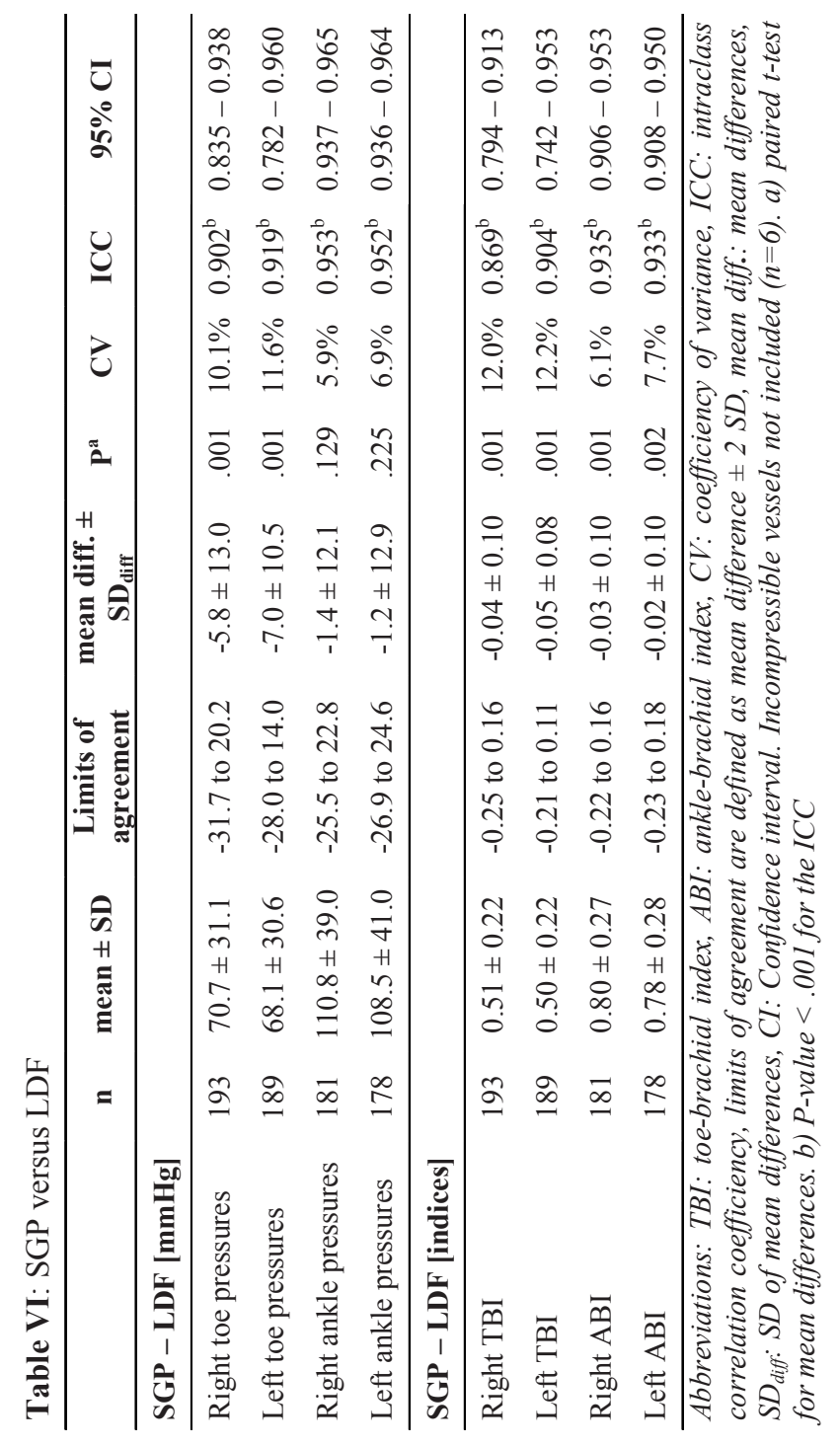


difference of $5.8 \mathrm{mmHg}$ for right limbs and $7.0 \mathrm{mmHg}$ for left limbs (both, $\mathrm{P}<0.001)$. There were no significant differences between the two methods regarding mean ankle pressures on either side (both, $\mathrm{P}>0.129$ ). The LDF method showed higher values for TBI and ABI compared to SGP for both limbs (for all, $\mathrm{P}<0.002$ ). The Bland-Altman plots for toe and ankle pressure measurements (Figure 10) did not reveal a systematic difference in any pressure range.

\subsubsection{Agreement in diagnostic classification}

The two methods agreed in the diagnostic classification of PAD in 191 of 200 patients, as displayed in Table VII. Cohen's Kappa showed an agreement of $\kappa=0.775$ (95\% CI: $0.631-0.919)$.

A total of 82 patients had Fontaine III or IV. Agreement in CLI diagnosis in terms of ankle pressures $<50 \mathrm{mmHg}$ or/and toe pressures $<30 \mathrm{mmHg}$ was found in 75 patients, as shown in Table VIII. The agreement according to Cohen's Kappa was $\kappa=0.780$ (95\% CI: $0.624-0.936)$.

Table VII: Agreement in diagnostic classification of PAD.

\begin{tabular}{lccc}
\hline SGP & \multicolumn{3}{c}{ LDF } \\
\cline { 2 - 3 } & PAD & Not PAD & Total \\
\hline PAD & 173 & 6 & 179 \\
Not PAD & 3 & 18 & 21 \\
\hline Total & 176 & 24 & 200 \\
\hline
\end{tabular}

Table VIII: Agreement in diagnostic classification of critical limb ischemia (CLI) for patients with Fontaine III-IV.

\begin{tabular}{lccc}
\hline SGP & \multicolumn{3}{c}{ LDF } \\
\cline { 2 - 3 } & CLI & Not CLI & Total \\
\hline CLI & 18 & 5 & 23 \\
Not CLI & 2 & 57 & 59 \\
\hline Total & 20 & 62 & 82 \\
\hline
\end{tabular}




\subsubsection{Reproducibility}

For the LDF method, the number of measurements required to generate a dataset according to our reproducibility criterion was $2.4 \pm 0.7$ for toe pressures and $2.4 \pm 0.6$ for ankle pressure measurements. The required measurements for SGP were $2.4 \pm 0.7$ for toe pressures and $2.4 \pm 0.7$ for the SGP ankle pressures. Analysis of repeated measurements showed a mean coefficient of variance for the LDF method of $6.5 \%$ for the right toe, $7.2 \%$ for left toe pressures, $4.6 \%$ for right ankle pressures, and $4.0 \%$ for left ankle pressures. The corresponding numbers for SGP were $6.1 \%$ for right toe pressures, $7.1 \%$ for left toe pressures, $4.5 \%$ for right ankle pressures, and $4.0 \%$ for left ankle pressure measurements.
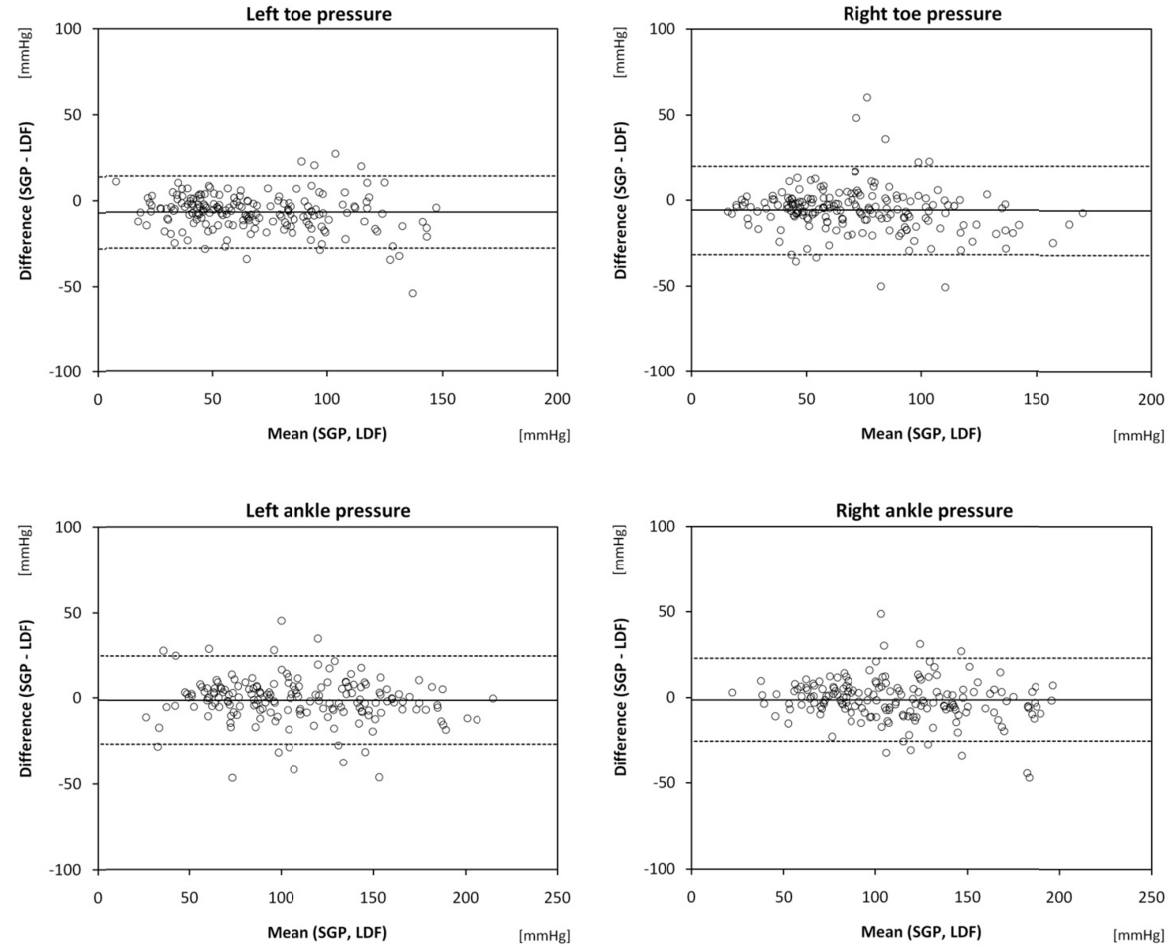

Figure 10. Bland-Altman plots showing the difference in toe pressures (top row) and ankle pressures (bottom row) obtained by SGP versus LDF for left limbs (left side) and right limbs (right side) respectively. The lines show the mean (full line) \pm 2 SD (dotted line). 


\subsection{Discussion}

The study showed good correlation for LDF toe and ankle pressure measurements with the well validated SGP method over a wide range of pressures. The two methods showed substantial agreement in disease classification with respect to the diagnosis of PAD and CLI. Generally, the agreement between the methods was excellent, including subgroup analysis of diabetes, body mass index, or Fontaine classification.

Although the LDF method is increasingly used as a reference standard in vascular laboratories, few studies have been conducted to study the interchangeability with other methods on a large scale. ${ }^{64,74,75,79,185}$ Previously, a small study pioneering the use of LDF in segmental pressure measurements by Andersson et al. (1986) compared the method to SGP. ${ }^{75}$ The study included a small number of highly selected patients. The authors showed an excellent correlation between the two methods for both ankle and toe pressures when the methods were used simultaneously. However, the agreement was markedly reduced when the comparison was performed using successive measurements. The authors suggested that the variation in the comparison was caused by variation in the lower limb blood pressure. This finding is in agreement with the known test-retest variation, as shown in prior studies using SGP or LDF measurements. ${ }^{64,169}$ Our setup did not allow for simultaneous measurements because of the incompatibility between the systems. For this reason, we did not expect perfect agreement between the methods. In our study, the LDF method systematically yielded results that were 5-7 mmHg lower than the SGP method at the toe level but were only 1-2 mmHg lower than SGP at the ankle level. However, the mean brachial pressures were $3 \mathrm{mmHg}$ higher during ankle pressure measurements made by SGP compared to LDF. The instantaneous inflation of the occlusion cuff used by the SGP method may induce discomfort, particularly in patients with leg ulcers. This discomfort may have induced elevated systemic arterial pressure and potentially masked a greater true difference between the methods. ${ }^{108}$ In agreement with this finding, both the TBI and ABI values were significantly lower for SGP than for LDF. It could be hypothesized that the flow changes (LDF) after deflation can be detected prior to the detection of volume changes (SGP).

Previous, studies on LDF toe pressure measurements have shown good correlation with other methods, such as photo-plethysmography. ${ }^{64,74,81,103}$ 
In most of these studies, LDF was shown to produce slightly higher pressure readings than photo-plethysmography. In general, the studies showed a more pronounced variation between the methods than we encountered in our study. The approach to limb heating prior to the tests in the mentioned studies is markedly different. Measurements of toe pressures have been shown to be highly susceptible to distal temperature changes, and it has been argued that insufficient heating can lead to disease misclassification. ${ }^{97}$ Thus, lower limb heating has been recommended to improve standardization. ${ }^{96,97}$ The LDF signal can also be optimized by local heating in the vicinity of the probe, as shown by Ubbink et al. (2004). ${ }^{74}$ However, the sole use of local heating would likely challenge the test-retest reproducibility due to the effects on limb temperature by hyperemia induced by inflammation, recent surgery, or seasonal temperature changes, as the measured toe pressures correspond to the limb temperature. ${ }^{96}$ The impact on laboratory and clinical conditions on disease classification (PAD/no PAD) remains largely unknown.

Although the mechanism behind the various blood flow detection systems differs, they share a signal curve that reflects changes in absolute blood flow/volume increment and return of pulsation. ${ }^{63}$ It is likely that weak AC signals are better detected in some techniques than in others. In agreement with this, LDF has been shown to be a more sensitive detection method for low pressures (reduced signal) compared to photoplethysmography. ${ }^{64,74}$ Accuracy in low pressures is vital because diagnosing CLI entails measuring toe pressures below $30 \mathrm{mmHg}$. ${ }^{2}$ In our study, which included a large proportion of patients with recent surgery and distal wounds, the completion rate for the LDF was comparable to that of SGP.

In guideline recommendations, the methods used for toe or ankle pressure measurements are generally considered fully interchangeable. ${ }^{2,40}$ However, it is evident that a high level of variation is present among the different techniques. It remains undetermined whether that variation is due to biological blood pressure variation, experimental test conditions, or technical variation in the different detection systems. These features complicate the identification of an optimal laboratory reference standard for the measurement of segmental blood pressure. Additionally, in order to correctly interpret the readings from the various methods on patient management, future studies should include clinical outcome such as wound healing. SGP is the only method that has been subjected to 
comparison to the true reference standard, which is intra-arterial pressure measurement. ${ }^{70,158}$ However, the findings of our study indicate a high degree of interchangeability between LDF and SGP for such measurements.

\subsection{Conclusions}

LDF showed good correlation with SGP over a wide range of toe and ankle pressures as well as substantial agreement in the diagnostic classification for PAD including CLI. The LDF method yielded systematically higher TBI and ABI indices, as well as higher toe pressure readings than SGP; however, no significant difference was found in absolute ankle pressure measurements. 



\section{Study IV: Number of distal limb and brachial pressure measurements required when diagnosing peripheral arterial disease by laser Doppler flowmetry}

\subsection{Major findings}

\subsubsection{Patients and data sampling}

A total of 200 patients were enrolled of which 52 patients $(26 \%)$ were diagnosed with diabetes, 49 (25\%) with chronic kidney insufficiency, 151 (76\%) with arterial hypertension, and 55 (28\%) were current smokers. The majority of patients $(159,79 \%)$ were referred from the Department of Vascular Surgery. The Fontaine classification were distributed as follows; I: 37 (18\%), II: 81 (40\%), III: 41 (21\%), and IV: 41 (21\%).

The patients presented with 195 right and 191 left limbs (limb amputations, $\mathrm{n}=12$ ) with 1816 pressure curves produced. A total of 24 ankle pressures were not obtained due to recent surgery, fractures, or large wounds. Two toe pressures were not obtained due to amputations. Accepted measurements were acquired in 195 right toes, 191 left toes, 188 right ankles, and 188 left ankles. Following the reproducibility criterion, more than two measurements were acquired in $60(31 \%)$ right toe pressures, 61 $(32 \%)$ left toe pressures, $57(30 \%)$ right ankle pressures, and $57(30 \%)$ left ankle pressures.

\subsubsection{Brachial blood pressure}

The baseline brachial blood pressure, measured after $15 \mathrm{~min}$ of rest, averaged at $144.0 \pm 21.4 \mathrm{mmHg}$. The average brachial blood pressures 
during the toe pressure measurements $(138.0 \pm 20.9 \mathrm{mmHg})$ and ankle pressure measurements $(137.3 \pm 21.4 \mathrm{mmHg})$ were significantly lower than the baseline brachial blood pressure $(\mathrm{P}$ both $<0.001)$. There were no significant difference in mean brachial blood pressure during the ankle and toe pressure measurements $(\mathrm{P}=0.187)$. The average coefficient of variation for brachial blood pressure measurements was $2.86 \%$ during the toe pressure measurement, and $2.99 \%$ during the ankle pressure measurements.

\subsubsection{Diagnostic classification}

When using the standard RC method for calculating the indices, a total of $175(87 \%)$ patients were classified as having PAD and $25(13 \%)$ as not having PAD. A total of three patients were re-categorized following recalculation of the indices based on one measurement (M-1) with an agreement of $\kappa=0.930$ (95\% CI: $0.852-1.000)$. One patient was recategorized when using the first two obtained measurements (M-2) compared to the RC standard with $\kappa=0.977$ (95\% CI: $0.931-1.000)$. The diagnostic grouping is displayed in table IX.

Table IX: Agreement in diagnostic classification of PAD for three strategies using correspondent brachial blood pressures as reference.

\begin{tabular}{lccccc}
\hline \multirow{2}{*}{$\mathrm{RC}$} & \multicolumn{3}{c}{$\mathrm{M}-1$} & & \multicolumn{2}{c}{$\mathrm{M}-2$} \\
\cline { 2 - 3 } \cline { 5 - 6 } & $\mathrm{PAD}$ & Not PAD & & PAD & not PAD \\
\hline PAD & 174 & 1 & & 175 & 0 \\
not PAD & 2 & 23 & & 1 & 24 \\
\hline \multicolumn{3}{r}{$\kappa=0.930$} & \multicolumn{3}{c}{$\kappa=0.977$} \\
\hline
\end{tabular}

Abbreviations: RC: reproducibility criterion, M-1: one measurement only, M-2: the first two measurements.

When reanalysing the data by using the baseline brachial blood pressure as reference only, a total of seven patients were reclassified using the RC approach, eight patients were reclassified using the M-1 method, and six 
were reclassified using the M-2 method, as displayed in table X. Analysis of agreement in diagnostic classification showed a $\kappa=0.831(95 \% \mathrm{CI}$ : $0.709-0.954), \kappa=0.804$ (95\% CI: $0.670-0.937)$, and $\kappa=0.847$ (95\% CI: $0.726-0.968$ ) for the $\mathrm{RC}, \mathrm{M}-1$, and $\mathrm{M}-2$ comparison respectively.

Table X: Agreement in diagnostic classification of PAD using only baseline brachial-blood pressure as reference vs. using all correspondent brachial blood pressures.

\begin{tabular}{lccccc}
\hline $\begin{array}{l}\text { One } \\
\text { only }\end{array}$ & BBP & \multicolumn{2}{c}{ RC (all BBP) } & & \multicolumn{2}{c}{ M-1 (all BBP) } \\
\cline { 2 - 3 } \cline { 5 - 6 } & PAD & Not PAD & & PAD & not PAD \\
\hline PAD & 173 & 5 & & 173 & 5 \\
not PAD & 2 & 20 & & 3 & 19 \\
\hline & \multicolumn{2}{c}{$\kappa=0.831$} & \multicolumn{3}{c}{$\kappa=0.804$} \\
\hline
\end{tabular}

\begin{tabular}{lcc}
\hline $\begin{array}{l}\text { One } \\
\text { only }\end{array}$ & BBP & \multicolumn{2}{c}{ M-2 (all BBP) } \\
\cline { 2 - 3 } & PAD & PAD \\
\hline PAD & 175 & 175 \\
not PAD & 1 & 1 \\
\hline
\end{tabular}

Abbreviations: All BBP: brachial blood pressures used correspondent to all distal limb pressures, One BBP only: only baseline brachial-blood used as reference.

\subsubsection{Agreement and reliability in calculated indices}

There was no systematic bias for any of the measuring sites when comparing the TBI or ABI derived by the $\mathrm{RC}$ method to the indices derived by M-1 or M-2 (all P values > 0.104). The data is presented in table XI. Bland Altman plots are shown in Fig. 11, and they did not show discordance in any range of pressures or sign of heteroscedasticity (no variation related to the magnitude of the indices). 


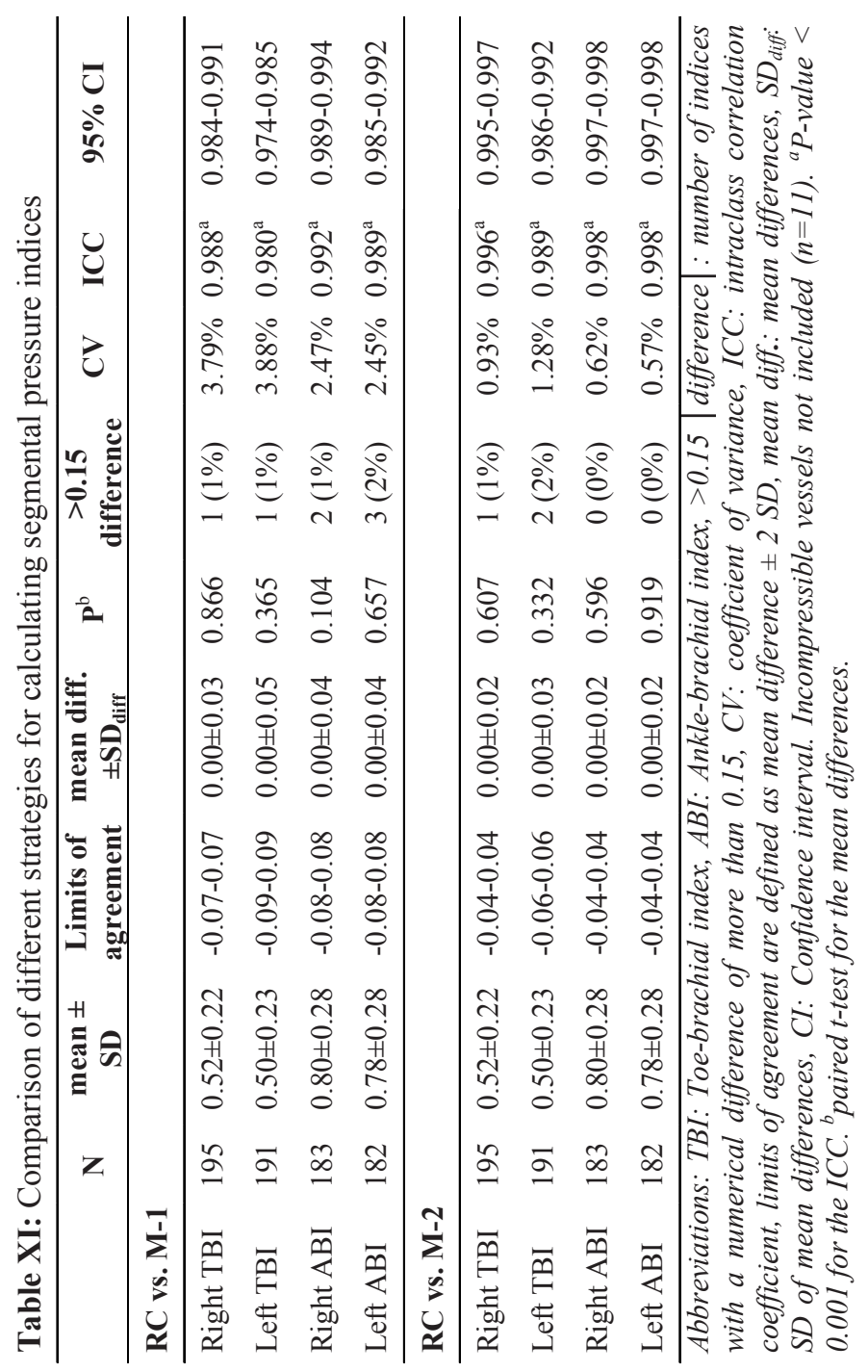



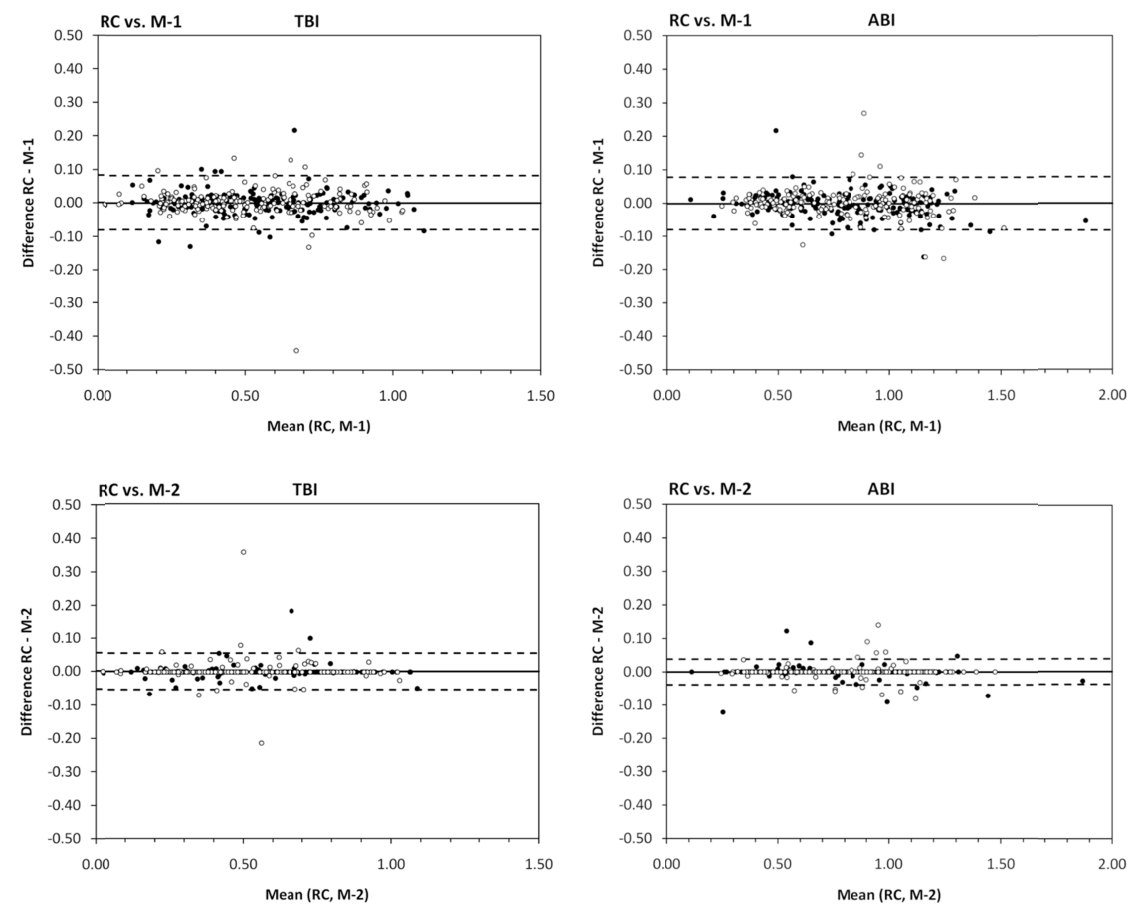

Figure 11. Difference-mean plots for the toe-brachial index and ankle-brachial index calculated by RC versus M-1 and M-2 for right limb (full dots) and left limbs (holllow dots). The data is shown as mean (full line) and \pm 2 standard deviations (dotted line).

A subgroup analysis was performed for agreement of indices in patients with diabetes $(n=52)$ vs nondiabetics $(n=148)$ for $R C$ versus $M-1$ and $M-$ 2 respectively. No systematic bias was observed in the mean difference for the comparisons in any of the four measuring sites (all $\mathrm{P}>0.20$ ). No significant differences were shown between the limits of agreement except for significantly higher variation in diabetic vs nondiabetic patients for left TBI ( -0.14 to 0.15 vs. -0.06 to 0.07$)$ in the $\mathrm{RC}$ vs. M-1 comparison.

The data was re-analysed by calculating the indices based on the first brachial blood pressure obtained only, and the results are shown in table XII. All four measuring sites showed significantly lower indices when 


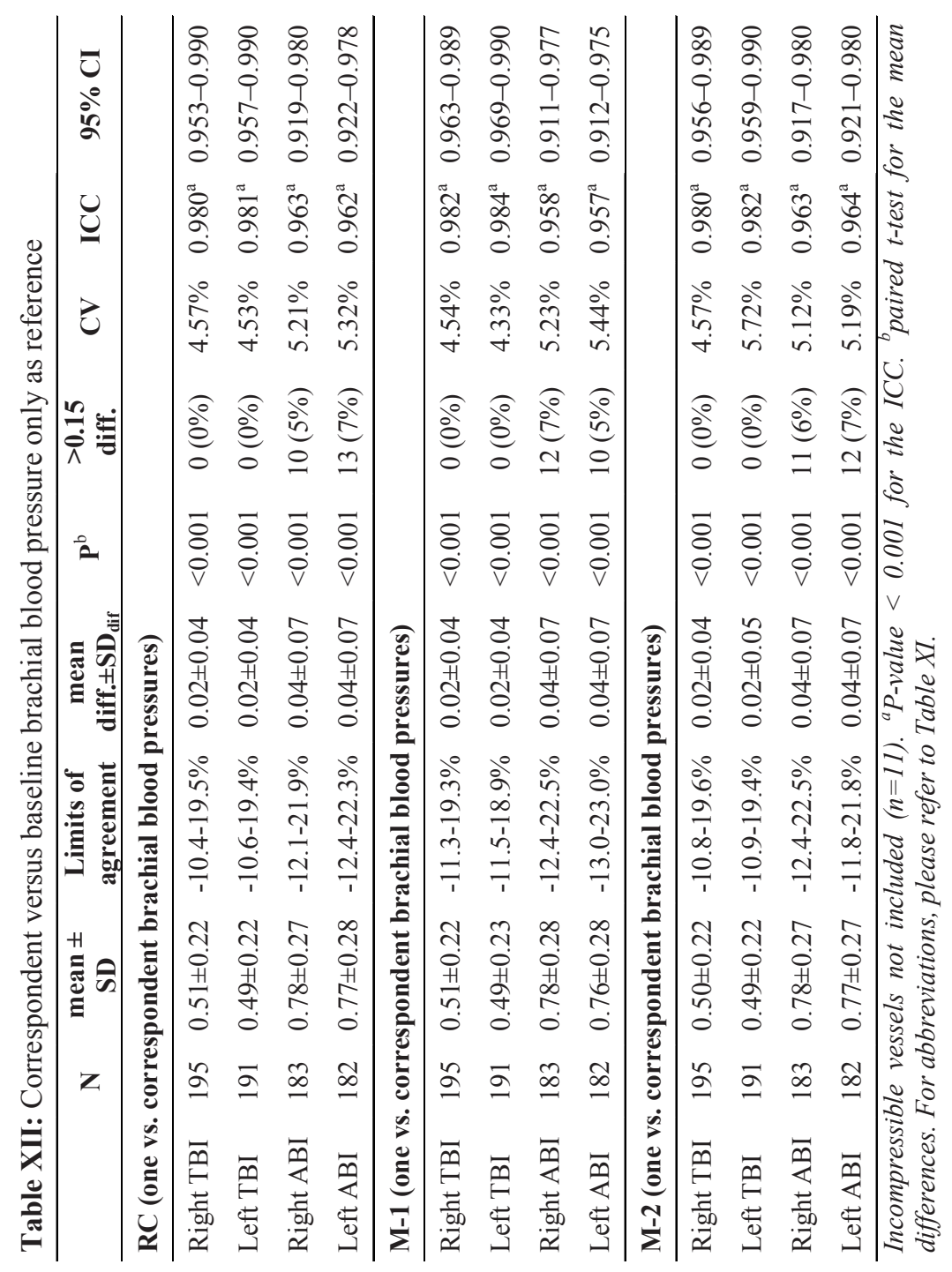



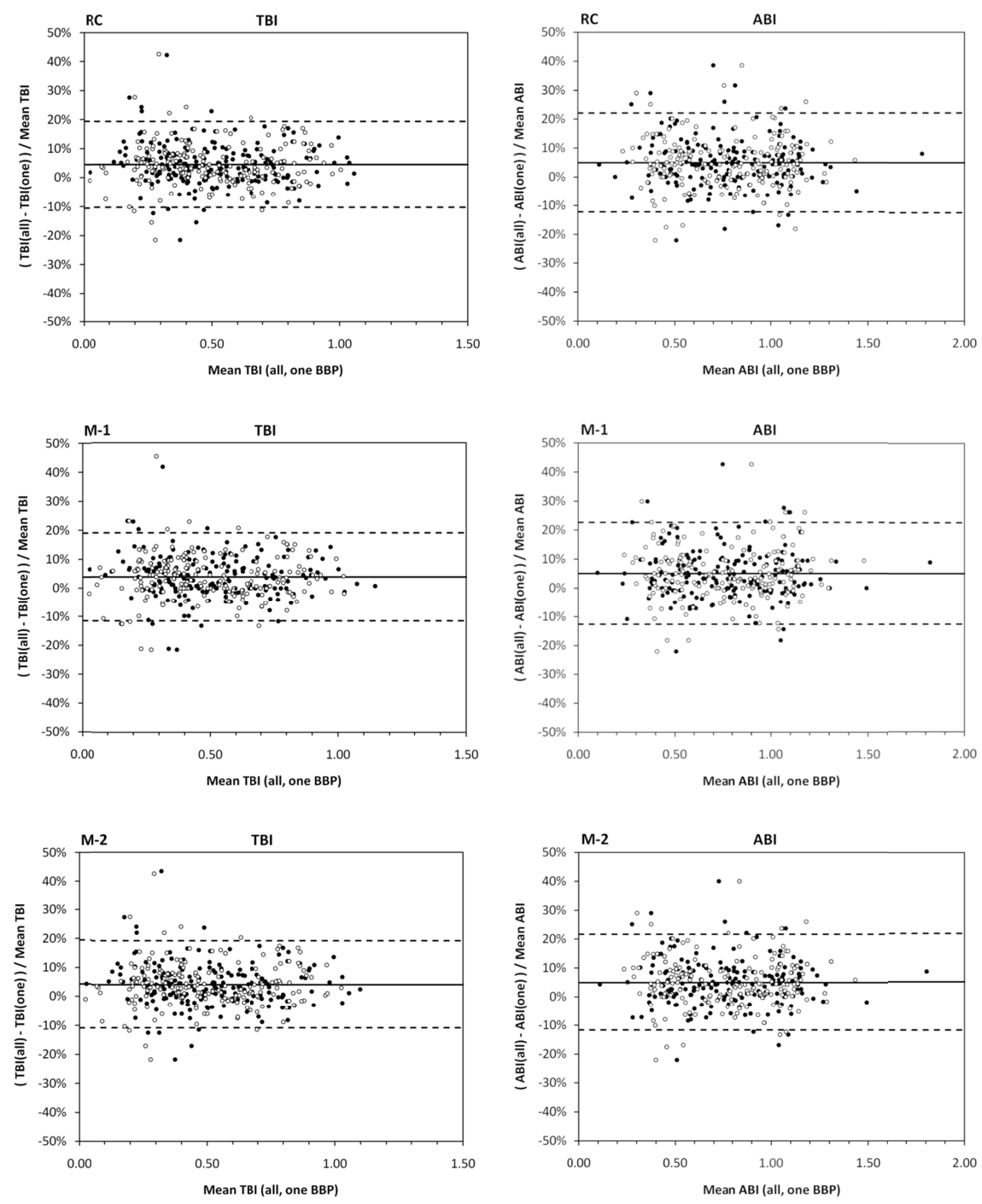

Figure 12. Relative differences vs. mean plots for the toe-brachial index and ankle-brachial index calculated by using only one brachial blood pressure as reference versus using brachial blood pressures correspondent to all segmental pressures for RC versus M-1 and M2 for right limb (full dots) and left limbs (hollow dots). The data is shown as mean (full line) and \pm 2 standard deviations (dotted line). 
using just the first brachial blood pressure as compared to using all correspondent brachial blood pressures measured (P all $<0.01$ ). Differencemean plots constructed for TBI and $\mathrm{ABI}$ calculations showed increasing variation related to the magnitude of the indices (plots not shown). Plots showing the relative difference versus mean values are displayed in Figure 12 .

Subgroup analysis was likewise performed for patients with diabetes versus nondiabetics for the three comparisons. No systematic bias was observed for the mean difference relative to the mean value for any of the comparisons in the various measuring sites (all $\mathrm{P}>0.40$ ). No significant differences were shown between the limits of agreement in any of the comparisons.

\subsection{Discussion}

\subsubsection{Impact of using different strategies for calculating the indices}

The study showed an excellent agreement in diagnostic classification regarding PAD when comparing the reproducibility criterion consisting of at least two measurements with no more than $10 \mathrm{mmHg}$ of difference to indices calculated by using one or two measurements respectively. In particularly, the difference between the calculations based on two pressures and pressures based on the reproducibility criterion were negligible. This can be explained by the fact that approximately $70 \%$ of the indices based on the reproducibility criterion are calculated by the first two pressures derived. Generally, the presence of diabetes did not influence the overall agreement in indices.

The principle underlying the reproducibility criterion is to minimize the risk of falsely low or falsely high measurements. In laser Doppler flowmetry, as well as other methods, it is well known that several factors, e.g. tremor, sudden movement of the feet, coughing, etc. can influence the signal leading to misinterpretation of the pressures. This type of strategy to improve the reliability of measurements of brachial blood pressure measurements for diagnosis of arterial hypertension is recommended by the American Heart Association. ${ }^{87}$ Earlier studies have shown that diagnostic accuracy can be enhanced in ankle pressure measurements by increasing the number of measurements used. ${ }^{130}$ Moreover, it has been suggested that 
repeated measurement in ankle pressure measurements should be reserved for patients with $0.80<\mathrm{ABI}<1.00^{130}$ However, an optimal diagnostic accuracy for patients with low ABI is clinically relevant since the level often guide the clinicians in choosing the optimal management for the PAD patient.

Due to the substantial test-retest variation of segmental pressure assessment in general, a difference of more than 0.15 for the $\mathrm{ABI}$ is usually considered significant in a clinical setup. ${ }^{83}$ The overall variation among the strategies demonstrated in this study was smaller than this threshold difference. Studies have shown that the variation in absolute ankle pressures is comparable to that of toe pressures but there are no correspondent limits in use regarding variation for the TBI. ${ }^{169}$

Based on our finding, the overall impact of using the presented reproducibility criterion compared to using one or two measurements is minimal. However, from a clinical point of view, it should be kept in mind that the time used to obtain an additional measurement is less than two minutes.

\subsubsection{Importance of measuring corresponding brachial blood pressures}

The study results underlined that using one brachial blood pressure for calculation of the indices differ to some extent in terms of diagnostic classification and indices in comparison to simultaneous arm and leg pressure measurements. The baseline brachial blood pressures were significantly higher than values obtained during the subsequent toe and ankle pressure measurements. It could be speculated that the experimental setup induce vascular reactions similar to "white-coat hypertension". ${ }^{87,146}$ However, elevated brachial blood pressures prior to the subsequent segmental pressure measurements is a well-described problem despite implementing a pre-test resting period. ${ }^{83}$ This is particularly an issue with the hand-held Doppler methods, since brachial blood pressures are traditionally obtained prior to the lower limb pressure measurement.

Since the distal pressure is affected of changes in the central blood pressure as well as reflection from resistant distal arterioles, it has been speculated that the indices are not fixed. ${ }^{83}$ Such indices may vary based on changes in 
the general hemodynamics which can be altered by pain or anxiety. However, the impact of changes in systemic blood pressures or heart rate on the ABI has been shown to be minimal. ${ }^{12,}{ }^{113}$ According to these findings, it is imperative to secure measurement of brachial blood pressures correspondent to each segmental pressure in order to minimize the effect of changes in systemic blood pressure when calculating the indices.

\subsubsection{Study limitations}

In the present setup, there was not a reference standard (such as angiography) to verify the presence or absence of PAD. Thus a true reference for disease classification was not available. However, the correlation of $\mathrm{ABI}$ and TBI to angiographic findings remains unclear. Studies have shown sensitivities ranging from $15-79 \%$ and specificity from $83-100 \%$ for detecting $>50 \%$ vessel stenosis in the lower limb by using the established diagnostic limits. ${ }^{131}$ The evidence supporting the diagnostic

limits is stronger as a prognostic indicator for cardiovascular morbidity and mortality but this is not plausible to include in a setup such as ours. ${ }^{4}$

\subsection{Conclusions}

The present study shows minimal differences in diagnostic classification and pressure indices when comparing calculations based on the reproducibility criterion, one, or two measurements. However, the study showed that it is important to measure brachial blood pressures correspondent to each segmental pressure. 


\section{Study V: Reliability of laser Doppler flowmetry curve reading for measurement of toe and ankle pressures: Intra- and inter-observer variation}

\subsection{Major findings}

\subsubsection{Patients and data sampling}

A total of 200 patients were enrolled from which 52 patients $(26 \%)$ were diagnosed with diabetes, 49 (25\%) with chronic kidney insufficiency, 151 $(76 \%)$ with arterial hypertension, and $55(28 \%)$ were current smokers. The majority of patients $(159,79 \%)$ were referred from the Department of Vascular Surgery. The Fontaine classification were distributed as follows; I: 37 (18\%), II: 81 (40\%), III: 41 (21\%), and IV: 41 (21\%).

The patients presented with 195 right and 193 left limbs (limb amputations, $\mathrm{n}=12$ ) with 1816 pressure curves produced. A total of 24 ankle pressures were not obtained due to recent surgery, fractures, or large wounds. Two toe pressures were not obtained due to amputations. Measurements were acquired in 195 right toes, 189 left toes, 188 right ankles, and 188 left ankles. The measuring site was excluded from analysis if one of the observers deemed the entire dataset unacceptable. This was the case in nine of the 760 datasets (1\%). Individual mean segmental blood pressure was based on 2-3 measurements in most patients. An average of $2.4 \pm 0.7$ curves were used for toe pressures and $2.4 \pm 0.6$ curves were used for ankle pressures in order to achieve a dataset according to the reproducibility criteria. More than two measurements were acquired in $60(31 \%)$ right toe pressures, $61(32 \%)$ left toe pressures, $57(30 \%)$ right ankle pressures, and $57(30 \%)$ left ankle pressures. The distal skin temperatures averaged $30.8^{\circ} \mathrm{C}$ $( \pm 1.9)$ during the toe pressure measurements and $29.9^{\circ} \mathrm{C}( \pm 1.8)$ during the 
ankle pressure measurements. For further details about patient demographics, medical history and clinical variables please refer to appendix C.

Figure 13 [next page]. Examples of LDF toe pressure curves. Following inflation of the occlusion-cuff to supra-systolic pressure, the signal stabilizes at the biological zero. The occlusion cuff is slowly deflated, and as the flow returns, the arterial inflow (A) can be detected (Phase I). The capillary flow is restricted until the venous stasis is gradually released (V) allowing unrestricted flow (Phase II). In curve (a), there is a clear distinction between the phases and in curve (b) they are partly merged. In curve (c) and (d), there is no clear distinction of the onset of the two phases as well as an initially weak DC signal. In curve (a), (b), and (c), there is a good quality in the AC signal (pulsation) as opposed to curve (d). 

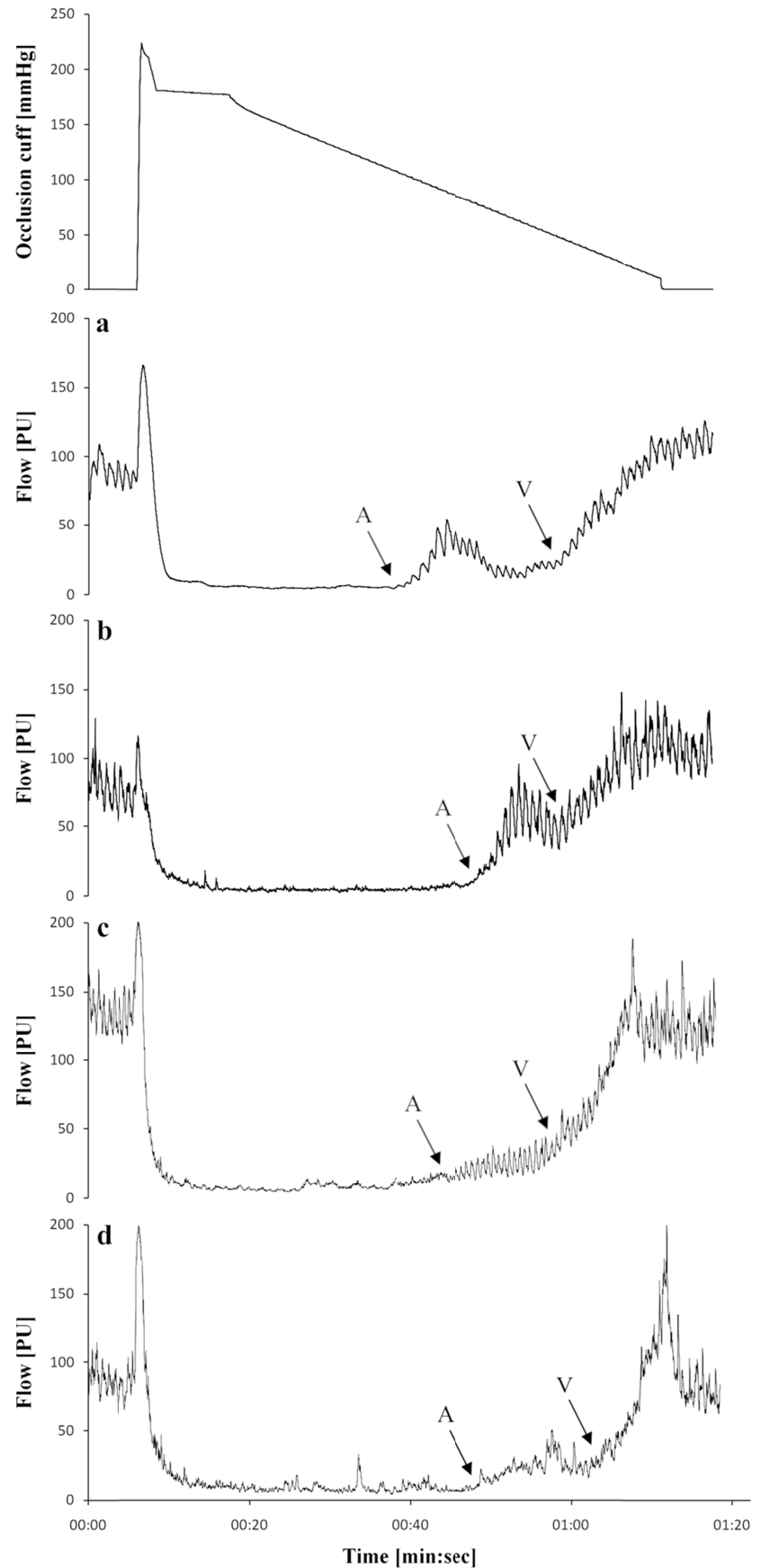


\subsubsection{Diagnostic classification}

In the intra-observer readings, $173(86.5 \%)$ patients were diagnosed with PAD and $21(10.5 \%)$ as not meeting the criteria for PAD by both observers. The observer disagreed in the diagnosis of six patients $(3.5 \%)$. The overall agreement for inter-observer readings was 194/200 (97.0\%) with $\kappa=0.858$ (95\% CI: $0.746-0.970)$. Among the 82 patients with Fontaine III-IV, the intra-observer reading agreed in the diagnosis of CLI in 22 and agreed that 54 did not have CLI. The observers disagreed in six cases leading to an agreement of a $\kappa=0.828$ (95\% CI: $0.696-0.961)$.

In the inter-observer comparison, 175 (87.5\%) were classified as having PAD and $17(10.5 \%)$ as not having PAD by both observers. The observers disagreed in eight cases $(4.0 \%)$, leading to an agreement in diagnostic classification on a patient basis in 192/200 (96.0\%). Analysis using Cohen's kappa showed an agreement of $\kappa=0.787$ (95\% CI: $0.643-0.932$ ). The observers agreed in the diagnosis of CLI in 76 patients (23 as having CLI, and 53 as not having CLI). The observers disagreed in six cases leading to an agreement in 76 of the 82 patients with Fontaine III-IV with $\kappa$ $=0.832(95 \%$ CI: $0.702-0.961)$.

\subsubsection{Observer variation}

Comparison of curve-reading for the intra-observer and inter-observer data are presented in Table XIII. The second reading showed lower readings than the first reading for all four measuring sites in the intra-observer comparison and in three of the four sites in the inter-observer comparison ( $p$ values $<0.008$ ). However, the mean differences are less than $2.4 \mathrm{mmHg}$ in all instances. Intraclass correlation coefficients showed excellent correlation for both intra- and inter-observer data (all $\geq 0.947$ ). BlandAltman plots for intra-observer data are shown in Figure 14, and for interobserver data in Figure 15. In both comparisons, the plots show less variation in ankle pressure readings than toe pressure readings with no indication of heteroscedasicity. 


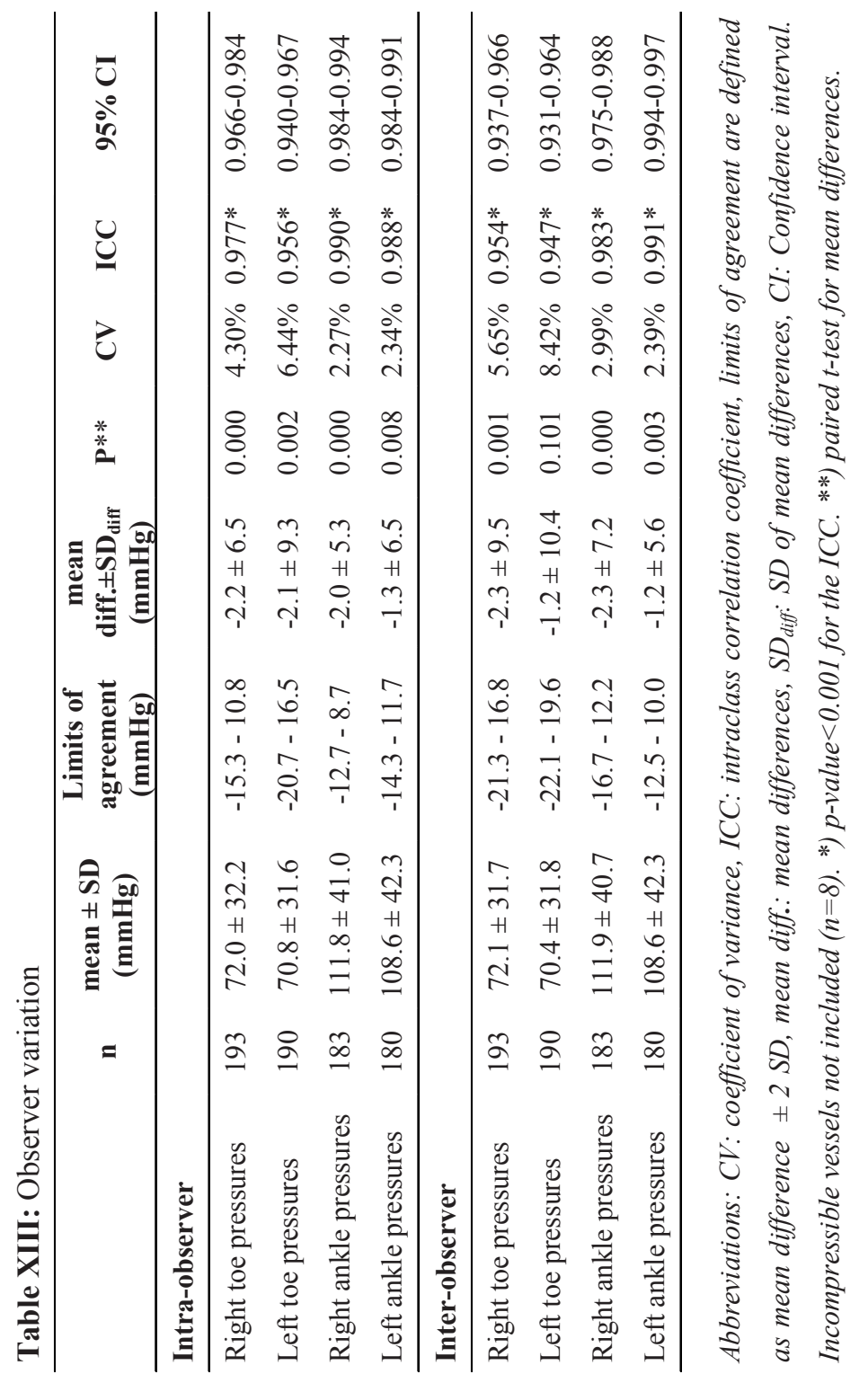



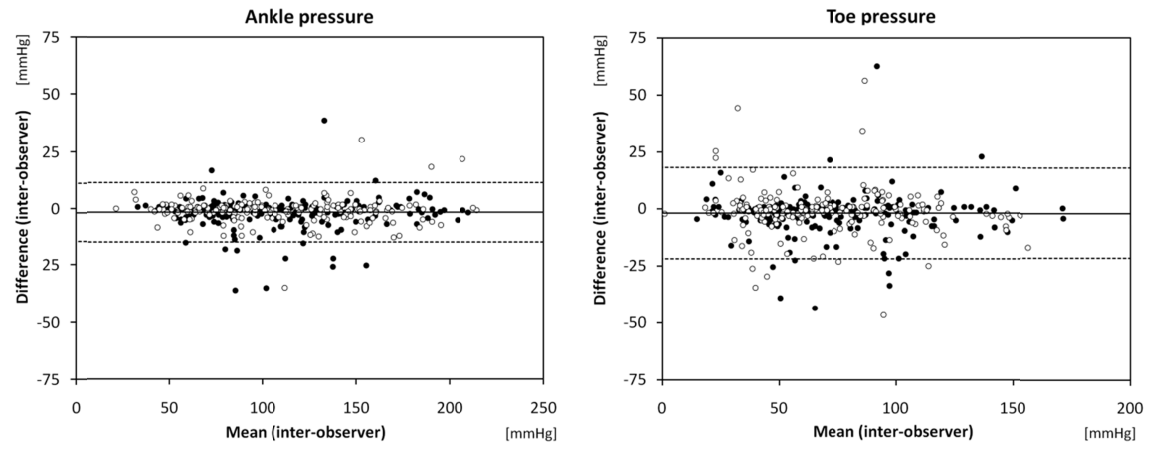

Figure 14. Difference-mean plots for intra-observer readings for right (open circles) and left limbs (closed circles). Dotted lines indicate $\pm 2 \mathrm{SD}$, and full lines indicate means.
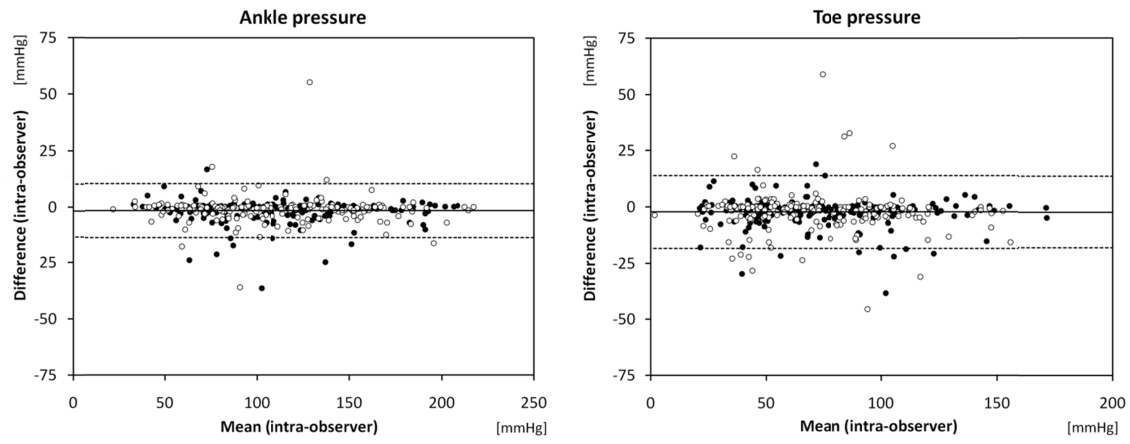

Figure 15. Difference-mean plots for inter-observer readings for right (open circles) and left limbs (closed circles). Dotted lines indicate $\pm 2 \mathrm{SD}$, and full lines indicate means.

Subgroup analysis was performed for patients suspected of vascular stiffness (diabetes, chronic kidney failure, or an ankle-brachial index $>$ 1.40) $(\mathrm{n}=86)$ versus patients not suspected of vascular stiffness $(\mathrm{n}=114)$. Analysis by t-test did not show a significant difference for the mean difference in any of the four measuring sites for the intra or inter-observer comparisons (all $\mathrm{P}>0.132$ ). The Limits of agreement with $95 \%$ confidence intervals are displayed graphically in Figure 16 for intra-observer and interobserver data. In both the intra and inter-observer comparisons the data show non-overlapping $95 \%$ confidence intervals for toe pressure readings 
indicating higher variation in the group suspected of vascular stiffness, than in the group not suspected of vascular stiffness. This was also the case for left ankle pressure in the intra-observer comparison, but not the remaining ankle-pressure comparisons.
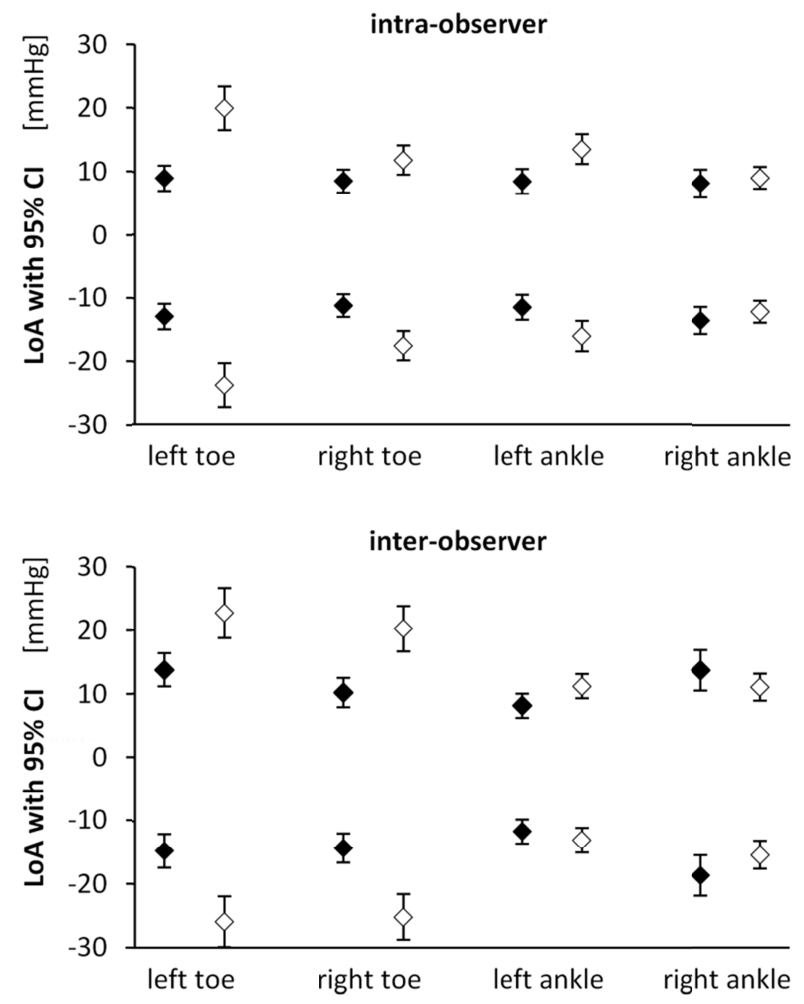

Figure 16. Upper and lower limits of agreement for intra-observer and inter-observer data with $95 \%$ confidence interval showing patients suspected of vascular stiffness (solid square) versus patients not suspected of vascular stiffness (hollow square).

\subsection{Discussion}

The LDF method is increasingly used internationally and considered the reference standard for distal pressure assessment in numerous wascular laboratories. However, the knowledge concerning observer variation of 
curve reading is sparse. In this study, we demonstrated substantial intraand inter-observer agreement among in the diagnostic classification of PAD and CLI. Additionally, we found a low inter- and intra-observer variation for reading of ankle pressures. However, the variation for reading of toe pressures curve reading was more pronounced. The observer variation for reading of toe pressures was smaller in patients with diabetes or chronic kidney failure than in patients not diagnosed with these conditions. There were no similar associations in ankle pressure readings.

So far, only one previous study has shown the observer variation of LDF curve readings. Påhlsson et al. (2008) found a mean intra-observer variability of $2-3 \mathrm{mmHg}$ for toe pressure measurements in a small study $(\mathrm{n}=16)$ with diabetic patients using nurses and vascular technologists as observers. ${ }^{104}$ Another study have shown limits of agreement for one-week reproducibility of LDF measurements of approximately $+/-30 \mathrm{mmHg}{ }^{64}$ Combined with the findings in our study, observer variation in curve readings is likely an important factor in reproducibility. The reproducibility of signal interpretation for other methods such as strain gauge plethysmography has previously been investigated. ${ }^{169,} 186$ The observer variation in those studies regarding reading of ankle pressures is comparable to the variation found in our study. However, the variation in reading of toe pressures encountered in our study was more pronounced for the LDF method.

Påhlsson et. al. (2008) proposed the frequent presence of biphasic curve patterns in LDF toe pressure measurements as a potential source of variation, as they can be difficult to interpret. ${ }^{104}$ Based on findings in earlier animal and clinical studies, they hypothesized that this could be attributed to the response to post occlusive reactive hyperemia in the presence the combination of a vascular stenosis along with a normal capillary bed. The normal response to reactive hyperemia following arterial occlusion, such as during segmental pressure measurement, is brief vasodilation followed by vasoconstriction. In micro-vascular pathology such as endothelial dysfunction which is associated with e.g. diabetes, and chronic kidney failure, this response pattern is dampened. ${ }^{118}$

However, the LDF signal produced in distal pressure measurement is even more complex. In addition to the effects of post occlusive reactive hyperemia, the return of blood-flow involves re-flow in the different blood 
vessels in a given order, systolic pressure reached followed by diastolic pressure, inflow until venous stasis compromise capillary flow followed by release of venous stasis. In theory, all curves would thus produce a biphasic pattern caused by the latter. In our study, the onset of the second slope in case of a biphasic pattern was consistently near $40-50 \mathrm{mmHg}$ as shown in Figure 13. The release of the venous stasis in this pressure range is particularly prominent in measurement with strain gauge plethysmography, which is based on measurement of distal volume changes. ${ }^{186}$ However, in cases with low arterial pressure (close to the venous pressure), the phases in the LDF signal would likely merge. Additionally, factors such as vasospasm, limb tremor, edema, and multiple vessel stenosis can also affect the signal. ${ }^{50,73}$ The magnitude of the inflow following opening of the ankle vessels is markedly higher than following opening of the toe vessels, which is a likely explanation for the high reproducibility demonstrated for ankle pressures.

When a venous stasis is present, the so called veno-arteriolar reflex is activated leading to vasoconstriction and ultimately a reduction in peripheral blood flow. ${ }^{119}$ This reflex is activated when a venous pressure larger than $40 \mathrm{mmHg}$ is present and can induce up to $50 \%$ reduction of the arterial inflow. ${ }^{120}$ Studies have shown that this reflex is diminished in patients with micro-vascular disease such as seen in diabetes. ${ }^{121}$ In patients with a normal capillary capacity a fully active reflex would hypothetically lead to curves that are difficult to interpret, as it would induce a dampened signal until release of the venous stasis. This is in line with the findings in our study, as we found a lower variation in curve reading in patients diagnosed with diabetes or chronic kidney disease. However, given the generalized nature of these co-morbidities, there could be potential masked confounders such as medication or distribution of vessel lesion that could also explain the variation encountered. The anatomical distribution of lesions in arteriosclerosis have been shown to vary according to the risk factors such as diabetes and smoking. ${ }^{19}$ For instance serially linked vessel stenosis are known to induce weak signals. ${ }^{50}$ In cases with poor signal quality, the influence of a reduced signal during venous occlusion is especially critical, as the massive upslope following release of the venous stasis, could be falsely interpreted as the arterial pressure. An example of this situation is displayed in curve (d) in Figure 13. 


\subsection{Conclusions}

This study shows substantial intra and inter-observer agreement in diagnostic classification and absolute pressures when using laboratory technologists as observers. However, the study reveals that intra and interobserver variation for reading of toe and ankle pressures is an important factor regarding the overall reproducibility of the laser Doppler flowmetry method. The variation of toe pressure reading was higher than that encountered in ankle pressures, and our data suggests influence of comorbidity related to vascular stiffness such as diabetes, and chronic kidney failure on reproducibility. 


\section{General conclusions}

Study I showed, in combination with findings in other studies (Table II), that automated, portable methods are a feasible approach to select patients eligible for at full vascular investigation. The particular method investigated study I showed high sensitivity and acceptable specificity for detecting PAD using SGP as a reference. In addition, the study showed a good correlation in absolute toe pressures for the two methods.

Despite the known considerable variation in distal pressure measurement, an important factor in overall reproducibility for the given method is correct interpretation of the derived flow curve. Study II showed excellent reproducibility for SGP in both ankle and toe pressure readings and indicated low bias related to knowledge on patient history and clinical clues.

Regarding testing of a potential new reference method, Study III showed substantial agreement in diagnostic classification and absolute pressures for LDF and SGP. However, Study V indicated issues regarding reproducibility of toe pressures readings for LDF, possibly related to micro-vasculature disease, when comparing to the findings for SGP in Study II. The reproducibility for ankle pressures for LDF was comparable to that found for the SGP method.

The findings in study IV revealed that it is important to measure brachial blood pressures correspondent to each segmental pressure. However, the study showed minimal differences in diagnostic classification and pressure indices when comparing calculations based on the reproducibility criterion, one, or two measurements. This ultimately indicates that findings among diagnostic accuracy studies between different laboratories using different strategies for calculating the indices are comparable (Table I). 



\section{0}

\section{Perspectives}

A number of interesting research questions emerge from the findings in this thesis. First, from a technical point of view, the measurement of toe pressures by portable methods seems feasible, especially if the methods are improved further. As mentioned previously, TBI assessment by low cost methods could potentially be used as a gatekeeper in screening programs to select patients eligible for more advanced diagnostic methods, and thus detect patients who remain undiagnosed by the current standards. Systemic arteriosclerosis remains one of the leading causes of death in industrialised countries. However, the literature supporting the TBI as a marker of generalised arteriosclerosis and a prognostic indicator of the risk of cardiovascular disease and death remain sparse, although studies imply that the TBI is in some aspects superior to the ABI. The ample validation of the $\mathrm{ABI}$ is mainly due to the easy access of ABI measurement in screening programs. Large-scale studies are needed to further validate the prognostic value of TBI, particularly in patients with normal ABI.

Currently, a study is being conducted by the author of this thesis comprising approximately 7,000 distal pressure measurements performed over a four-year period in referred patients suspected of PAD, of which approximately $20 \%$ of the patients have a low TBI but a normal ABI. The aim of the study is to analyse the demographic characteristics of this group of patients, including comorbidity related to vascular stiffness and the analysis of risk of cardiovascular disease and death. Furthermore, is would be interesting to implement TBI in other large-scale arteriosclerotic screening programs in order to assess whether it is a viable prognostic marker. In particular, the limits used for the TBI need to be revised because they are currently based on normal values and not based on verified disease. Furthermore, another logical step would be to clarify the diagnostic agreement between TBI measurements using portable methods, for instance at general practitioners to laboratory standards. 
Despite the low-cost methods for distal pressure assessment, reliable and standardised methods for distal pressure measurement are still required for accurate assessment. This is particularly important in appropriate management of critical limb ischaemia and wound management. Despite the overall, satisfactory agreement between laser Doppler flowmetry and other lab methods in diagnostic test accuracy studies, the complex pathophysiological basis for the signal is not currently fully elucidated. It seems that, various factors can affect the curve characteristics and compromise reproducibility. In general, the compound neurovascular physiology affecting the micro-vasculature during limb pressure measurements needs to be investigated further in order to fully understand the signal. This has also been planned as a succession to this thesis.

Due to the complex nature of tissue oxygenation and deliverance of nutrients, it seems that the newly emerged methods for detection of local perfusion such as transcutaneous oxygen measurement can provide valuable additional information in addition to distal pressure measurement. However, further studies targeting hard endpoints such as the need for intervention, amputation, and wound healing are necessary. 
Atherosclerosis is the leading cause of death in the Western world. It is a generalised disease that can affect the blood flow to the heart and brain as well as the lower limbs. In the lower limbs, arteriosclerosis leads to peripheral arterial disease (PAD), which ranges from asymptomatic disease to critical limb ischaemia. PAD can be diagnosed non-invasively by measuring blood pressure at the ankle or toe level and calculating a ratio with the arm pressure. Blood pressure measurements at the ankle level have been used for years to screen for PAD and for risk stratification of patients. However, the ankle pressure measurements can be unreliable, especially in patients with vascular stiffness, which can, for example, be observed in patients with diabetes or chronic kidney failure. Toe pressure measurements are less affected by vascular stiffness but have historically been limited to vascular laboratories due to expensive and cumbersome techniques as well as requiring considerable observer experience. In the first study, a new automated portable method for toe pressure measurement was compared to the existing reference method, strain gauge plethysmography (SGP). The study showed substantial agreement between the two methods in measurements of 204 patients and showed that the new method has the potential to improve current PAD diagnostics, including in general practice.

However, there will be a continuous need for reliable reference methods for measuring toe and ankle pressure, especially in relation to the proper assessment of wound healing potential and the assessment of critical ischaemia. In another study, a potential new reference method, laser Doppler flowmetry (LDF), was compared with SGP. 200 patients had measurements performed with both methods. The study showed substantial agreement between the methods regarding toe and ankle pressures as well as diagnostic classification. 
When blood pressure is measured, a cuff is inflated above the systolic pressure and gradually deflated. When the pressure in the cuff reaches the toe or ankle systolic pressure, the blood flow returns and can be detected. The SGP method measures the volume changes, whereas LDF measures blood flow in the capillaries. Both methods involve reading a curve, and interpretation of these curves is an important source of variation. The observer variation of these methods was examined in two separate studies by investigating the agreement for the two methods using 1,950 LDF and 1,816 SGP curves, respectively. The studies showed very good agreement for the SGP method of toe and ankle pressure assessment. Agreement was likewise substantial regarding LDF ankle pressure, but showed a higher variation in reading toe pressure. Additionally, the study showed an association between the variation and presence of micro-vascular disease, which poses a problem for the LDF method.

Different laboratories use a different number of measurements to calculate blood pressure. In yet another study, the variation among various approaches was investigated using different methods of calculation. Additionally, the study showed that it is important to measure the arm pressure simultaneously with each toe or ankle pressure measurement due to significant haemodynamic changes during the measurement process. 


\section{Dansk resumé (Danish summary)}

Åreforkalkning er den hyppigste dødsårsag i den vestlige verden. Der er tale om en generaliseret sygdom, som kan ramme hjerte og hjerne såvel som underekstremiteterne. I underekstremiteterne kan åreforkalkning give anledning til perifer arteriel sygdom (PAD) og kan spænde fra asymptomatisk sygdom til kritisk iskæmi. PAD kan diagnosticeres ved at måle blodtrykket på ankel eller tåniveau og sætte det $\mathrm{i}$ forhold til armtrykket. Blodtryksmålinger på ankelniveau har i en årrække været brugt til screening for PAD samt til risikostratificering af patienter. Imidlertid kan ankeltrykmålinger være upålidelige, især ved patienter med karstivhed, hvilket fx kan ses hos patienter med sukkersyge eller nedsat nyrefunktion. Tåtryksmålinger påvirkes langt mindre af karstivhed, men har traditionelt krævet tunge tidskrævende laboratoriemetoder med store krav til observatørerfaring. I første delstudie blev en ny automatiseret transportabel metode til tåblodtryksmåling sammenholdt med den nuværende referencemetode; strain gauge pletysmografi (SGP). Studiet viste god overensstemmelse mellem de to metoder ved målinger på 204 patienter og viste, at den nye metode har potentiale $\mathrm{i}$ forhold til at forbedre den nuværende PAD diagnostik herunder i almen praksis.

Der vil dog fortsat være brug for pålidelige referencemetoder til måling af tå- og ankeltryk, især $i$ forhold til korrekt bedømmelse af sårhelingspotentiale samt vurdering af kritisk iskæmi. I et andet delstudie blev en potentiel ny referencemetode, laser Doppler flowmetri (LDF), sammenholdt med SGP. I studiet fik 200 patienter foretaget målinger med begge metoder, og studiet viste betydelig overensstemmelse $\mathrm{i}$ forhold til både diagnose samt tå- og ankeltryk.

Når blodtrykket skal måles, blæses en manchet op over det systolisk tryk og luftes herefter gradvis ud. Når trykket i manchetten når det systoliske tåeller ankeltryk vender blodgennemstrømningen tilbage og kan måles. SGP 
metoden måler volumenændringer, hvorimod LDF måler blodgennemstrømningen på kapillærniveau. Ved begge metoder fremkommer en kurve, der skal aflæses, og fortolkning af disse kurver er en vigtig fejlkilde. Observatørvariationen for disse metoder blev belyst $\mathrm{i}$ yderligere to delstudier ved at se overensstemmelsen ved fortolkning af hhv. 1.950 LDF og 1.816 SGP kurver. Studierne viste særdeles god overensstemmelse for SGP metoden for tå- og ankeltryk. Overensstemmelsen var tilsvarende god for LDF ankeltryk, men mindre god mht. tåtryk. Derudover blev der fundet en sammenhæng mellem fortolkningsproblemer for kurverne og mikrovaskulær sygdom, hvilket udgør et problem for LDF metoden.

Forskellige laboratorier bruger et forskelligt antal målinger til at beregne blodtryk med. I yderligere et delstudie blev afvigelsen mellem de forskellige metoder søgt belyst ved at bruge forskellige beregningsmetoder. Derudover viste studiet, at det er vigtigt at måle armblodtrykket sammen med hver tå-eller ankeltrykmåling pga. betydelig variation undervejs $\mathrm{i}$ måleforløbet. 


\section{References}

(1) Kalanuria AA, Nyquist P, Ling G. The prevention and regression of atherosclerotic plaques: emerging treatments. Vasc Health Risk Manag 2012;8:549-61.

(2) Norgren L, Hiatt WR, Dormandy JA, Nehler MR, Harris KA, Fowkes FG, et al. Inter-Society Consensus for the Management of Peripheral Arterial Disease (TASC II). Eur J Vasc Endovasc Surg 2007;33 Suppl 1:S1-75.

(3) Peach G, Griffin M, Jones KG, Thompson MM, Hinchliffe RJ. Diagnosis and management of peripheral arterial disease. BMJ 2012;345:e5208.

(4) Fowkes FG, Murray GD, Butcher I, Heald CL, Lee RJ, Chambless LE, et al. Ankle brachial index combined with Framingham Risk Score to predict cardiovascular events and mortality: a metaanalysis. JAMA 2008 Jul 9;300(2):197-208.

(5) Aboyans V, McClelland RL, Allison MA, McDermott MM, Blumenthal RS, Macura K, et al. Lower extremity peripheral artery disease in the absence of traditional risk factors. The Multi-Ethnic Study of Atherosclerosis. Atherosclerosis 2010 Oct 21.

(6) Criqui MH, Langer RD, Fronek A, Feigelson HS, Klauber MR, McCann TJ, et al. Mortality over a period of 10 years in patients with peripheral arterial disease. N Engl J Med 1992 Feb 6;326(6):381-6.

(7) Fowkes FG, Housley E, Cawood EH, Macintyre CC, Ruckley CV, Prescott RJ. Edinburgh Artery Study: prevalence of asymptomatic and symptomatic peripheral arterial disease in the general population. Int J Epidemiol 1991 Jun;20(2):384-92.

(8) Ferreira AC, Macedo FY. A review of simple, non-invasive means of assessing peripheral arterial disease and implications for medical management. Ann Med 2010 Mar;42(2):139-50. 
(9) Amann K. Media calcification and intima calcification are distinct entities in chronic kidney disease. Clin J Am Soc Nephrol 2008 Nov;3(6):1599-605.

(10) Mackey RH, Venkitachalam L, Sutton-Tyrrell K. Calcifications, arterial stiffness and atherosclerosis. Adv Cardiol 2007;44:234-44.

(11) Leskinen Y, Salenius JP, Lehtimaki T, Huhtala H, Saha H. The prevalence of peripheral arterial disease and medial arterial calcification in patients with chronic renal failure: requirements for diagnostics. Am J Kidney Dis 2002 Sep;40(3):472-9.

(12) Young MJ, Adams JE, Anderson GF, Boulton AJ, Cavanagh PR. Medial arterial calcification in the feet of diabetic patients and matched non-diabetic control subjects. Diabetologia 1993 Jul;36(7):615-21.

(13) Garimella PS, Hart PD, O'Hare A, Deloach S, Herzog CA, Hirsch AT. Peripheral Artery Disease and CKD: A Focus on Peripheral Artery Disease as a Critical Component of CKD Care. Am J Kidney Dis 2012 Oct;60(4):641-54.

(14) Becker F, Robert-Ebadi H, Ricco JB, Setacci C, Cao P, de DG, et al. Chapter I: Definitions, epidemiology, clinical presentation and prognosis. Eur J Vasc Endovasc Surg 2011 Dec;42 Suppl 2:S4-12.

(15) Cao P, Eckstein HH, De RP, Setacci C, Ricco JB, de DG, et al. Chapter II: Diagnostic methods. Eur J Vasc Endovasc Surg 2011 Dec;42 Suppl 2:S13-S32.

(16) Gardner AW, Afaq A. Management of lower extremity peripheral arterial disease. J Cardiopulm Rehabil Prev 2008 Nov;28(6):34957.

(17) Simmons A, Steffen K, Sanders S. Medical therapy for peripheral arterial disease. Curr Opin Cardiol 2012 Nov;27(6):592-7.

(18) Resnick HE, Lindsay RS, McDermott MM, Devereux RB, Jones KL, Fabsitz RR, et al. Relationship of high and low ankle brachial index to all-cause and cardiovascular disease mortality: the Strong Heart Study. Circulation 2004 Feb 17;109(6):733-9.

(19) Aboyans V, Lacroix P, Criqui MH. Large and small vessels atherosclerosis: similarities and differences. Prog Cardiovasc Dis $2007 \mathrm{Sep} ; 50(2): 112-25$. 
(20) Ross R. Atherosclerosis is an inflammatory disease. Am Heart J 1999 Nov; 138(5 Pt 2):S419-S420.

(21) Sahli D, Eliasson B, Svensson M, Blohme G, Eliasson M, Samuelsson P, et al. Assessment of toe blood pressure is an effective screening method to identify diabetes patients with lower extremity arterial disease. Angiology 2004 Nov;55(6):641-51.

(22) Bird CE, Criqui MH, Fronek A, Denenberg JO, Klauber MR, Langer RD. Quantitative and qualitative progression of peripheral arterial disease by non-invasive testing. Vasc Med 1999;4(1):1521.

(23) Kallio M, Forsblom C, Groop PH, Groop L, Lepantalo M. Development of new peripheral arterial occlusive disease in patients with type 2 diabetes during a mean follow-up of 11 years. Diabetes Care 2003 Apr;26(4):1241-5.

(24) Aboyans V, Criqui MH, Denenberg JO, Knoke JD, Ridker PM, Fronek A. Risk factors for progression of peripheral arterial disease in large and small vessels. Circulation 2006 Jun 6;113(22):2623-9.

(25) Mukherjee D, Eagle K. The importance of early diagnosis and treatment in peripheral arterial disease: insights from the PARTNERS and REACH registries. Curr Vasc Pharmacol 2010 May 1;8(3):293-300.

(26) Bhatt DL, Steg PG, Ohman EM, Hirsch AT, Ikeda Y, Mas JL, et al. International prevalence, recognition, and treatment of cardiovascular risk factors in outpatients with atherothrombosis. JAMA 2006 Jan 11;295(2):180-9.

(27) Criqui MH, Fronek A, Klauber MR, Barrett-Connor E, Gabriel S. The sensitivity, specificity, and predictive value of traditional clinical evaluation of peripheral arterial disease: results from noninvasive testing in a defined population. Circulation 1985 Mar;71(3):516-22.

(28) Criqui MH, Coughlin SS, Fronek A. Noninvasively diagnosed peripheral arterial disease as a predictor of mortality: results from a prospective study. Circulation 1985 Oct;72(4):768-73. 
(29) Criqui MH, Fronek A, Barrett-Connor E, Klauber MR, Gabriel S, Goodman D. The prevalence of peripheral arterial disease in a defined population. Circulation 1985 Mar;71(3):510-5.

(30) Criqui MH, Browner D, Fronek A, Klauber MR, Coughlin SS, Barrett-Connor E, et al. Peripheral arterial disease in large vessels is epidemiologically distinct from small vessel disease. An analysis of risk factors. Am J Epidemiol 1989 Jun;129(6):1110-9.

(31) Morimoto S, Nakajima F, Yurugi T, Morita T, Jo F, Nishikawa M, et al. Risk factors of normal ankle-brachial index and low toebrachial index in hemodialysis patients. Ther Apher Dial 2009 Apr;13(2):103-7.

(32) Suominen V, Rantanen T, Venermo M, Saarinen J, Salenius J. Prevalence and risk factors of PAD among patients with elevated ABI. Eur J Vasc Endovasc Surg 2008 Jun;35(6):709-14.

(33) Criqui MH. Peripheral arterial disease-epidemiological aspects. Vasc Med 2001;6(3 Suppl):3-7.

(34) Diehm C, Lange S, Darius H, Pittrow D, von SB, Tepohl G, et al. Association of low ankle brachial index with high mortality in primary care. Eur Heart J 2006 Jul;27(14):1743-9.

(35) Hogh AL. The use of secondary medical prevention after primary vascular reconstruction: studies on usage and effectiveness. Dan Med J 2012 Sep;59(9):B4514.

(36) Ferket BS, Spronk S, Colkesen EB, Hunink MG. Systematic review of guidelines on peripheral artery disease screening. Am J Med 2012 Feb;125(2):198-208.

(37) Greenland P, Alpert JS, Beller GA, Benjamin EJ, Budoff MJ, Fayad ZA, et al. 2010 ACCF/AHA guideline for assessment of cardiovascular risk in asymptomatic adults: a report of the American College of Cardiology Foundation/American Heart Association Task Force on Practice Guidelines. Circulation 2010 Dec 21;122(25):e584-e636.

(38) Hirsch AT, Criqui MH, Treat-Jacobson D, Regensteiner JG, Creager MA, Olin JW, et al. Peripheral arterial disease detection, awareness, and treatment in primary care. JAMA 2001 Sep 19;286(11):1317-24. 
(39) Diehm C, Allenberg JR, Pittrow D, Mahn M, Tepohl G, Haberl RL, et al. Mortality and vascular morbidity in older adults with asymptomatic versus symptomatic peripheral artery disease. Circulation 2009 Nov 24;120(21):2053-61.

(40) Rooke TW, Hirsch AT, Misra S, Sidawy AN, Beckman JA, Findeiss LK, et al. 2011 ACCF/AHA Focused Update of the Guideline for the Management of Patients With Peripheral Artery Disease (Updating the 2005 Guideline) A Report of the American College of Cardiology Foundation/American Heart Association Task Force on Practice Guidelines. J Am Coll Cardiol 2011 Nov 1;58(19):2020-45.

(41) Bonham P. Measuring Toe Pressures Using a Portable Photoplethysmograph to Detect Arterial Disease in High-risk Patients: An Overview of the Literature. Ostomy Wound Manage 2011 Nov;57(11):36-44.

(42) Green S. Haemodynamic limitations and exercise performance in peripheral arterial disease. Clin Physiol Funct Imaging 2002 Mar;22(2):81-91.

(43) de Graaff JC, Ubbink DT, Legemate DA, de Haan RJ, Jacobs MJ. Interobserver and intraobserver reproducibility of peripheral blood and oxygen pressure measurements in the assessment of lower extremity arterial disease. J Vasc Surg 2001 May;33(5):1033-40.

(44) Comerota AJ, Throm RC, Kelly P, Jaff M. Tissue (muscle) oxygen saturation (StO2): a new measure of symptomatic lower-extremity arterial disease. J Vasc Surg 2003 Oct;38(4):724-9.

(45) Ganapathy P, Tamminedi T, Qin Y, Nanney L, Cardwell N, Pollins A, et al. Dual-imaging system for burn depth diagnosis. Burns 2013 Jun 18.

(46) Khan NA, Rahim SA, Anand SS, Simel DL, Panju A. Does the clinical examination predict lower extremity peripheral arterial disease? JAMA 2006 Feb 1;295(5):536-46.

(47) Collins R, Burch J, Cranny G, Aguiar-Ibanez R, Craig D, Wright $\mathrm{K}$, et al. Duplex ultrasonography, magnetic resonance angiography, and computed tomography angiography for diagnosis and 
assessment of symptomatic, lower limb peripheral arterial disease: systematic review. BMJ 2007 Jun 16;334(7606):1257.

(48) Wikstrom J, Hansen T, Johansson L, Lind L, Ahlstrom H. Ankle brachial index $<0.9$ underestimates the prevalence of peripheral artery occlusive disease assessed with whole-body magnetic resonance angiography in the elderly. Acta Radiol 2008 Mar;49(2):143-9.

(49) Banerjee S, Badhey N, Lichtenwalter C, Varghese C, Brilakis ES. Relationship of walking impairment and ankle-brachial index assessments with peripheral arterial translesional pressure gradients. J Invasive Cardiol 2011 Sep;23(9):352-6.

(50) Allen J, Oates CP, Lees TA, Murray A. Photoplethysmography detection of lower limb peripheral arterial occlusive disease: a comparison of pulse timing, amplitude and shape characteristics. Physiol Meas 2005 Oct;26(5):811-21.

(51) Holling HE, Boland HC, Russ E. Investigation of arterial obstruction using a mercury-in-rubber strain gauge. Am Heart J 1961 Aug;62:194-205.

(52) de Liefde II, Hoeks SE, van Gestel YR, Bax JJ, Klein J, van Domburg RT, et al. Usefulness of hypertensive blood pressure response during a single-stage exercise test to predict long-term outcome in patients with peripheral arterial disease. Am J Cardiol 2008 Oct 1;102(7):921-6.

(53) de Liefde II, Verhagen HJ, Stolker RJ, van Domburg RT, Poldermans D. The value of treadmill exercise test parameters together in patients with known or suspected peripheral arterial disease. Eur J Prev Cardiol 2012 Apr;19(2):192-8.

(54) Ouriel K, McDonnell AE, Metz CE, Zarins CK. Critical evaluation of stress testing in the diagnosis of peripheral vascular disease. Surgery 1982 Jun;91(6):686-93.

(55) Gardner AW, Skinner JS, Cantwell BW, Smith LK. Progressive vs single-stage treadmill tests for evaluation of claudication. Med Sci Sports Exerc 1991 Apr;23(4):402-8. 
(56) Engvall J, Nylander E, Wranne B. Arm and ankle blood pressure response to treadmill exercise in normal people. Clin Physiol 1989 Dec;9(6):517-24.

(57) Arveschoug AK, Vammen B, Yoshinaka E, Sorensen D, Jodal L, Brochner-Mortensen J. Reference data for distal blood pressure in healthy elderly and middle-aged individuals measured with the strain gauge technique. Part II: Distal blood pressure after exercise. Scand J Clin Lab Invest 2008;68(4):317-22.

(58) de Liefde II, Klein J, Bax JJ, Verhagen HJ, van Domburg RT, Poldermans D. Exercise ankle brachial index adds important prognostic information on long-term out-come only in patients with a normal resting ankle brachial index. Atherosclerosis 2011 Jun;216(2):365-9.

(59) Stein R, Hriljac I, Halperin JL, Gustavson SM, Teodorescu V, Olin JW. Limitation of the resting ankle-brachial index in symptomatic patients with peripheral arterial disease. Vasc Med 2006 Feb;11(1):29-33.

(60) Bonham PA. Get the LEAD out: noninvasive assessment for lower extremity arterial disease using ankle brachial index and toe brachial index measurements. J Wound Ostomy Continence Nurs 2006 Jan;33(1):30-41.

(61) Riva-Rocci S. Un nuovo sfingmomanometro. Gaz Med Torino 1896;47:981.

(62) Alnaeb ME, Alobaid N, Seifalian AM, Mikhailidis DP, Hamilton G. Optical techniques in the assessment of peripheral arterial disease. Curr Vasc Pharmacol 2007 Jan;5(1):53-9.

(63) Wright CI, Kroner CI, Draijer R. Non-invasive methods and stimuli for evaluating the skin's microcirculation. J Pharmacol Toxicol Methods 2006 Jul;54(1):1-25.

(64) de Graaff JC, Ubbink DT, Legemate DA, de Haan RJ, Jacobs MJ. The usefulness of a laser Doppler in the measurement of toe blood pressures. J Vasc Surg 2000 Dec;32(6):1172-9.

(65) Clark CE, Taylor RS, Shore AC, Ukoumunne OC, Campbell JL. Association of a difference in systolic blood pressure between arms 
with vascular disease and mortality: a systematic review and metaanalysis. Lancet 2012 Jan 27.

(66) Smith FC, Shearman CP, Simms MH, Gwynn BR. Falsely elevated ankle pressures in severe leg ischaemia: the pole test--an alternative approach. Eur J Vasc Surg 1994 Jul;8(4):408-12.

(67) Sahli D, Svensson M, Lidgren J, Ojbrandt K, Eriksson JW. Evaluation of simple non-invasive techniques for assessment of lower extremity arterial disease. Clin Physiol Funct Imaging 2005 May;25(3):129-34.

(68) Nielsen PE, Bell G, Lassen NA. The measurement of digital systolic blood pressure by strain gauge technique. Scand J Clin Lab Invest 1972;29(4):371-9.

(69) Strandness DE, Jr., Bell JW. Peripheral vascular disease: diagnosis and objective evaluation using a mercury strain gauge. Ann Surg 1965 Apr;161(Suppl 4):4-35.

(70) Lezack JD, Carter SA. The relationship of distal systolic pressures to the clinical and angiographic findings in limbs with arterial occlusive disease. Scand J Clin Lab Invest Suppl 1973;128:97-101.

(71) Carter SA. The relationship of distal systolic pressures to healing of skin lesions in limbs with arterial occlusive disease, with special reference to diabetes mellitus. Scand J Clin Lab Invest Suppl 1973;128:239-43.

(72) Rosfors S, Blomgren L. Venous occlusion plethysmography in patients with post-thrombotic venous claudication. J Vasc Surg 2013 Mar 30.

(73) Wahlberg E, Olofsson P, Swedenborg J, Fagrell B. Effects of local hyperemia and edema on the biological zero in laser Doppler fluxmetry (LD). Int J Microcirc Clin Exp 1992 May;11(2):157-65.

(74) Ubbink DT. Toe blood pressure measurements in patients suspected of leg ischaemia: a new laser Doppler device compared with photoplethysmography. Eur J Vasc Endovasc Surg 2004 Jun;27(6):629-34.

(75) Andersson S, Linderholm H, Rinnstrom O, Burlin L. A laser Doppler technique for measuring distal blood-pressure: a 
comparison with conventional strain-gauge technique. Clin Physiol 1986 Aug;6(4):329-35.

(76) Ludyga T, Kuczmik WB, Kazibudzki M, Nowakowski P, Orawczyk T, Glanowski M, et al. Ankle-brachial pressure index estimated by laser Doppler in patients suffering from peripheral arterial obstructive disease. Ann Vasc Surg 2007 Jul;21(4):452-7.

(77) Allen J, Overbeck K, Nath AF, Murray A, Stansby G. A prospective comparison of bilateral photoplethysmography versus the ankle-brachial pressure index for detecting and quantifying lower limb peripheral arterial disease. J Vasc Surg 2008 Apr;47(4):794-802.

(78) Allen J. Photoplethysmography and its application in clinical physiological measurement. Physiol Meas 2007 Mar;28(3):R1-39.

(79) Perez-Martin A, Meyer G, Demattei C, Boge G, Laroche JP, Quere I, et al. Validation of a fully automatic photoplethysmographic device for toe blood pressure measurement. Eur J Vasc Endovasc Surg 2010 Oct;40(4):515-20.

(80) Bonham PA, Kelechi T, Mueller M, Robison J. Are toe pressures measured by a portable photophlethysmograph equivalent to standard laboratory tests? J Wound Ostomy Continence Nurs 2010 Sep;37(5):475-86.

(81) Widmer LW, Vikatmaa P, Aho P, Lepantalo M, Venermo M. Reliability and repeatability of toe pressures measured with laser Doppler and portable and stationary photoplethysmography devices. Ann Vasc Surg 2012 Apr;26(3):404-10.

(82) Pahlsson HI, Wahlberg E, Wei SZ, Jörneskog G, Olofsson P, Swedenborg J, et al. Toe blood pressure measurement with laser Doppler. J Vasc Inv 1996;2(2):82-6.

(83) Aboyans V, Criqui MH, Abraham P, Allison MA, Creager MA, Diehm $\mathrm{C}$, et al. Measurement and interpretation of the anklebrachial index: a scientific statement from the American Heart Association. Circulation 2012 Dec 11;126(24):2890-909.

(84) Bonham PA, Cappuccio M, Hulsey T, Michel Y, Kelechi T, Jenkins $\mathrm{C}$, et al. Are ankle and toe brachial indices (ABI-TBI) obtained by a pocket Doppler interchangeable with those obtained 
by standard laboratory equipment? J Wound Ostomy Continence Nurs 2007 Jan;34(1):35-44.

(85) Sorensen TL, Perner A, Hansen L, Schroeder TV. [Can Doppler ultrasound replace strain gauge in the measurement of ankle blood pressure?]. Ugeskr Laeger 1992 Dec 14;154(51):3662-5.

(86) Kroger K, Stewen C, Santosa F, Rudofsky G. Toe pressure measurements compared to ankle artery pressure measurements. Angiology 2003 Jan;54(1):39-44.

(87) Pickering TG, Hall JE, Appel LJ, Falkner BE, Graves J, Hill MN, et al. Recommendations for blood pressure measurement in humans and experimental animals: part 1: blood pressure measurement in humans: a statement for professionals from the Subcommittee of Professional and Public Education of the American Heart Association Council on High Blood Pressure Research. Circulation 2005 Feb 8;111(5):697-716.

(88) Park CS, Choi CY, Ha YI, Yang HE. Utility of Toe-brachial Index for Diagnosis of Peripheral Artery Disease. Arch Plast Surg 2012 Mar 9;39(3):227-31.

(89) Mehlsen J, Wiinberg N, Bruce C. Oscillometric blood pressure measurement: a simple method in screening for peripheral arterial disease. Clin Physiol Funct Imaging 2008 Nov;28(6):426-9.

(90) Korno M, Eldrup N, Sillesen H. Comparison of ankle-brachial index measured by an automated oscillometric apparatus with that by standard Doppler technique in vascular patients. Eur J Vasc Endovasc Surg 2009 Nov;38(5):610-5.

(91) Carmo GA, Mandil A, Nascimento BR, Arantes BD, Bittencourt JC, Falqueto EB, et al. Can we measure the ankle-brachial index using only a stethoscope? A pilot study. Fam Pract 2009 Feb;26(1):22-6.

(92) Chesbro SB, Asongwed ET, Brown J, John EB. Reliability of Doppler and stethoscope methods of determining systolic blood pressures: considerations for calculating an ankle-brachial index. J Natl Med Assoc 2011 Sep;103(9-10):863-9. 
(93) Migliacci R, Nasorri R, Ricciarini P, Gresele P. Ankle-brachial index measured by palpation for the diagnosis of peripheral arterial disease. Fam Pract 2008 Aug;25(4):228-32.

(94) Aboyans V, Lacroix P, Doucet S, Preux PM, Criqui MH, Laskar M. Diagnosis of peripheral arterial disease in general practice: can the ankle-brachial index be measured either by pulse palpation or an automatic blood pressure device? Int J Clin Pract 2008 Jul;62(7):1001-7.

(95) Whiting PF, Rutjes AW, Westwood ME, Mallett S, Deeks JJ, Reitsma JB, et al. QUADAS-2: a revised tool for the quality assessment of diagnostic accuracy studies. Ann Intern Med 2011 Oct 18;155(8):529-36.

(96) Sawka AM, Carter SA. Effect of temperature on digital systolic pressures in lower limb in arterial disease. Circulation 1992 Mar;85(3):1097-101.

(97) McCollum PT, Stanley ST, Kent P, Grouden MC, Moore DJ, Shanik GD. Assessment of arterial disease using digital systolic pressure measurement. Ann Vasc Surg 1988 Oct;2(4):349-51.

(98) Carter SA, Tate RB. The effect of body heating and cooling on the ankle and toe systolic pressures in arterial disease. J Vasc Surg 1992 Aug;16(2):148-53.

(99) Ubbink DT, Verhaar EE, Lie HK, Legemate DA. Effect of betablockers on peripheral skin microcirculation in hypertension and peripheral vascular disease. J Vasc Surg 2003 Sep;38(3):535-40.

(100) Pahlsson HI, Laskar C, Stark K, Andersson A, Jogestrand T, Wahlberg E. The optimal cuff width for measuring toe blood pressure. Angiology 2007 Aug;58(4):472-6.

(101) Manning DM, Kuchirka C, Kaminski J. Miscuffing: inappropriate blood pressure cuff application. Circulation 1983 Oct;68(4):763-6.

(102) Takahashi O, Shimbo T, Rahman M, Musa R, Kurokawa W, Yoshinaka $\mathrm{T}$, et al. Validation of the auscultatory method for diagnosing peripheral arterial disease. Fam Pract 2006 Feb;23(1):10-4. 
(103) Wahlberg E, Gush R. A new automated toe blood pressure monitor for assessment of limb ischemia. Eur J Vasc Endovasc Surg 2002 Oct;24(4):304-8.

(104) Pahlsson HI, Lund K, Jorneskog G, Gush R, Wahlberg E. The validity and reliability of automated and manually measured toe blood pressure in ischemic legs of diabetic patients. Eur J Vasc Endovasc Surg 2008 Nov;36(5):576-81.

(105) Joensen JB, Juul S, Abrahamsen J, Henneberg EW, Lindholt JS. Doppler ultrasound compared with strain gauge for measurement of systolic ankle blood pressure. Angiology 2008 Jun;59(3):296-300.

(106) Høyer C, Sandermann J, Paludan JP, Pavar S, Petersen LJ. Diagnostic accuracy of laser Doppler flowmetry versus strain gauge plethysmography for segmental pressure measurement. J Vasc Surg 2013 Dec;58(6):1563-70.

(107) Harrison ML, Lin HF, Blakely DW, Tanaka H. Preliminary assessment of an automatic screening device for peripheral arterial disease using ankle-brachial and toe-brachial indices. Blood Press Monit 2011 Jun;16(3):138-41.

(108) Høyer C, Sandermann J, Petersen LJ. Randomised diagnostic accuracy study of a fully automated portable device for diagnosing peripheral arterial disease by measuring the toe-brachial index. Eur J Vasc Endovasc Surg 2013 Jan;45(1):57-64.

(109) Rutherford RB. Vascular Surgery. 6 ed. Philadelphia, Pensylvania: Elsevier, Saunders; 2005.

(110) London GM, Guerin AP, Pannier B, Marchais SJ, Stimpel M. Influence of sex on arterial hemodynamics and blood pressure. Role of body height. Hypertension 1995 Sep;26(3):514-9.

(111) Hiatt WR, Hoag S, Hamman RF. Effect of diagnostic criteria on the prevalence of peripheral arterial disease. The San Luis Valley Diabetes Study. Circulation 1995 Mar 1;91(5):1472-9.

(112) Su HM, Chang JM, Lin FH, Chen SC, Voon WC, Cheng KH, et al. Influence of different measurement time points on brachial-ankle pulse wave velocity and ankle-brachial index in hemodialysis patients. Hypertens Res 2007 Oct;30(10):965-70. 
(113) Abraham P, Desvaux B, Colin D, Leftheriotis G, Saumet JL. Heart rate-corrected ankle-to-arm index in the diagnosis of moderate lower extremity arterial disease. Angiology 1995 Aug;46(8):673-7.

(114) Benetos A, Waeber B, Izzo J, Mitchell G, Resnick L, Asmar R, et al. Influence of age, risk factors, and cardiovascular and renal disease on arterial stiffness: clinical applications. Am J Hypertens 2002 Dec;15(12):1101-8.

(115) Westerhof N, Lankhaar JW, Westerhof BE. The arterial Windkessel. Med Biol Eng Comput 2009 Feb;47(2):131-41.

(116) Lau WL, Ix JH. Clinical detection, risk factors, and cardiovascular consequences of medial arterial calcification: a pattern of vascular injury associated with aberrant mineral metabolism. Semin Nephrol 2013 Mar;33(2):93-105.

(117) Stiefel P, Moreno-Luna R, Vallejo-Vaz AJ, Beltran LM, Costa A, Gomez L, et al. Which parameter is better to define endothelial dysfunction in a test of postocclusive hyperemia measured by laserDoppler flowmetry? Coron Artery Dis 2012 Jan;23(1):57-61.

(118) Tousoulis D, Kampoli AM, Stefanadis C. Diabetes mellitus and vascular endothelial dysfunction: current perspectives. Curr Vasc Pharmacol 2012 Jan;10(1):19-32.

(119) Henriksen O. Sympathetic reflex control of blood flow in human peripheral tissues. Acta Physiol Scand Suppl 1991;603:33-9.

(120) Petersen LJ, Kristensen JK. Local sympathetic reflex control of blood flow in human skin following topical corticosteroid treatment. Scand J Clin Lab Invest 1990 Apr;50(2):199-201.

(121) Cacciatori V, Dellera A, Bellavere F, Bongiovanni LG, Teatini F, Gemma ML, et al. Comparative assessment of peripheral sympathetic function by postural vasoconstriction arteriolar reflex and sympathetic skin response in NIDDM patients. Am J Med 1997 Apr;102(4):365-70.

(122) Setacci C, de DG, Setacci F, Chisci E. Ischemic foot: definition, etiology and angiosome concept. J Cardiovasc Surg (Torino) 2010 Apr;51(2):223-31. 
(123) Taylor GI, Pan WR. Angiosomes of the leg: anatomic study and clinical implications. Plast Reconstr Surg 1998 Sep;102(3):599616.

(124) Begelman SM, Jaff MR. Noninvasive diagnostic strategies for peripheral arterial disease. Cleve Clin J Med 2006 Oct;73 Suppl 4:S22-S29.

(125) Schroedder VS, Ebskov LB, Egeblad M, Husted S, Jelnes R, Jensen $\mathrm{T}$, et al. Underekstremitetsiskæmi. Forbyggelse og behandling. Laegeforeningens forlag; 2005.

(126) Lau JF, Weinberg MD, Olin JW. Peripheral artery disease. Part 1: clinical evaluation and noninvasive diagnosis. Nat Rev Cardiol $2011 \mathrm{Jul} ; 8(7): 405-18$.

(127) Olin JW, Allie DE, Belkin M, Bonow RO, Casey DE, Jr., Creager MA, et al. ACCF/AHA/ACR/SCAI/SIR/SVM/SVN/SVS 2010 performance measures for adults with peripheral artery disease: a report of the American College of Cardiology Foundation/American Heart Association Task Force on performance measures, the American College of Radiology, the Society for Cardiac Angiography and Interventions, the Society for Interventional Radiology, the Society for Vascular Medicine, the Society for Vascular Nursing, and the Society for Vascular Surgery (Writing Committee to Develop Clinical Performance Measures for Peripheral Artery Disease). Circulation 2010 Dec 14;122(24):2583618.

(128) Azam SM, Carman TL. Diagnostic approach to peripheral arterial disease. Cardiol Clin 2011 Aug;29(3):319-29.

(129) Chan D, Anderson ME, Dolmatch BL. Imaging evaluation of lower extremity infrainguinal disease: role of the noninvasive vascular laboratory, computed tomography angiography, and magnetic resonance angiography. Tech Vasc Interv Radiol 2010 Mar;13(1):11-22.

(130) Stoffers HE, Kester AD, Kaiser V, Rinkens PE, Kitslaar PJ, Knottnerus JA. The diagnostic value of the measurement of the ankle-brachial systolic pressure index in primary health care. J Clin Epidemiol 1996 Dec;49(12):1401-5. 
(131) Dachun X, Jue L, Liling Z, Yawei X, Dayi H, Pagoto SL, et al. Sensitivity and specificity of the ankle-brachial index to diagnose peripheral artery disease: a structured review. Vasc Med 2010 Oct;15(5):361-9.

(132) Suominen V, Uurto I, Saarinen J, Venermo M, Salenius J. PAD as a risk factor for mortality among patients with elevated ABI--a clinical study. Eur J Vasc Endovasc Surg 2010 Mar;39(3):316-22.

(133) Potier L, Halbron M, Bouilloud F, Dadon M, Le DJ, Ha VG, et al. Ankle-to-brachial ratio index underestimates the prevalence of peripheral occlusive disease in diabetic patients at high risk for arterial disease. Diabetes Care 2009 Apr;32(4):e44.

(134) Emanuele MA, Buchanan BJ, Abraira C. Elevated leg systolic pressures and arterial calcification in diabetic occlusive vascular disease. Diabetes Care 1981 Mar;4(2):289-92.

(135) Quigley FG, Faris IB, Duncan HJ. A comparison of Doppler ankle pressures and skin perfusion pressure in subjects with and without diabetes. Clin Physiol 1991 Jan;11(1):21-5.

(136) Apelqvist J, Castenfors J, Larsson J, Stenstrom A, Agardh CD. Prognostic value of systolic ankle and toe blood pressure levels in outcome of diabetic foot ulcer. Diabetes Care 1989 Jun;12(6):3738.

(137) McDermott MM, Guralnik JM, Tian L, Liu K, Ferrucci L, Liao Y, et al. Associations of borderline and low normal ankle-brachial index values with functional decline at 5-year follow-up: the WALCS (Walking and Leg Circulation Study). J Am Coll Cardiol 2009 Mar 24;53(12):1056-62.

(138) Hirsch AT, Haskal ZJ, Hertzer NR, Bakal CW, Creager MA, Halperin JL, et al. ACC/AHA 2005 guidelines for the management of patients with peripheral arterial disease (lower extremity, renal, mesenteric, and abdominal aortic): executive summary a collaborative report from the American Association for Vascular Surgery/Society for Vascular Surgery, Society for Cardiovascular Angiography and Interventions, Society for Vascular Medicine and Biology, Society of Interventional Radiology, and the ACC/AHA Task Force on Practice Guidelines (Writing Committee to Develop Guidelines for the Management of Patients With Peripheral Arterial 
Disease) endorsed by the American Association of Cardiovascular and Pulmonary Rehabilitation; National Heart, Lung, and Blood Institute; Society for Vascular Nursing; TransAtlantic Inter-Society Consensus; and Vascular Disease Foundation. J Am Coll Cardiol 2006 Mar 21;47(6):1239-312.

(139) Aboyans V, McClelland RL, Allison MA, McDermott MM, Blumenthal RS, Macura K, et al. Lower extremity peripheral artery disease in the absence of traditional risk factors. The Multi-Ethnic Study of Atherosclerosis. Atherosclerosis 2011 Jan;214(1):169-73.

(140) Liu H, Shi H, Yu J, Chen F, Jiang Q, Hu D. Is chronic kidney disease associated with a high ankle brachial index in adults at high cardiovascular risk? J Atheroscler Thromb 2011;18(3):224-30.

(141) Wang Y, Guo X, Li J, Hu D, Zhao D, Ma H, et al. Predictive value of ankle-brachial index to all-cause mortality and cardiovascular mortality in Chinese patients with chronic kidney disease. Vasa 2012 May;41(3):205-13.

(142) Lilly SM, Qasim AN, Mulvey CK, Churchill TW, Reilly MP, Eraso LH. Non-compressible arterial disease and the risk of coronary calcification in type-2 diabetes. Atherosclerosis 2013 Sep;230(1):17-22.

(143) Carter SA. Ankle and toe systolic pressures comparison of value and limitations in arterial occlusive disease. Int Angiol 1992 Oct;11(4):289-97.

(144) Ix JH, Miller RG, Criqui MH, Orchard TJ. Test characteristics of the ankle-brachial index and ankle-brachial difference for medial arterial calcification on X-ray in type 1 diabetes. J Vasc Surg 2012 Sep;56(3):721-7.

(145) Weinberg I, Giri J, Calfon MA, Hawkins BM, Weinberg MD, Margey R, et al. Anatomic correlates of supra-normal ankle brachial indices. Catheter Cardiovasc Interv 2012 Aug 17.

(146) Høyer C, Sandermann J, Petersen LJ. The toe-brachial index in the diagnosis of peripheral arterial disease. J Vasc Surg 2013 Jul;58(1):231-8.

(147) Carter SA, Tate RB. The value of toe pulse waves in determination of risks for limb amputation and death in patients with peripheral 
arterial disease and skin ulcers or gangrene. J Vasc Surg 2001 Apr;33(4):708-14.

(148) Ramsey DE, Manke DA, Sumner DS. Toe blood pressure. A valuable adjunct to ankle pressure measurement for assessing peripheral arterial disease. J Cardiovasc Surg (Torino) 1983 Jan;24(1):43-8.

(149) Williams DT, Price P, Harding KG. The influence of diabetes and lower limb arterial disease on cutaneous foot perfusion. J Vasc Surg 2006 Oct;44(4):770-5.

(150) Mäkisalo H, Lepantalo M, Halme L, Lund T, Peltonen S, Salmela $\mathrm{K}$, et al. Peripheral arterial disease as a predictor of outcome after renal transplantation. Transpl Int 1998;11 Suppl 1:S140-S143.

(151) Reinhard H, Wiinberg N, Hansen PR, Kjaer A, Petersen CL, Winther K, et al. NT-proBNP levels, atherosclerosis and vascular function in asymptomatic type 2 diabetic patients with microalbuminuria: peripheral reactive hyperaemia index but not NT-proBNP is an independent predictor of coronary atherosclerosis. Cardiovasc Diabetol 2011;10:71.

(152) Papanas N, Tziakas D, Maltezos E, Kekes A, Hatzinikolaou E, Parcharidis G, et al. Peripheral arterial occlusive disease as a predictor of the extent of coronary atherosclerosis in patients with coronary artery disease with and without diabetes mellitus. J Int Med Res 2004 Jul;32(4):422-8.

(153) Brooks B, Dean R, Patel S, Wu B, Molyneaux L, Yue DK. TBI or not TBI: that is the question. Is it better to measure toe pressure than ankle pressure in diabetic patients? Diabet Med 2001 Jul;18(7):528-32.

(154) Arveschoug AK, Vammen B, Yoshinaka E, Sorensen D, Jodal L, Brochner-Mortensen J. Reference data for distal blood pressure in healthy elderly and middle-aged individuals measured with the strain gauge technique. Part I: resting distal blood pressure. Scand J Clin Lab Invest 2008;68(3):249-53.

(155) Carter SA. Ankle and toe systolic pressures comparison of value and limitations in arterial occlusive disease. Int Angiol 1992 Oct;11(4):289-97. 
(156) Williams DT, Harding KG, Price P. An evaluation of the efficacy of methods used in screening for lower-limb arterial disease in diabetes. Diabetes Care 2005 Sep;28(9):2206-10.

(157) Muro Y, Sugiura K, Morita Y, Tomita Y. An evaluation of the efficacy of the toe brachial index measuring vascular involvement in systemic sclerosis and other connective tissue diseases. Clin Exp Rheumatol 2009 May;27(3 Suppl 54):26-31.

(158) Carter SA, Lezack JD. Digital systolic pressures in the lower limb in arterial disease. Circulation 1971 Jun;43(6):905-14.

(159) Criqui MH, Langer RD, Fronek A, Feigelson HS, Klauber MR. Large vessel and isolated small vessel disease. In: Fowkes FGR, editor. Epidemiology of peripheral arterial disease.London: Springer-Verlag; 1991. p. 85-96.

(160) Aboyans V, Ho E, Denenberg JO, Ho LA, Natarajan L, Criqui MH. The association between elevated ankle systolic pressures and peripheral occlusive arterial disease in diabetic and nondiabetic subjects. J Vasc Surg 2008 Nov;48(5):1197-203.

(161) Fukui M, Tanaka M, Hamaguchi M, Senmaru T, Sakabe K, Asano $\mathrm{M}$, et al. Toe-brachial index is associated more strongly with albuminuria or glomerular filtration rate than ankle-brachial index in patients with type 2 diabetes. Hypertens Res 2012 Feb 16.

(162) Aso Y, Okumura K, Inoue $\mathrm{T}$, Matsutomo R, Yoshida N, Wakabayashi S, et al. Results of blood inflammatory markers are associated more strongly with toe-brachial index than with anklebrachial index in patients with type 2 diabetes. Diabetes Care 2004 Jun;27(6):1381-6.

(163) Aso Y, Okumura K, Wakabayashi S, Takebayashi K, Taki S, Inukai T. Elevated pregnancy-associated plasma protein-a in sera from type 2 diabetic patients with hypercholesterolemia: associations with carotid atherosclerosis and toe-brachial index. J Clin Endocrinol Metab 2004 Nov;89(11):5713-7.

(164) Uccioli L, Monticone G, Durola L, Russo F, Mormile F, Mennuni $\mathrm{G}$, et al. Autonomic neuropathy influences great toe blood pressure. Diabetes Care 1994 Apr;17(4):284-7. 
(165) Sheen YJ, Lin JL, Lee IT, Hsu YN, Li TC, Sheu WH. Low estimated glomerular filtration rate is a major determinant of low ankle-brachial index and toe-brachial index in type 2 diabetes. Angiology 2012 Jan;63(1):55-61.

(166) Sahli D, Eriksson JW, Boman K, Svensson MK. Tissue plasminogen activator (tPA) activity is a novel and early marker of asymptomatic LEAD in type 2 diabetes. Thromb Res 2009 Mar;123(5):701-6.

(167) Fukui M, Tanaka M, Okada H, Iwase H, Mineoka Y, Senmaru T, et al. Five-item version of the international index of erectile function correlated with albuminuria and subclinical atherosclerosis in men with type 2 diabetes. J Atheroscler Thromb 2011;18(11):991-7.

(168) Ray SA, Buckenham TM, Belli AM, Taylor RS, Dormandy JA. The nature and importance of changes in toe-brachial pressure indices following percutaneous transluminal angioplasty for leg ischaemia. Eur J Vasc Endovasc Surg 1997 Aug;14(2):125-33.

(169) Arveschoug AK, Revsbech P, Brochner-Mortensen J. Sources of variation in the determination of distal blood pressure measured using the strain gauge technique. Clin Physiol 1998 Jul;18(4):3618.

(170) Romanos MT, Raspovic A, Perrin BM. The reliability of toe systolic pressure and the toe brachial index in patients with diabetes. J Foot Ankle Res 2010;3:31.

(171) Paaske WP, Tonnesen KH. Prognostic significance of distal blood pressure measurements in patients with severe ischaemia. Scand J Thorac Cardiovasc Surg 1980;14(1):105-8.

(172) Gundersen J. Segmental measurements of systolic blood pressure in the extremities including the thumb and the great toe. Acta Chir Scand Suppl 1972;426:1-90.

(173) Nielsen PE. Digital blood pressure in patients with peripheral arterial disease. Scand J Clin Lab Invest 1976 Dec;36(8):731-7.

(174) Høyer C, Biurrun Manresa JA, Petersen LJ. Number of distal limb and brachial pressure measurements required when diagnosing peripheral arterial disease by laser Doppler flowmetry. Physiol Meas 2013 Sep 18;34(10):1351-62. 
(175) Bossuyt PM, Reitsma JB, Bruns DE, Gatsonis CA, Glasziou PP, Irwig LM, et al. Towards complete and accurate reporting of studies of diagnostic accuracy: the STARD initiative. Standards for Reporting of Diagnostic Accuracy. Clin Chem 2003 Jan;49(1):1-6.

(176) Schunemann HJ, Oxman AD, Brozek J, Glasziou P, Jaeschke R, Vist GE, et al. Grading quality of evidence and strength of recommendations for diagnostic tests and strategies. BMJ 2008 May 17;336(7653):1106-10.

(177) Lucas NP, Macaskill P, Irwig L, Bogduk N. The development of a quality appraisal tool for studies of diagnostic reliability (QAREL). J Clin Epidemiol 2010 Aug;63(8):854-61.

(178) Whiting PF, Weswood ME, Rutjes AW, Reitsma JB, Bossuyt PN, Kleijnen J. Evaluation of QUADAS, a tool for the quality assessment of diagnostic accuracy studies. BMC Med Res Methodol 2006;6:9.

(179) Reitsma JB, Rutjes AWS, Whiting P, Vlassov VV, Leeflang MMG, Deeks JJ. Assessing methodological quality. In: Deeks JJ, Bossuyt PM, Gatsonis C, editors. Cochrane Handbook for Systematic Reviews of Diagnostic Test Accuracy. 1.0 ed. The Cochrane Collaboration; 2009.

(180) Hrobjartsson A, Thomsen AS, Emanuelsson F, Tendal B, Hilden J, Boutron I, et al. Observer bias in randomised clinical trials with binary outcomes: systematic review of trials with both blinded and non-blinded outcome assessors. BMJ 2012;344:e1119.

(181) Viera AJ, Garrett JM. Understanding interobserver agreement: the kappa statistic. Fam Med 2005 May;37(5):360-3.

(182) Bland JM, Altman DG. Statistical methods for assessing agreement between two methods of clinical measurement. Lancet $1986 \mathrm{Feb}$ 8;1(8476):307-10.

(183) Bland JM, Altman DG. Measuring agreement in method comparison studies. Stat Methods Med Res 1999 Jun;8(2):135-60.

(184) Dewitte K, Fierens C, Stockl D, Thienpont LM. Application of the Bland-Altman plot for interpretation of method-comparison studies: a critical investigation of its practice. Clin Chem 2002 May;48(5):799-801. 
(185) Beinder E, Hoffmann U, Franzeck UK, Huch A, Huch R, Bollinger A. Laser Doppler technique for the measurement of digital and segmental systolic blood pressure. Vasa 1992;21(1):15-21.

(186) Høyer C, Pavar S, Pedersen BH, Biurrun Manresa JA, Petersen LJ. Reliability of mercury-in-silastic strain gauge plethysmography curve reading: Influence of clinical clues and observer variation. Scand J Clin Lab Invest 2013 Aug;73(5):380-6. 



\section{Appendix A}

Paper I Høyer C, Sandermann J, Petersen LJ. Randomised diagnostic accuracy study of a fully automated portable device for diagnosing peripheral arterial disease by measuring the toe-brachial index. Eur $J$ Vasc Endovasc Surg 2013 Jan;45(1):57-64. 
A part of this thesis has been removed from this publication due to copyright. 


\section{Appendix B}

Paper II Høyer C, Pavar S, Pedersen BH, Manresa JAB, Petersen LJ. Reliability of mercury-in-silastic strain gauge plethysmography curve reading: influence of clinical clues and observer variation. Scand J Clin Lab Invest 2013 Aug;73(5):380-6 
A part of this thesis has been removed from this publication due to copyright. 


\section{Appendix C}

Paper III Høyer C, Sandermann J, Paludan JP, Pavar S, Petersen LJ. Diagnostic accuracy study of laser Doppler flowmetry vs. mercury-in-silastic strain gauge pletysmography for segmental pressure measurement. J Vasc Surg 2013 Dec;58(6):1563-70. 
A part of this thesis has been removed from this publication due to copyright. 


\section{Appendix D}

Paper IV Høyer C, Manresa JAB, Petersen LJ. Number of measurements required and influence of brachial blood pressure when diagnosing peripheral arterial disease by laser Doppler flowmetry. Physiol Meas 2013 Sep 18;34(10):1351-62. 
A part of this thesis has been removed from this publication due to copyright. 


\section{Appendix E}

Paper V Høyer C, Paludan JP, Pavar S, Manresa JAB, Petersen LJ. Reliability of laser Doppler flowmetry curve reading for measurement of toe and ankle pressures: Intra and interobserver variation. Eur J Vasc Endovasc Surg 2014 Mar;47(3):311-318. 
A part of this thesis has been removed from this publication due to copyright. 


\section{About the author}

Christian Høyer was born in 1980 in Aarhus, Denmark. He defended a research year thesis in 2005 at Aarhus University, and received the M.D. degree from Aarhus University in 2007. In the period 2007-2014, he has worked as a medical doctor in the areas of clinical physiology and nuclear medicine, oncology, abdominal surgery, general practitioning, urology, and internal medicine. He currently holds a fellowship in clinical physiology and nuclear medicine. His primary research fields entail diagnosis of peripheral arterial disease, intestinal ischemia, and cardiac dysfunction. In the years 2011-2013, he has been enrolled as a PhD student at Aalborg University. 